NBER WORKING PAPER SERIES

\title{
SPATIAL CORRELATION, TRADE, AND INEQUALITY: EVIDENCE FROM THE GLOBAL CLIMATE
}

\author{
Jonathan I. Dingel \\ Kyle C. Meng \\ Solomon M. Hsiang \\ Working Paper 25447 \\ http://www.nber.org/papers/w25447 \\ NATIONAL BUREAU OF ECONOMIC RESEARCH \\ 1050 Massachusetts Avenue \\ Cambridge, MA 02138 \\ January 2019, Revised December 2022
}

Dingel and Meng contributed equally to this work. We thank Rodrigo Adão, Treb Allen, Costas Arkolakis, Mark Cane, Chris Costello, Arnaud Costinot, Tatyana Deryugina, Pedro DiNezio, Dave Donaldson, Robert Feenstra, Kinda Hachem, Christian Hansen, Matthew Kahn, Yuhei Miyauchi, Brent Neiman, Ben Olken, Esteban Rossi-Hansberg, Veronica Rappaport, and Michael Waugh for valuable discussions and suggestions. Thanks to seminar participants at numerous institutions and conferences for helpful comments. Kevin Dano provided excellent research assistance. This work was completed in part with resources provided by the University of Chicago Research Computing Center. Dingel thanks the James S. Kemper Foundation Faculty Research Fund at the University of Chicago Booth School of Business for financial support. A previous version of this paper circulated as "The Spatial Structure of Productivity, Trade, and Inequality: Evidence from the Global Climate." The views expressed herein are those of the authors and do not necessarily reflect the views of the National Bureau of Economic Research.

NBER working papers are circulated for discussion and comment purposes. They have not been peer-reviewed or been subject to the review by the NBER Board of Directors that accompanies official NBER publications.

(C) 2019 by Jonathan I. Dingel, Kyle C. Meng, and Solomon M. Hsiang. All rights reserved. Short sections of text, not to exceed two paragraphs, may be quoted without explicit permission provided that full credit, including $(\odot$ notice, is given to the source. 
Spatial Correlation, Trade, and Inequality: Evidence from the Global Climate Jonathan I. Dingel, Kyle C. Meng, and Solomon M. Hsiang

NBER Working Paper No. 25447

January 2019, Revised December 2022

JEL No. F11,F14,F18,O13,Q17,Q54,Q56

\begin{abstract}
$\underline{\text { ABSTRACT }}$
Global phenomena, such as climate change, often have local impacts that are spatially correlated. We show that greater spatial correlation of productivities can increase international inequality by increasing the correlation between a country's productivity and its gains from trade. We confirm this prediction using a half-century of exogenous variation in the spatial correlation of agricultural productivities induced by a global climatic phenomenon. We introduce this generalequilibrium effect into projections of climate-change impacts that typically omit spatial linkages and therefore do not account for the global scope of climate change. We project greater international inequality, with higher welfare losses across Africa.
\end{abstract}

Jonathan I. Dingel

Booth School of Business

University of Chicago

5807 South Woodlawn Avenue

Chicago, IL 60637

and NBER

jdingel@ chicagobooth.edu

Kyle C. Meng

Bren School of Environmental

Science and Management

Department of Economics

University of California, Santa Barbara

4416 Bren Hall

Santa Barbara, CA 93106

and NBER

kmeng@bren.ucsb.edu
Solomon M. Hsiang

Goldman School of Public Policy

University of California, Berkeley

2607 Hearst Avenue

Berkeley, CA 94720-7320

and NBER

shsiang@ berkeley.edu 


\section{Introduction}

Global phenomena often have heterogeneous local impacts. In many cases, these impacts are spatially correlated: neighboring locations experience similar conditions, a pattern dubbed the "first law of geography" (Tobler, 1970). The effects of anthropogenic climate change on cereal yields, depicted in Figure 1, offer a prime example. Projected productivity losses are spatially concentrated near the equator, while economies that will experience smaller losses and even some gains tend to be in mid-latitude locations. That is, a key feature of global climate change is that an economy suffering reduced productivity will tend to have neighboring economies that also have lowered productivity. ${ }^{1}$ Empirical studies of climate change impacts have largely neglected the consequences of such spatial correlation, and thus the global nature of climate change, by studying isolated local temperature variation.

Figure 1: Change in log cereal yields under climate change (2013-2099)

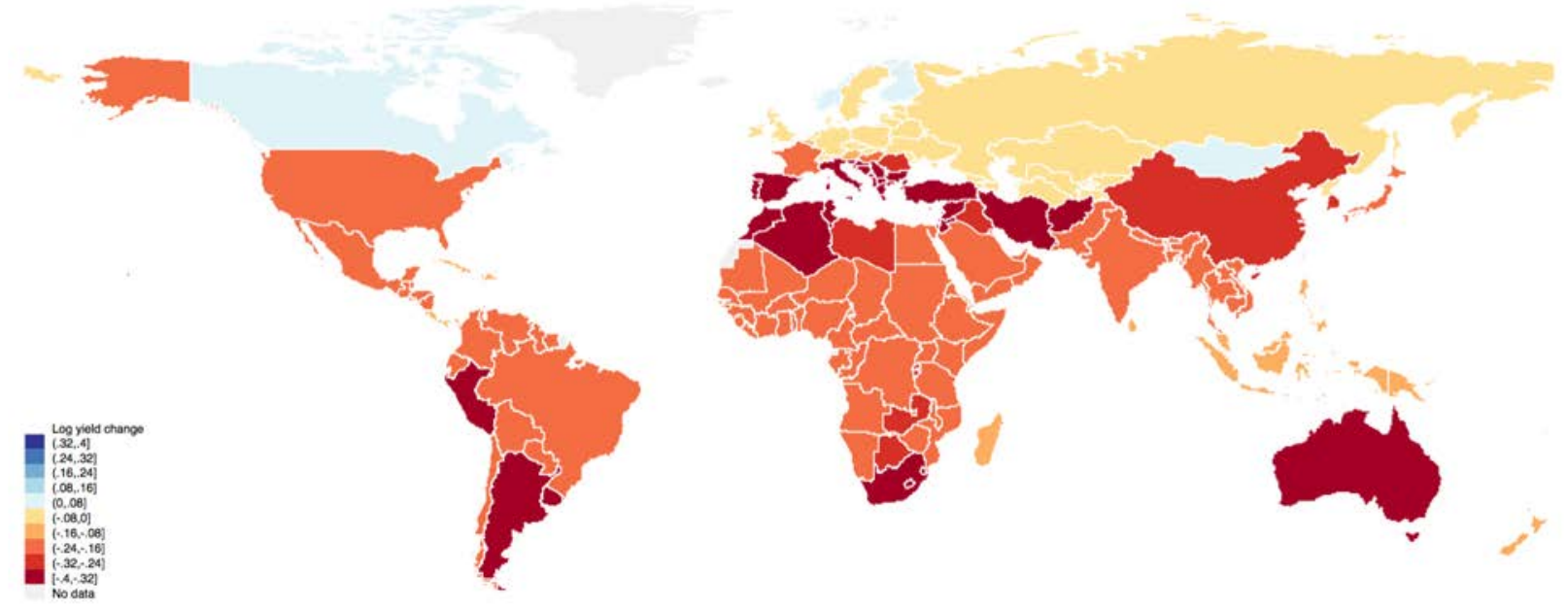

Notes: Map shows the projected change in country-level log cereal yields under climate change between $2013-2099$. See details in Section 5.1.

This paper shows that greater spatial correlation of productivities increases welfare inequality by altering the pattern of international trade. Theoretically, the spatial structure of productivity shapes countries' gains from trade because they trade more with their neighbors than distant countries. Our empirical investigation leverages exogenous variation in the spatial correlation of agricultural productivities induced by a naturally-occurring global climatic phenomenon over the last half-century. We find that gains from trade respond to spatial correlation in a manner that increases international inequality. When we amend projections of anthropogenic-climate-change impacts based on quasi-experimental estimates to incorporate this general-equilibrium effect, projected international inequality rises.

Trade theory links the spatial correlation of productivities and international inequality, as we explain in Section 2. A country benefits by trading with more productive counterparts to the extent

\footnotetext{
${ }^{1}$ Other examples of global events with spatially correlated local consequences include the Great Recession (Piskorski and Seru, 2018), food price shocks (McGuirk and Burke, 2020), and pandemics (Barro, Ursúa and Weng, 2020; Dong, Du and Gardner, 2020).
} 
that they demand more of its exports and sell it cheaper imports. Since trade costs increase with geographic distance, a country enjoys larger gains from trade when its neighbors, rather than its distant trading partners, are more productive. We show that when productivities are more spatially correlated, more productive countries gain more from trade because they are near other productive countries, while less productive countries gain less from trade because they are far from productive trading partners. All else equal, greater spatial correlation raises welfare inequality.

Our main contribution is to estimate the empirical relationship between the spatial correlation of productivities and the distribution of gains from trade. Estimating causal effects of common shocks is generally challenging because there are few or no unaffected units (Donaldson, 2015; Fuchs-Schündeln and Hassan, 2016; Nakamura and Steinsson, 2018; Ramey, 2019). In our setting, the treatment of interest affects the entire global trading network. Thus, comparisons must be made across time using exogenous variation from a global common shock. That is, one needs a natural experiment at a global scale.

To that end, our empirical investigation exploits a naturally-occurring climatic phenomenon known as the El Niño-Southern Oscillation (ENSO), described in Section 3. In years when ENSO is strong, there is a large, spatially contiguous region across the tropics that experience hotter conditions, shown in red in Figure 2. As a result, ENSO approximates the ideal experiment by increasing the global spatial correlation of cereal productivities without altering their mean or variance.

Figure 2: ENSO and the global spatial structure of temperature

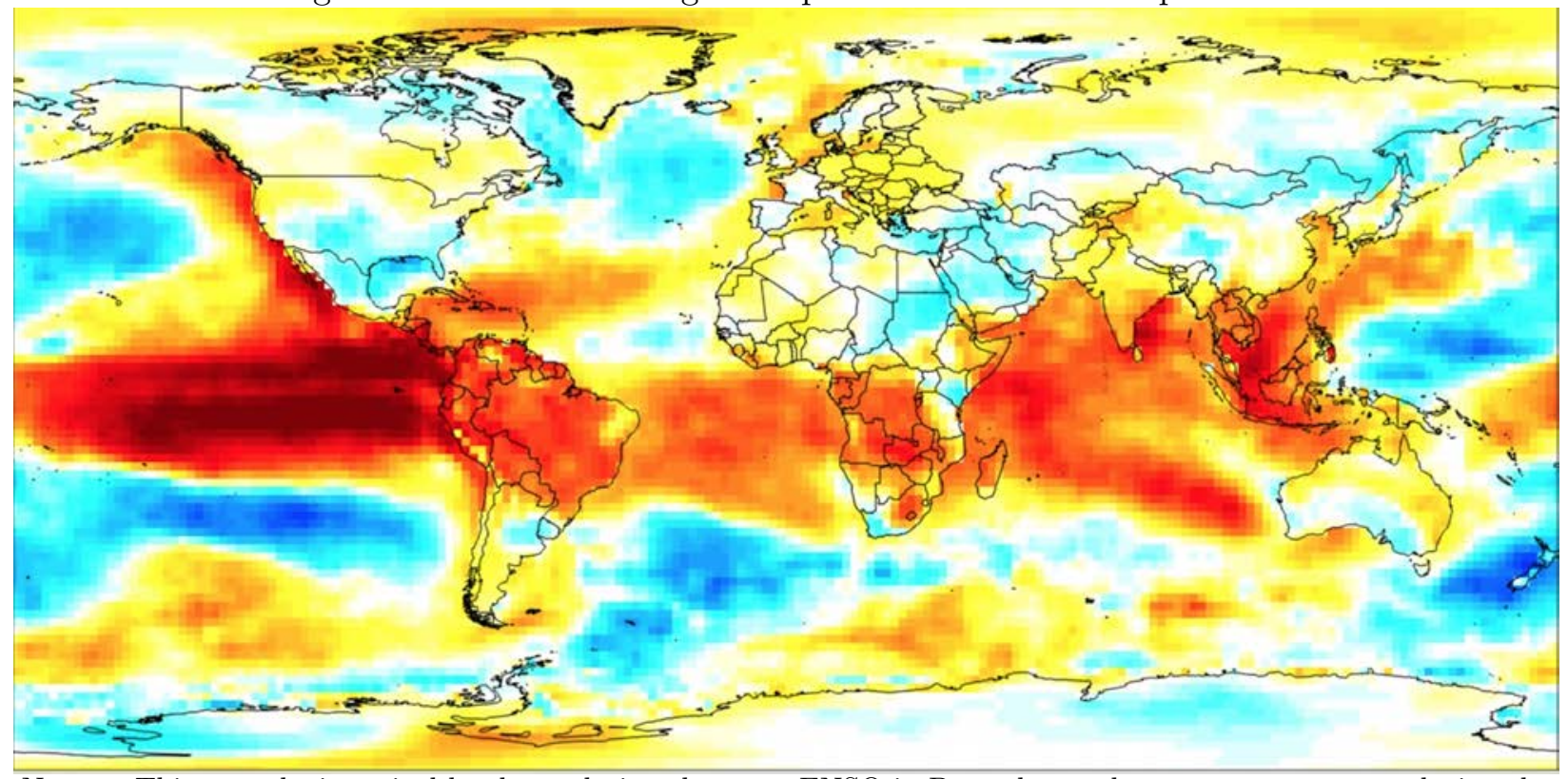

Notes: This map depicts pixel-level correlations between ENSO in December and average temperature during the following February for 1961-2013. Red areas are hotter with warmer ENSO conditions. Blue areas are cooler with warmer ENSO conditions.

In Section 4, we examine the effect of this global natural experiment on the distribution of the gains from trade in cereals. In an important class of trade models, a country's gains from trade are revealed by the share of its expenditure devoted to imports (Arkolakis, Costinot and 
Rodríguez-Clare, 2012). We estimate how local temperature-driven and global ENSO-driven variation in cereal productivities affect these expenditure shares. When productivities are more spatially correlated, more productive countries import more. According to the model, greater spatial correlation of productivities causes more productive countries to gain relatively more from trade and less productive countries to gain less. Specifically, increasing the cross-sectional spatial correlation of cereal productivities by one standard deviation increases the inequality of welfare attributable to cereal consumption by $2 \%$.

We take several steps to validate this interpretation of the difference in trade patterns. In particular, our welfare quantification relies on a class of trade models in which there is no spatial correlation in the pattern of comparative advantage within the cereals sector. In alternative trade models with spatially correlated comparative advantage (see Appendix A.4), a country may have lower gains from trade when its neighbors are more productive, so that higher spatial correlation of all-cereals productivity would decrease welfare inequality. Three results suggest this is unlikely. First, sufficiently spatially correlated comparative advantage within cereals would imply that ENSO would alter the expenditure-productivity relationship with the opposite sign of our estimated effect. Second, gravity regressions do not reject the hypothesis that the trade elasticity is invariant to bilateral distance, suggesting comparative advantage within the cereals sector is not spatially correlated. Third, we examine an alternative outcome variable that accommodates arbitrary patterns of comparative advantage: a local approximation of the change in the terms of trade (Dixit and Norman, 1980). This measure also shows that greater spatial correlation of all-cereals productivity increases welfare inequality.

Understanding the consequences of global phenomena like anthropogenic climate change requires quantifying both local direct effects and indirect effects due to spatial linkages. Researchers often face a trade-off between using plausibly exogenous variation to estimate treatment effects and capturing indirect effects due to spatial linkages. Quasi-experimental research designs typically estimate local direct effects but ignore spatial linkages, while structural models quantify indirect effects but impose many functional-form assumptions.

In Section 5, we develop a hybrid approach that incorporates the spatial correlation of productivities when projecting climate-change impacts without imposing the full structure of quantitative trade models. A growing empirical literature examines how economic outcomes respond to quasi-experimental variation in local temperatures. ${ }^{2}$ Typically, projected climate impacts for any location are the product of these estimated effects and that location's temperature trajectory under climate change, holding temperatures in other locations fixed. The projected global impact of climate change is then the sum of these isolated impacts across locations. This calculation, however, amounts to asking what would happen if, say, Kenya were to warm by itself, without acknowledging that global climate change will also simultaneously warm Ethiopia, Tanzania, and Canada. In doing so, this approach fundamentally overlooks the global scope of anthropogenic climate change

\footnotetext{
${ }^{2}$ Following seminal studies of the United States (Deschênes and Greenstone, 2007a,b; Schlenker and Roberts, 2009), quasi-experimental local temperature variation has been used to study various economic effects around the world (e.g., Dell, Jones and Olken 2012; Burke, Hsiang and Miguel 2015; Carleton et al. 2020).
} 
(Dell, Jones and Olken, 2014; Hsiang, 2016; Auffhammer, 2018; Deschênes and Meng, 2018).

We produce new climate impact projections that leverage quasi-experimental estimates while accounting for changes in the spatial correlation of cereal productivity. Prior quasi-experimental studies project increased dispersion in various economic outcomes across countries (Dell, Jones and Olken, 2012; Burke, Hsiang and Miguel, 2015). We show that incorporating spatial linkages leads to a $20 \%$ greater increase in the inequality of welfare from cereal consumption by the end of the twenty-first century. Notably, a projection that omits the change in spatial correlation considerably understates the climate-driven welfare losses for most countries in Africa because these countries jointly experience larger productivity losses. While these projections are not literal forecasts of future climate impacts because they abstract from adaptation, migration, and other possible responses, they demonstrate how one can extend quasi-experimental research designs to examine the consequences of spatial interdependence. In doing so, this paper brings the quasi-experimental approach to climate-change impacts conceptually closer to recent structural analyses of the spatial distribution of economic activity under climate change (Brock, Engström and Xepapadeas, 2014; Desmet and Rossi-Hansberg, 2015; Krusell and Smith, 2022).

This paper connects studies of environmental determinants of economic outcomes to the literature on economic geography. Local environmental conditions alter economic activity by influencing factor productivities, human capital accumulation, and institutional quality (Bloom and Sachs, 1998; Easterly and Levine, 2003; Nordhaus, 2006; Bleakley, 2007; Nunn and Puga, 2012). We explore how local economic outcomes depend on environmental conditions elsewhere via trade. Generally, countries with better access to trading partners have higher incomes (Head and Mayer, 2004; Redding and Venables, 2004). Our results link the distribution of the gains from trade to the spatial correlation of productivities. The most closely related study of global agricultural trade is by Costinot, Donaldson and Smith (2016), who examine the consequences of climate change using a model of international trade and an agronomic productivity forecast. While we focus on the spatial correlation of absolute advantage, they focus on changes in comparative advantage and within-country crop switching. While they employ agronomic forecasts to predict changes in trade flows, we investigate the trade effects of historical variation in agricultural productivities.

\section{Theoretical framework}

This section introduces a theoretical framework to show how the spatial correlation of productivities may affect international inequality and to guide our empirical investigation of this prediction. Section 2.1 introduces a class of models in which a country's gains from trade are revealed by the share of its expenditure devoted to its own output. We use a stylized example to illustrate how the spatial correlation of the productivity distribution affects welfare inequality by altering the covariance between a country's productivity and its domestic share of expenditure. ${ }^{3}$ Section 2.2

\footnotetext{
${ }^{3}$ Spatial correlation of productivity need not alter average welfare: on a symmetric geography, proximity to productivity is necessarily zero-sum. Hence our focus on its consequences for international inequality.
} 
describes how we can estimate this relationship using panel data and why we study the cereals sector. Further details and derivations are available in Appendix A.

\subsection{Spatial correlation and welfare inequality}

We study the class of models characterized by Arkolakis, Costinot and Rodríguez-Clare (2012), in which the gains from trade can be inferred from the domestic share of expenditure. This class includes Armington (1969), Krugman (1980), Eaton and Kortum (2002), and Melitz (2003) with a Pareto productivity distribution. ${ }^{4}$ We summarize the perfect-competition case in the main text, while Appendix A.1 provides details and covers the monopolistic-competition models. The world economy consists of $j=1, \ldots, N$ countries.

Preferences. Individuals in country $j$ have constant-elasticity-of-substitution preferences over goods.

Production. There is one factor of production. Perfectly competitive firms employ a production technology that exhibits constant returns to scale and depends on productivity $A_{j}$. Each country $j$ inelastically supplies $L_{j}$ units that earn factor price $w_{j}$, so national income is $Y_{j}=w_{j} L_{j}$.

Trade costs. There are iceberg trade costs, such that selling one unit of a good to $j$ from $i$ requires producing $\tau_{i j} \geq 1$ units, with $\tau_{i i}=1$.

Gravity equation. Denote sales from $i$ to $j$ by $X_{i j}$ and $j$ 's total expenditure by $X_{j} \equiv \sum_{i=1}^{N} X_{i j}$. The share of expenditure by $j$ on goods from $i, \lambda_{i j}$, is given by a gravity equation:

$$
\lambda_{i j}=\frac{X_{i j}}{X_{j}}=\frac{A_{i}^{\epsilon}\left(\tau_{i j} w_{i}\right)^{-\epsilon}}{\sum_{l=1}^{N} A_{l}^{\epsilon}\left(\tau_{l j} w_{l}\right)^{-\epsilon}},
$$

where $\epsilon$ is the "trade elasticity" governing how bilateral expenditures respond to bilateral trade costs.

Equilibrium. In equilibrium, labor markets clear, goods markets clear, and budget constraints are satisfied such that income $Y_{i}$ equals expenditure $X_{i}$. Thus, equilibrium incomes $\left\{Y_{i}\right\}_{i=1}^{N}$ satisfy $Y_{i}=\sum_{j=1}^{N} \lambda_{i j} Y_{j}$.

A country's welfare is the sum of its welfare in autarky and its gains from trade, and in this class of models the latter can be inferred from expenditure shares. Real consumption per capita is

$$
\ln \left(C_{i} / L_{i}\right)=\ln A_{i}+\gamma-\frac{1}{\epsilon} \ln \lambda_{i i}
$$

where $\gamma$ is a model-specific constant unrelated to productivity. The former term, $\ln A_{i}+\gamma$, is per capita welfare in autarky. Absent trade, a country's welfare depends on only its own productivity: it purchases only its own goods, so $\lambda_{i i}=1$ and $\ln \lambda_{i i}=0$. The latter term, $-\frac{1}{\epsilon} \ln \lambda_{i i}$, is its gains from trade relative to autarky. This sufficient statistic depends on the trade elasticity $\epsilon$ and the country's expenditure share on its own goods, which is a function of trade costs and all other countries' productivities. When a country imports goods from other countries, $\lambda_{i i}<1$ and its gains

\footnotetext{
${ }^{4}$ As is common in trade theory, we abstract from dynamics and risk by studying static models.
} 
from trade are positive. ${ }^{5}$ Importantly, the domestic share of expenditure is an observed outcome capturing the gains from trade: given the trade elasticity, a lower domestic share of expenditure implies larger gains from trade.

From equation (1), the variance of welfare across countries is the sum of the variance of productivity, the covariance of productivities and gains from trade, and the variance of those gains.

$$
\operatorname{var}\left(\ln \left(C_{i} / L_{i}\right)\right)=\operatorname{var}\left(\ln A_{i}\right)+2 \operatorname{cov}\left(\ln A_{i},-\frac{1}{\epsilon} \ln \lambda_{i i}\right)+\operatorname{var}\left(\frac{1}{\epsilon} \ln \lambda_{i i}\right)
$$

The spatial correlation of productivities affects international inequality through the second term: the covariance of productivity and gains from trade. ${ }^{6}$

By making neighboring countries have more similar productivities, spatial correlation interacts with two key features of international trade. First, a country benefits by trading with more productive counterparts, which demand more of its exports and sell it cheaper imports. Second, trade costs increase with geographic distance (Disdier and Head, 2008). Thus, when proximate countries have more similar productivity levels, more productive countries tend to enjoy greater gains from trade because more productive trading partners are nearby. Conversely, less productive countries experience lower gains from trade because more productive trading partners are farther away. When more productive countries gain more from trade than less productive countries, welfare inequality is greater. Appendix A.2 makes this argument in detail, presenting results of a local approximation, an analytical proof for a four-country model, and numerical simulations of a many-country model with a realistic geography. ${ }^{7}$ Here, we present the results from a highly stylized model in order to illustrate the economic logic and relevant empirical considerations.

The stylized model has productivity follow a sine wave over a one-dimensional space. There are $N$ countries with equal population sizes evenly spaced on the unit circle. Trade costs depend only on distance: the log trade cost between two countries is proportionate to the log distance between them. The trade elasticity is $\epsilon=1$, so that welfare is $\ln A_{i}-\ln \lambda_{i i}$, a difference that is easy to depict visually. Productivity $\ln A_{i}$ follows a sine-wave distribution, with an integer frequency of $\theta$ over the circle's circumference. This distribution has two convenient properties. First, its spatial correlation is governed by $\theta$ : lower frequencies exhibit greater spatial correlation. Second, its mean, variance, skewness, and kurtosis are independent of this frequency.

The left panel of Figure 3 depicts the spatial distributions of productivities ( $\ln A_{i}$, in black), welfare $\left(\ln C_{i}\right.$, in blue), and domestic shares of expenditure $\left(\ln \lambda_{i i}\right.$, in red) in this circular economy for the cases in which the sine wave has frequencies of $\theta=1$ and $\theta=4$. It is clear that the spatial correlation of productivities is greater in the $\theta=1$ case, as location "zero" divides the circle into

\footnotetext{
${ }^{5}$ Since expenditure shares depend on relative prices, this share is closely linked to the country's terms of trade, which is the relative price of its exports compared to its imports. We return to this insight later when considering an alternative gains-from-trade measure under weaker theoretical assumptions.

${ }^{6}$ The first term, the variance of productivity, is invariant to spatial correlation by definition. For empirically relevant values of $\epsilon$, the third term is an order of magnitude smaller than the second term, as explained in Appendix A.1.

${ }^{7}$ To examine our prediction with realistic productivities and trade costs, we simulate a global economy made up of 158 countries whose geographic coordinates, cereal yields, and crop areas are their 1961-2013 averages in our data.
} 
two contiguous regions with above-average and below-average productivity. In this case, productive economies only need to ship their goods a short distance to reach the most productive economy, while the least productive country must ship its goods halfway around the world to reach it. This contrasts with the $\theta=4$ case, in which distances between the most and least productive countries are shorter.

Figure 3: Circular geography with productivity sine wave
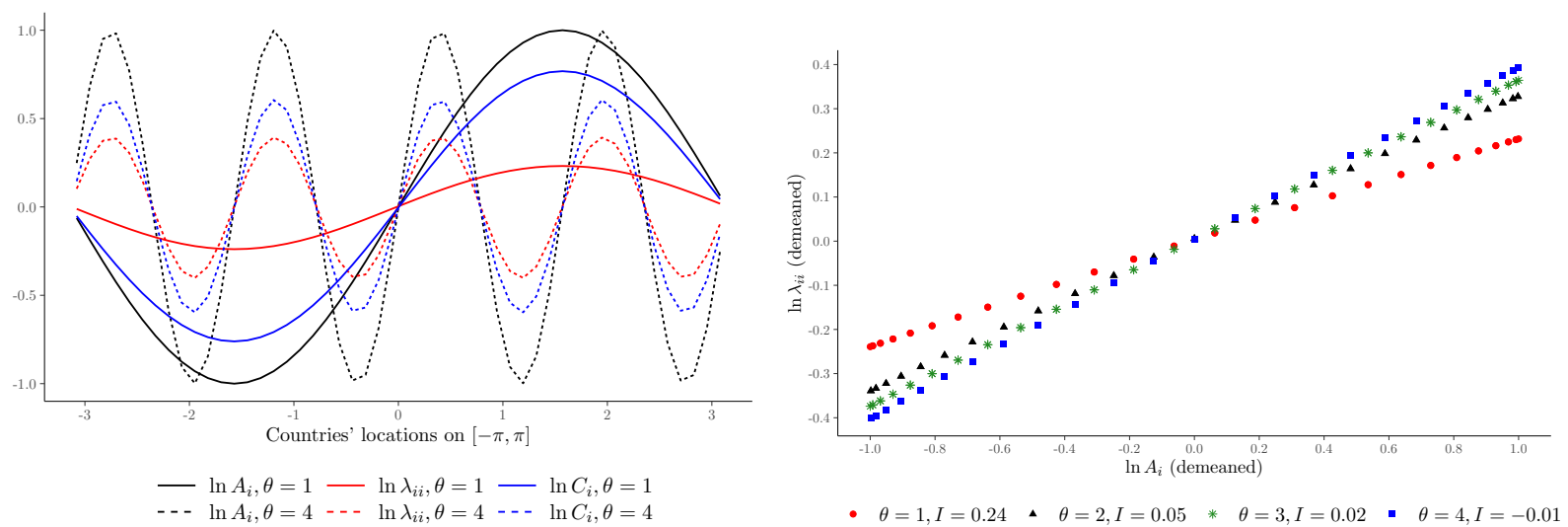

Notes: This figure depicts an economy with a circular geography and a productivity distribution that follows a sine wave with frequency $\theta$. There are $N=50$ locations evenly spaced on the unit circle. Bilateral log trade costs are proportionate to the log length of the arc between two points on the circle. The trade elasticity is $\epsilon=1$, so that welfare is simply the difference $\ln A_{i}-\ln \lambda_{i i}$. See Appendix A.2.3 for parameterization details. By Theorem 1 of Allen, Arkolakis and Takahashi (2020), the equilibrium solution depicted for each set of parameter values is unique. The left panel depicts the (demeaned) distributions of productivities, equilibrium domestic shares of expenditure, and welfare are depicted for the cases of $\theta=1$ and $\theta=4$. The right panel depicts the $\ln \lambda_{i i}-\ln A_{i}$ relationship for the cases of $\theta=1,2,3,4$. The right panel's legend reports the value of Moran's $I$ for each sine wave.

The frequency of the exogenous productivity sine wave affects the amplitude of the endogenous welfare sine wave. In the case of higher spatial correlation $(\theta=1)$, the amplitude of the welfare series is greater than in the $\theta=4$ case. This follows from the fact that the equilibrium domestic share of expenditure series has a smaller amplitude in the $\theta=1$ case, and welfare is the difference between the productivity and expenditure-share series. In other words, with greater spatial correlation, the expenditure series follows the productivity series less closely: $\operatorname{cov}\left(\ln A_{i}, \ln \lambda_{i i}\right)$ is smaller and thus $2 \operatorname{cov}\left(\ln A_{i},-\frac{1}{\epsilon} \ln \lambda_{i i}\right)$ is greater. ${ }^{8}$

The right panel of Figure 3 depicts the relationship between productivity and the domestic share of expenditure for more values of the sine-wave frequency, $\theta$. The scatter plot reveals an almost perfectly linear relationship between $\ln \lambda_{i i}$ and $\ln A_{i}$. The slope of this relationship, which is proportionate to $\operatorname{cov}\left(\ln A_{i}, \ln \lambda_{i i}\right)$, systematically varies with the spatial correlation of the sine wave. When the productivities are more spatially correlated, a location's domestic share of expenditure is less responsive to its own productivity level. Our empirical investigation examines the relationship between these observable outcomes to discern the consequences of spatial correlation for welfare inequality.

\footnotetext{
${ }^{8}$ We assume here that the trade elasticity $\epsilon$ is invariant to the global spatial correlation of productivities. Section 3.2 and Appendix $\mathrm{C}$ show that our empirical setting satisfies this assumption.
} 


\subsection{From theory to empirics}

We have illustrated the consequence of spatial correlation of productivities for global welfare inequality in an ideal environment that holds fixed all other economic elements. Our empirical investigation of how spatial correlation affects the covariance of productivity and gains from trade must further allow for a realistic geography, arbitrary productivity distributions, the presence of other determinants of equilibrium trade flows, and multiple sectors. Appendix A.2 presents a number of models with these features to motivate our empirical research design and Appendix A.3 shows that our prediction holds for each sector in a multi-sector gravity model. To summarize our empirical implementation, we examine our ceteris paribus prediction by exploiting year-to-year variation in the global cross-sectional spatial correlation of productivities for our sector of interest in a panel-data setting.

To accommodate a realistic geography, we measure the global spatial correlation of productivities in year $t$ using Moran's $I$, a measure defined on any geography endowed with a distance metric:

$$
I_{t} \equiv \frac{N}{\sum_{i} \sum_{j \neq i} \omega_{i j}} \frac{\sum_{i} \sum_{j \neq i} \omega_{i j}\left(\ln A_{i t}-\overline{\ln A_{t}}\right)\left(\ln A_{j t}-\overline{\ln A_{t}}\right)}{\sum_{\ell}\left(\ln A_{\ell t}-\overline{\ln A_{t}}\right)^{2}} .
$$

In this formula, $N$ is the number of countries, $\omega_{i j}=\omega_{j i}$ is a symmetric spatial weight that depends on the distance between countries $i$ and $j$, and $\overline{\ln A_{t}} \equiv \frac{1}{N} \sum_{i} \ln A_{i t}$ is average productivity in year $t$. In the circular sine-wave economy of Section 2.1, Moran's $I$ is 0.242 and -0.011 for the $\theta=1$ and $\theta=4$ cases, respectively.

We use panel data to address other determinants of the domestic share of expenditure that may be correlated with productivity. For example, remote countries face higher-than-average trade costs that raise their domestic share of expenditure and remote countries may also exhibit lower productivities. In our panel setting, time-invariant country characteristics that influence the domestic share of expenditure and might be correlated with productivity can be absorbed by country fixed effects. ${ }^{9}$ Likewise, year fixed effects absorb potentially confounding time-varying global shocks, and country-specific trends absorb secular local growth in productivity and trade.

Using a panel of countries at an annual frequency, we estimate the following regression:

$$
\ln \lambda_{i i t}=\beta_{0} \ln A_{i t}+\beta_{1} I_{t} \ln A_{i t}+\Pi^{\prime} \mathbb{Z}_{i t}+\mu_{i t},
$$

where $\lambda_{i i t}$ is country $i$ 's domestic share of expenditure in year $t, A_{i t}$ is its productivity, $I_{t}$ is the Moran's $I$ statistic for the spatial correlation of productivities, and the vector $\mathbb{Z}_{i t}$ includes country fixed effects, year fixed effects, and country-specific time trends. $\mu_{i t}$ is a residual due to unobserved shocks and the linear approximation.

$\beta_{0}$ and $\beta_{1}$ are reduced-form parameters describing the covariance of interest. $\beta_{0}$ captures the relationship between a country's gains from trade and productivity when Moran's $I$ is zero. $\beta_{1}$ captures the degree to which the global spatial correlation of productivities mediates this covariance

\footnotetext{
${ }^{9}$ Appendix A.2.3 illustrates this logic for the case of heterogeneous population sizes.
} 
between gains from trade and productivity. ${ }^{10}$ When $\beta_{1}<0$, greater spatial correlation lowers the covariance of productivity and the domestic share of expenditure, implying a higher covariance between productivity $\ln A_{i}$ and the sufficient statistic for the gains from trade, $\frac{-1}{\epsilon} \ln \lambda_{i i}$. When greater spatial correlation of productivities causes more productive countries to experience greater gains from trade and less productive countries to experience lower gains from trade, international inequality increases.

Our choice of empirical setting is guided by four criteria. First, trade flows must decline with distance so that countries tend to trade with their neighbors. Second, examining the role of the spatial correlation of productivities across a trade network requires a measure of productivity reported in comparable terms across the globe. Third, examining global spatial correlation requires sufficient time-series variation to identify its effects. Fourth, the identifying variation in productivities and their global spatial correlation needs to be plausibly exogenous to infer a causal relationship.

To satisfy these criteria, we study the cereals sector, which we define as the top eight cereals that account for more than $99 \%$ of global cereal production and trade. ${ }^{11}$ Trade in cereals declines with distance: column 1 of Table C.1 shows that bilateral trade in cereals declines with physical distance with an elasticity and overall explanatory power that is typical of prior estimates for aggregate trade flows (Head and Mayer, 2014). Cereals satisfy the second and third criteria because a measure of productivity, cereal yield (the output-land ratio), is available at the country-year level with nearly global coverage since 1961 from the United Nations Food and Agriculture Organization (FAO). ${ }^{12,13}$

Our fourth criteria requires exogenous variation in national cereal productivities and their global spatial correlation. Estimating equation (3) by ordinary least squares (OLS) is uninformative if expenditure shares and productivity are simultaneously determined or if there are omitted determinants of expenditure shares that are correlated with productivity. ${ }^{14}$ In an ideal experiment, a

\footnotetext{
${ }^{10}$ While equation (3) is a reduced-form regression, Appendix A.2.4 shows that it captures $93 \%$ of the welfare variance generated under our most realistic trade model.

${ }^{11}$ These cereals are barley, maize, millet, oats, rice, rye, sorghum, and wheat. According to the FAO, these eight cereals constituted $99.3 \%$ of global production (in metric tons) and $99.6 \%$ of global trade (in nominal US dollars) during 1961-2013. These cereals are not homogeneous goods. FAO data report quantities of wheat produced, but trade data distinguish durum and non-durum wheat. Trade data distinguish four types of rice, but the International Rice Genebank holds more than 125,000 rice varieties, which are differentiated by quality, appearance, and taste (Agcaoili-Sombilla and Rosegrant, 1994). Quantitative trade models make common predictions about trade flows while making different assumptions about the set of goods in the utility function. We study expenditure shares, so we need not map our data sources' product definitions to goods indexed by $\omega$ in the theoretical framework.

${ }^{12}$ If land and other inputs are perfect complements in the production of cereals, yield equals total factor productivity (TFP) (Costinot, Donaldson and Smith, 2016). More generally, land productivity and TFP may differ, in which case one needs an instrument for yield that shifts its TFP component. Using weather as a source of exogenous variation in cereal yields is a popular research design (e.g., Roberts and Schlenker 2013) that dates to the first application of instrumental variables (Wright, 1928).

${ }^{13}$ Unfortunately, data on other sectors' expenditure shares and productivities lack the spatial and temporal coverage necessary for our empirical analysis. Data availability also necessitates studying cereal trade at the level of countries. Annual data on agricultural productivity, internal trade, and population counts for subnational spatial units have not been collected by most countries for most years. We therefore focus on international trade and the spatial correlation of productivities across countries.

${ }^{14}$ For example, demand shocks could affect expenditure shares and elicit supply responses that change average yields. Similarly, if domestic cereal production employs imported intermediate goods, then unobserved trade-cost shocks could jointly affect domestic cereal yields and the domestic share of expenditure.
} 
researcher would manipulate productivities around the world in a way that alters the global spatial correlation of productivities without changing the global mean or variance of productivities. Such an experiment is obviously not possible. However, because of the well-established sensitivity of cereal yields to environmental conditions (Schlenker and Roberts, 2009; Hsiang and Meng, 2015), we are able to approximate this ideal experiment by exploiting productivity variation attributable to temperature variation and a global climatic phenomenon known as the El Niño-Southern Oscillation (ENSO), described in the following section.

Finally, translating the consequences of spatial correlation for trade patterns into welfare consequences relies on the assumptions made in the Arkolakis, Costinot and Rodríguez-Clare (2012) class of models. In particular, this theoretical framework assumes that the pattern of comparative advantage within the sector is symmetric across countries so that the exports of neighboring and distant economies are similarly substitutable. ${ }^{15}$ Most quantitative trade models assume this pattern of comparative advantage. ${ }^{16}$ However, as Appendix A.4 shows, in alternative trade models with spatially correlated patterns of comparative advantage, a country may have lower gains from trade when its neighbors are more productive.

Three empirical findings address this potential concern about spatially correlated comparative advantage. First, if comparative advantage were sufficiently spatially correlated, $\beta_{1}$ in equation (3) would be positive (see Appendix A.4). Our estimates of $\beta_{1}$ in Sections 4.2 and 4.3 are negative. Second, per Lind and Ramondo (2019), spatially correlated comparative advantage would require the trade elasticity to vary with the distance between trading partners. Gravity regressions cannot reject the hypothesis that the trade elasticity is invariant to bilateral distance (see column 3 of Table C.1), suggesting comparative advantage within cereals is not spatially correlated. Third, we find qualitatively consistent results when examining an alternative outcome variable that is informative under much weaker theoretical assumptions.

Specifically, we examine changes in the terms of trade - changes in the prices of exports relative to imports - as measured by the product of price changes and the previous period's traded quantities (Dixit and Norman, 1980, p.132). A country's terms of trade improve if its initial net import vector is cheaper at the new prices than at the old prices. ${ }^{17}$ This measure is attractive because it only requires a revealed-preference argument. Unfortunately, unlike the domestic share of expenditure modeled in equation (3), this measure limits any conclusions about the welfare consequences of trade to its sign: whether a country's terms of trade improved or deteriorated. We use this outcome variable in Section 4.4 and find the same welfare consequences of greater spatial correlation as we

\footnotetext{
${ }^{15}$ Comparative advantage causes countries to gain by specializing and trading with each other. Absolute advantage affects how these gains from trade are divided between countries through the terms of trade. Our prediction concerns the spatial correlation of absolute advantage. In Appendix A.4, we examine how the spatial correlation of comparative advantage may interact with the spatial correlation of absolute advantage.

${ }^{16}$ A notable exception is recent work by Lind and Ramondo (2019) that generalizes quantitative Ricardian models by tractably relaxing this assumption.

${ }^{17}$ To see the connection between gains from trade and terms of trade in quantitative trade models, consider the Armington case detailed in Appendix Section A.1. In that model, the gains from trade are given by the price of a country's export relative to its consumer price index, $\lambda_{i i}^{-\frac{1}{\epsilon}}=p_{i} /\left[\sum_{l=1}^{N}\left(p_{l i}\right)^{-\epsilon}\right]^{-1 / \epsilon}$.
} 
do when making stronger assumptions.

\section{The El Niño-Southern Oscillation}

This section first summarizes the basic physics of ENSO and then empirically demonstrates that it drives annual variation in the global spatial correlation of cereal productivity.

\subsection{Background}

ENSO is a naturally occurring, annual climatic phenomenon characterized by mutually reinforcing circulation patterns between the atmosphere and the tropical Pacific ocean. While ENSO originates in the tropical Pacific, it is a major determinant of weather conditions around the world. Indeed, at an annual frequency, ENSO is often recovered as the first principal component of various local atmospheric or oceanographic variables across the planet (Sarachik and Cane, 2010).

ENSO is often colloquially described as consisting of one neutral state and two extreme states. These conditions are broadly characterized by the amount of heat that is released from the tropical Pacific ocean into the atmosphere (Cane and Zebiak, 1985). In typical "ENSO neutral" years, normal circulation patterns pushing westward hold a pool of warm water against Indonesia and other land masses in the South Pacific. A positive "El Niño" state occurs when this circulation pattern weakens such that this pool of warm water spills eastward across a large area of the equatorial Pacific Ocean. With warm water exposed to the atmosphere over a greater sea surface area, El Niño years release more ocean heat into the atmosphere over a relatively short period. The opposite occurs during the negative "La Niña" state. In La Niña years, stronger circulation patterns push the same volume of warm water more firmly against the Indonesian landmass, reducing seasurface contact with the atmosphere and thus reducing heat released from the ocean. While these three distinct states are descriptively convenient, there is in fact a continuum of ENSO conditions corresponding to the amount of heat released into the tropical atmosphere.

ENSO conditions in the tropical Pacific affect the spatial pattern of weather conditions across the planet due to how heat travels when released in the tropics. Because there is almost no Coriolis effect near the equator (a result of the simple facts that the Earth is round and spins), atmospheric signals propagate rapidly throughout the tropics. During a positive ENSO event, the warm air initially released above the tropical Pacific Ocean is propagated throughout the tropics by a transport mechanism in the atmosphere known as an equatorial Kelvin wave that sweeps across the globe, altering weather conditions almost simultaneously throughout the tropics (Chiang and Sobel, 2002). ${ }^{18}$ For this reason, it is often said that the tropical atmosphere is "teleconnected" during a positive ENSO event, as atmospheric conditions in locations distant from each other are linked through this mechanism. Because the equatorial Kelvin wave that connects local weather around the equator is confined primarily to the tropics, the weather conditions that prevail during

\footnotetext{
${ }^{18}$ This tropical phenomenon is described in Hsiang and Meng (2015). For a complete scientific treatment of ENSO physics, see Sarachik and Cane (2010).
} 
a positive ENSO event do not generally extend to higher latitudes, which may in fact experience opposing weather conditions because of changes to atmospheric circulation.

This physical mechanism allows ENSO to induce large areas of the planet to experience similar local temperature, precipitation, humidity, and other weather conditions. The spatial consequences of a positive ENSO event are perhaps best illustrated by temperature. ${ }^{19}$ During a positive ENSO event, temperature conditions around the world are reorganized such that there is a spatially contiguous area of relatively warm temperatures across the tropics and subtropics while almost simultaneously there is a spatially contiguous area of relatively cooler temperatures in higherlatitude locations. The opposite occurs during negative ENSO events: less heat is released into the atmosphere and temperatures across the globe are less spatially organized.

ENSO conditions are typically summarized by the average sea-surface temperature over a fixed area in the tropical Pacific. In our main analysis, we employ the widely used NINO4 index, a statistic defined as average ocean temperature (in degrees Celsius) over a rectangular area bounded by $5^{\circ} \mathrm{S}-5^{\circ} \mathrm{N}, 160^{\circ} \mathrm{E}-150^{\circ} \mathrm{W}$ (see Figure E.2). ${ }^{20}$ Figure 4 plots this monthly ENSO index for 1856-2013, which extends back further than our estimation sample period of 1961-2013. There are two important features of ENSO relevant for our empirical application: (i) the monthly timing of a typical ENSO event and (ii) how an ENSO event influences local temperatures around the planet both spatially and temporally. Due to ENSO's tropical origins, the timing of ENSO events

Figure 4: Monthly ENSO index (1856-2013)

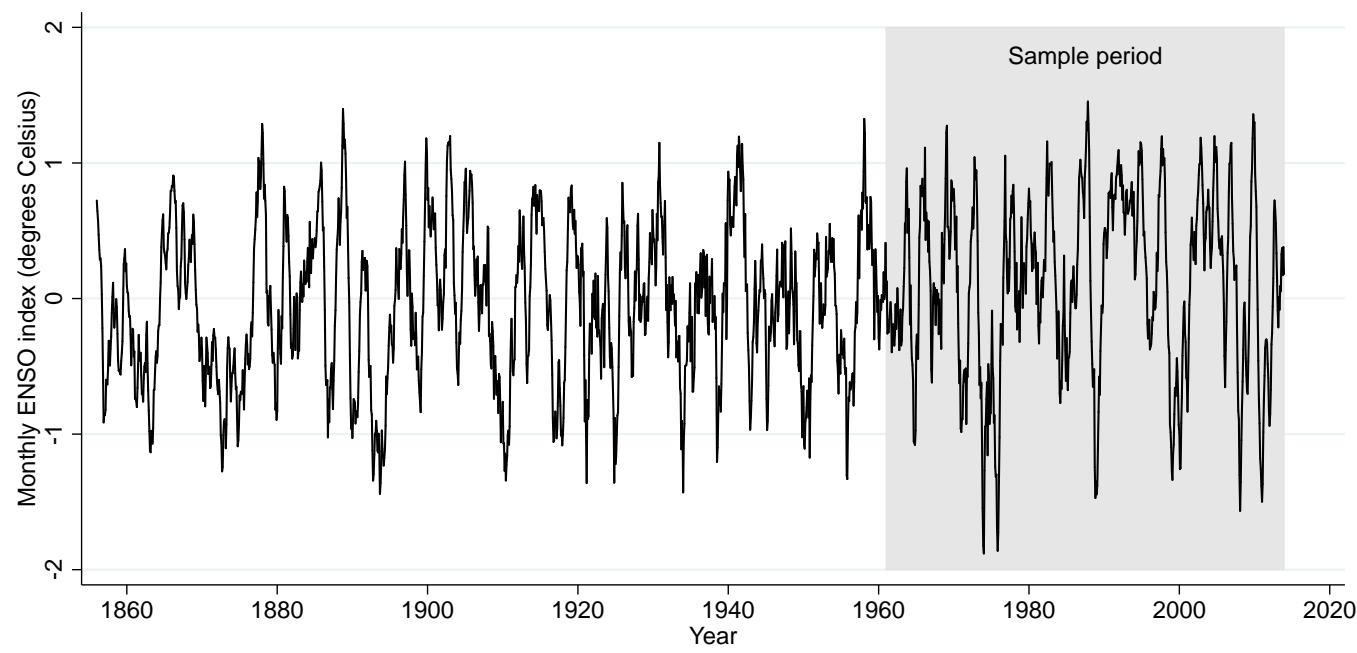

Notes: This figure depicts the monthly ENSO index (i.e., NINO4) during 1856-2013. The shaded area shows our 1961-2013 sample period.

is phase-shifted relative to the calendar year. Figure E.3 illustrates this timing by plotting the monthly ENSO index 12 months before and after a given December for the 10 most positive ENSO

\footnotetext{
${ }^{19}$ ENSO alters the spatial structure of other weather variables but these effects tend to be of smaller spatial scales. For example, during positive ENSO events there is typically flooding over the Pacific coast of South America while the Atlantic coast of South America primarily experiences droughts (Ropelewski and Halpert, 1987).

${ }^{20}$ In robustness checks, we show that using other measures of ENSO yields similar empirical results.
} 
events during 1961-2013. An ENSO event generally begins during April-May of a given year and lasts until the following April-May, an interval known as the "tropical year." Because the ENSO index typically peaks in December, the cleanest annual measure of any ENSO event is simply the December value of the index. ${ }^{21}$ In all following empirical analyses, we use December values as our year-to-year measure of ENSO.

A typical ENSO event affects local temperatures around the planet in a spatially and temporally distinct manner. Figure 5 depicts the month-by-month structure of warming that occurs when the ENSO index increases. Each map displays the time-series correlation of monthly temperatures for each pixel during the specified month and ENSO in month zero, defined as December. Yellow, orange, and red colors indicate locations that warm as the ENSO index increases; blues indicate locations that cool. In the May before a December ENSO event (month -7), the east equatorial Pacific begins to warm. Regions throughout the tropics, both over land and the oceans, continue to warm for the next several months, peaking in the eastern Pacific in December (month 0) and over the rest of the tropics in March and April (months +3 and +4 ). This warming then dissipates across the tropics, with little effect visible more than a year after the December peak. Higher latitudes experience some cooling through these months, though the effect is weaker.

Figure 5 also shows that the local impacts on temperatures around the planet from a single ENSO event straddles two calendar years. When using annual socioeconomic data reported by calendar years, one must therefore examine how outcomes in a given year depend on both ENSO in that year and ENSO in the previous year.

\subsection{ENSO and the spatial correlation of cereal productivity}

The spatial and temporal patterns shown in Figure 5 suggest that ENSO could drive the spatial correlation of cereal yields. Figure 6 shows country-level responses of log cereal yields to a 1-degree increase in the sum of contemporaneous and lagged December ENSO indices. ${ }^{22}$ Consistent with the climatic dynamics described above, increases in the ENSO index tend to lower cereal productivities in countries near the equator and raise cereal productivities in countries far from the equator. This pattern suggests an increase in the spatial correlation of cereal yields.

To quantify global spatial correlation in each year, we construct an annual Moran's I statistic for country-level log cereal yields. ${ }^{23}$ Figure 7 shows the relationship between ENSO and the global spatial correlation of cereal productivity. To characterize the ENSO phenomenon in terms of a scalar, we plot the sum of December ENSO indices in years $t$ and $t-1$ on the horizontal axis and Moran's $I$ in year $t$ on the vertical axis. An increase in the ENSO index raises this measure of

\footnotetext{
${ }^{21}$ This measure of ENSO is stationary and does not exhibit serial correlation. A Dickey-Fuller test strongly rejects the presence of a unit root in favor of stationarity $(\mathrm{p}=4.15 \mathrm{e}-21)$. We do not detect any statistically significant coefficients when estimating a time series regression of our annual December NINO4 measure of ENSO on a constant, a linear trend, and five lagged terms with optimal bandwidth Newey-West standard errors.

${ }^{22}$ Our country-by-year measure of aggregate cereal yield is the harvested area-weighted cereal-level yield across the eight major cereals. See Appendix B for data details.

${ }^{23}$ In our empirical applications, we use spatial weights $\omega_{i j}=1 /\left(d_{i j}+1\right)$, where $d_{i j}$ is the great-circle distance between the two countries' area-weighted centroids.
} 
Figure 5: Lead and lag local temperature correlation with December ENSO
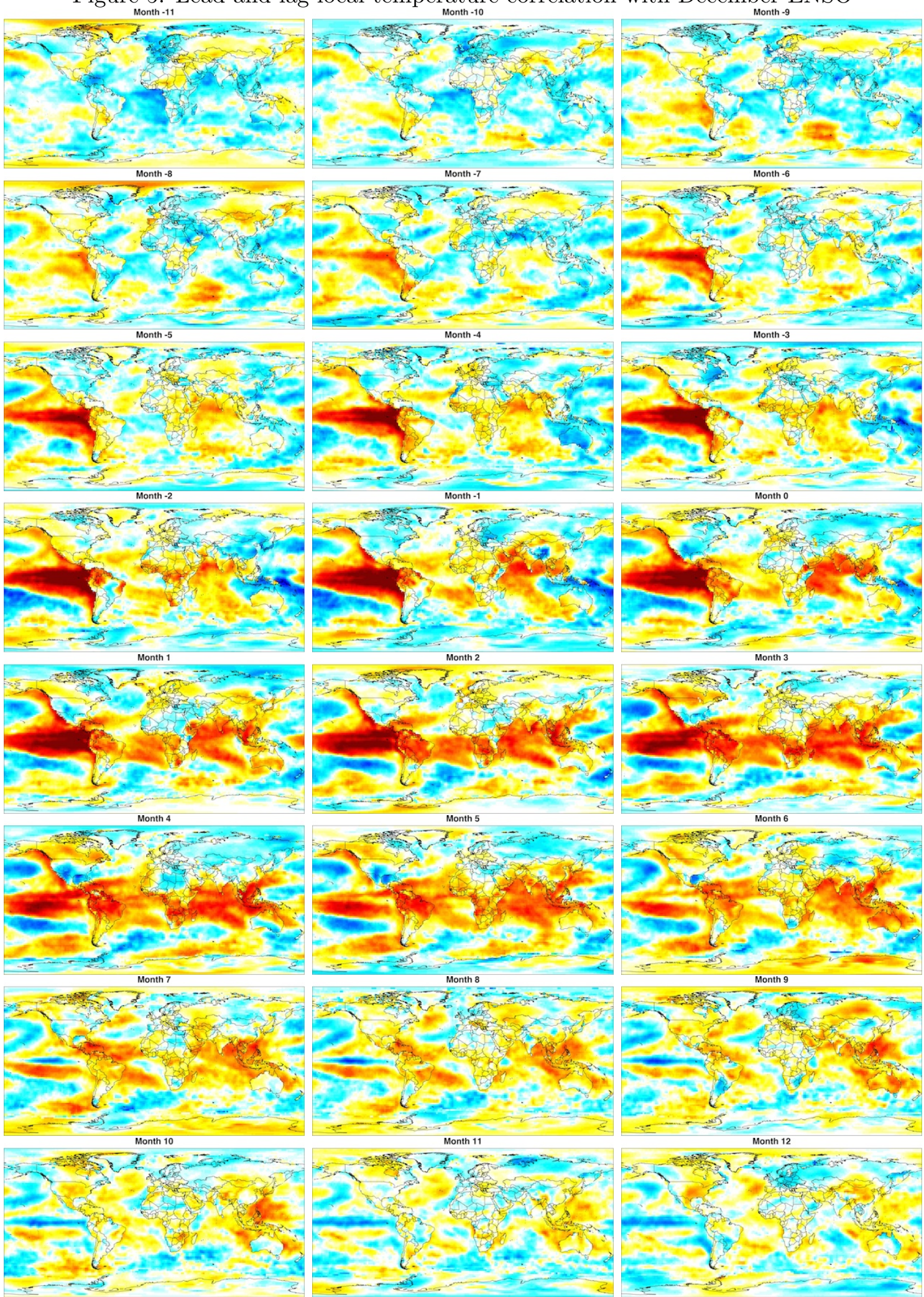

NOTES: Each panel shows pixel-level $\left(0.5^{\circ}\right.$ latitude by $0.5^{\circ}$ longitude resolution $)$ correlation between the ENSO index in December and pixel-level monthly temperatures for 11 months before (lead) and 12 months after (lag) December. Blue shows areas with negative correlation. Red shows areas with positive correlation. 
Figure 6: ENSO's effects on cereal yields

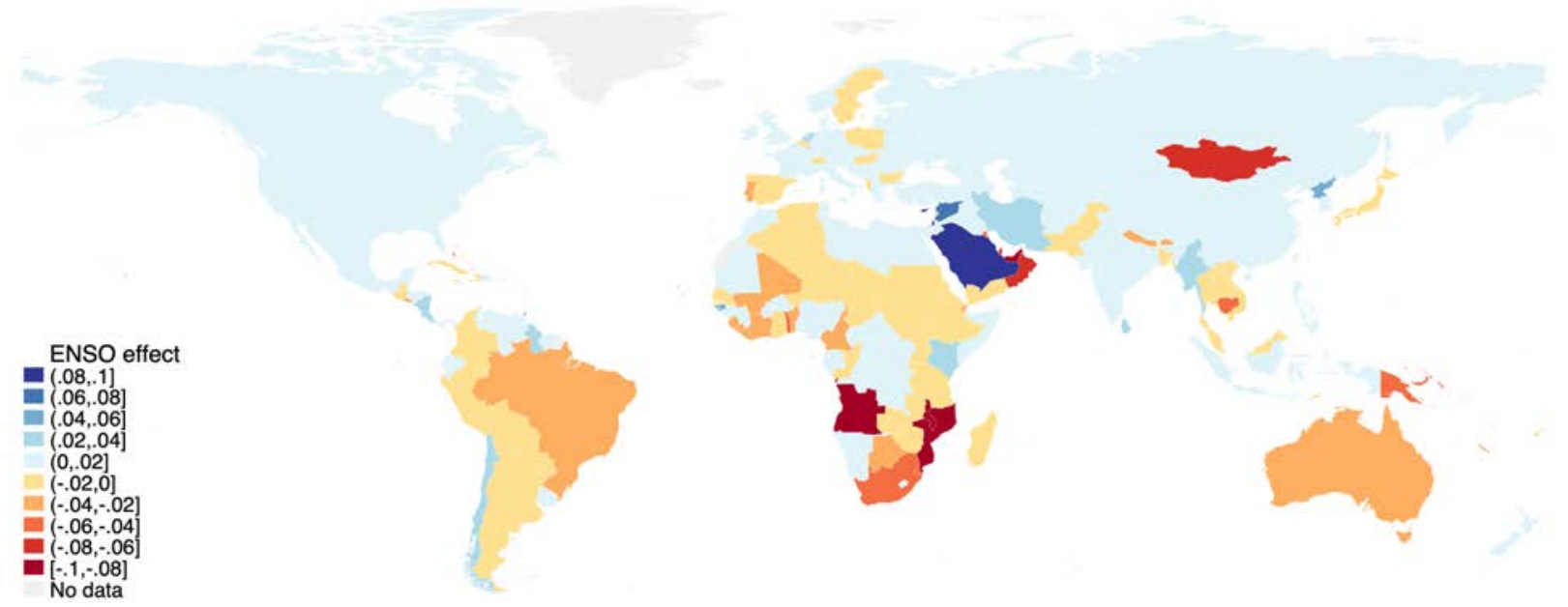

Notes: This map shows the linear coefficient on the sum of contemporaneous and lagged ENSO for each country's log cereal yield. Each country-specific time-series model includes a constant and a linear time trend.

spatial correlation. ENSO, in this simple bivariate model, explains $12 \%$ of annual variation in the spatial correlation of cereal productivities.

Figure 7: Moran's $I$ for log cereal yields and ENSO

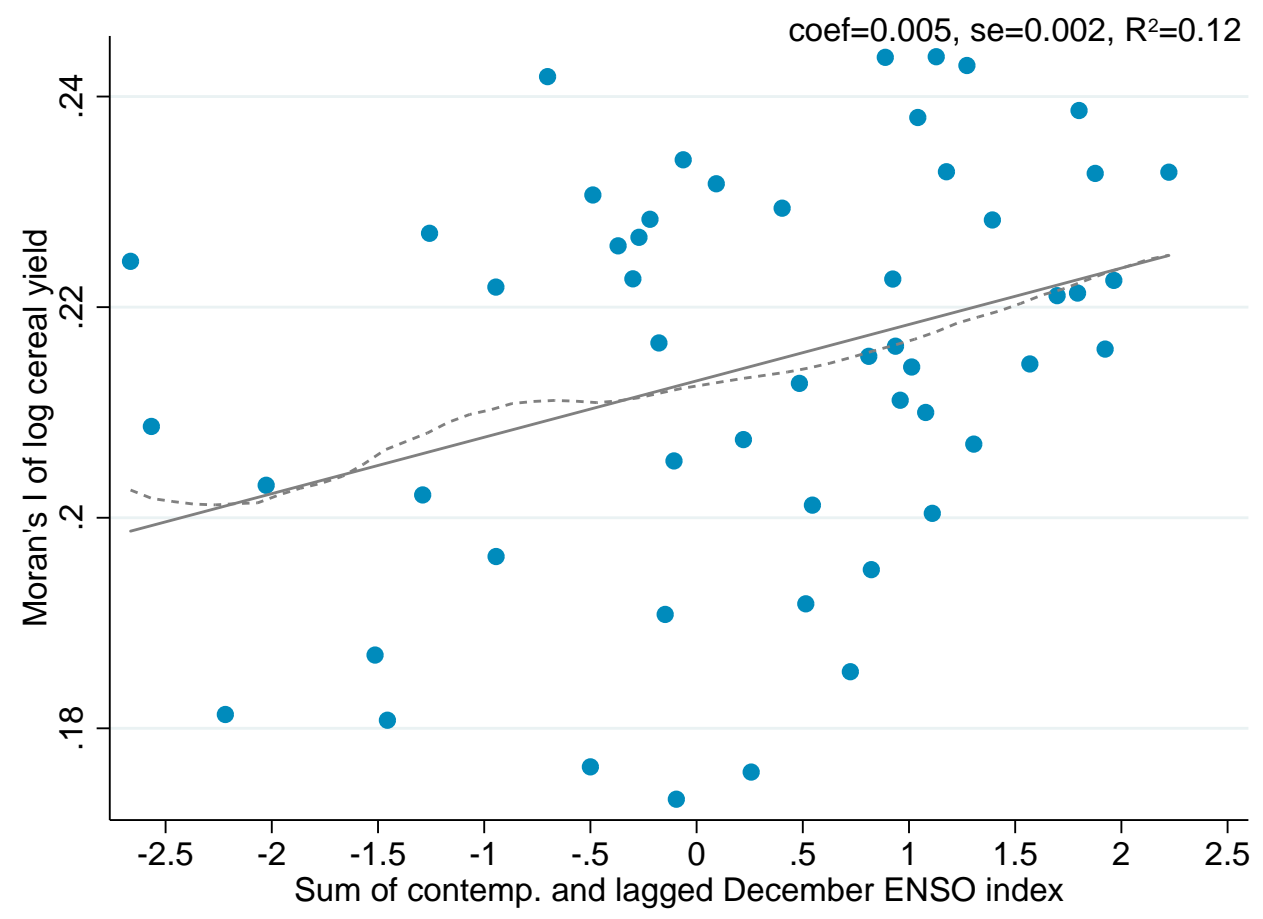

Notes: Figure shows the relationship between Moran's $I$ of crop-weighted country-level log cereal yields in year $t$ and the sum of contemporaneous and lagged December ENSO. The solid line depicts the line of best fit and the dashed series is a local polynomial.

To relax the timing simplification used in Figure 7, Table 1 presents regressions of the annual Moran's I statistic for log cereal yields on flexible polynomial functions of December ENSO in 
years $t$ and $t-1$. Each model includes a linear time trend and reports standard errors robust to serial correlation and heteroskedasticity. In column 1, we include only linear contemporaneous and lagged ENSO terms. Column 2 adds quadratic contemporaneous and lagged ENSO terms and a linear interaction term. Column 3 estimates the linear and quadratic effects for the sum of contemporaneous and lagged ENSO. This more parsimonious specification effectively imposes a common coefficient for $E N S O_{t}$ and $E N S O_{t-1}$ and a common coefficient for $E N S O_{t} \times E N S O_{t-1}$, $E N S O_{t}^{2}$, and $E N S O_{t-1}^{2}$. Looking across the columns of Table 1, two results are evident. First, both contemporaneous and lagged ENSO affect the spatial correlation of cereal productivity but only after controlling for higher-order terms, as shown in column 2. Second, the model in column 3 produces a stronger fit than that in column 2, as summarized by a lower Bayesian Information Criterion (BIC) value. To strike a balance between non-linear flexibility and avoiding overfitting, we use the functional form in column 3 to model the relationship between ENSO and the global spatial correlation of cereal productivity throughout Section 4.

It is natural to wonder whether one could simply drive global spatial correlation of cereal productivity using the global spatial correlation of temperatures rather than ENSO. That measure would capture temperature variation caused by both ENSO and other climatic factors. Column 4 shows that, while the annual Moran's $I$ statistic for temperatures is correlated with the annual Moran's I for cereal productivities, it has lower predictive power than ENSO, as reflected by a higher BIC statistic. This may be because cereal yields depend on other environmental conditions besides temperature, such as precipitation and humidity, many of which also become more spatially correlated under a positive ENSO event. These other environmental channels are captured by ENSO in columns 1-3 and not by the global spatial correlation of only temperature in column 4 . For this reason, our benchmark regression in the following section uses ENSO directly. Consistent with column 4 of Table 1, we show that the regression coefficients are less precisely estimated when we use the spatial correlation of temperatures in place of ENSO.

Finally, consistent with our thought experiment in Section 2.1, ENSO affects neither the global mean nor the variance of cereal productivity, as shown in Figure 8. We have also assumed that the trade elasticity is unaffected by changes in the spatial correlation of productivities. Consistent with this assumption, column 2 of Table C.1 shows that the estimated coefficient on distance in a gravity model of bilateral trade flows is invariant to ENSO. 
Table 1: Moran's I in cereal productivity and ENSO Outcome is Moran-I in log cereal yields

\begin{tabular}{|c|c|c|c|c|}
\hline & $(1)$ & $(2)$ & $(3)$ & $(4)$ \\
\hline$E N S O_{t}$ & $\begin{array}{l}0.008 \\
(0.002)\end{array}$ & $\begin{array}{l}0.008 \\
(0.002) \\
{[0.0001}\end{array}$ & & \\
\hline$E N S O_{t-1}$ & $\begin{array}{l}0.003 \\
(0.002) \\
{[0.121]}\end{array}$ & $\begin{array}{l}0.005 \\
(0.002) \\
{[0.008]}\end{array}$ & & \\
\hline$E N S O_{t} \times E N S O_{t-1}$ & & $\begin{array}{l}0.004 \\
(0.003) \\
{[0.148]}\end{array}$ & & \\
\hline$E N S O_{t}^{2}$ & & $\begin{array}{l}-0.001 \\
(0.002) \\
{[0.639]}\end{array}$ & & \\
\hline$E N S O_{t-1}^{2}$ & & $\begin{array}{c}0.004 \\
(0.003) \\
{[0.197]}\end{array}$ & & \\
\hline$\left(E N S O_{t}+E N S O_{t-1}\right)$ & & & $\begin{array}{c}0.006 \\
(0.001) \\
{[0.000]}\end{array}$ & \\
\hline$\left(E N S O_{t}+E N S O_{t-1}\right)^{2}$ & & & $\begin{array}{c}0.002 \\
(0.001) \\
{[0.070]}\end{array}$ & \\
\hline$I_{t}\left(T_{i t}\right)$ & & & & $\begin{array}{c}0.541 \\
(0.163) \\
{[0.001]}\end{array}$ \\
\hline BIC & -275.84 & -267.21 & -276.63 & -272.95 \\
\hline Observations & 53 & 53 & 53 & 53 \\
\hline
\end{tabular}

Figure 8: Global cross-sectional mean and variance in cereal productivity and ENSO
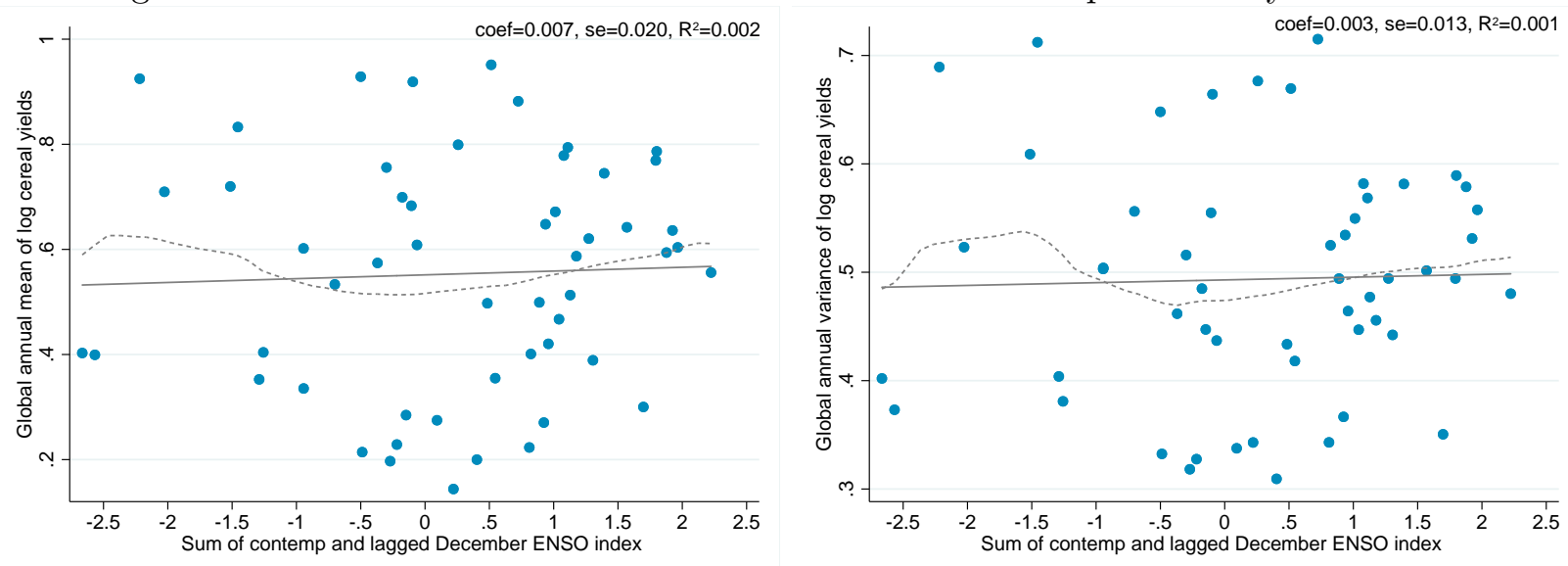

Notes: The left (right) panel shows the relationship between the mean (variance) of cross-sectional country $\log$ cereal yields and the sum of contemporaneous and lagged December ENSO. Linear fit shown as solid line. Local polynomial fit shown as dashed line. 


\section{Empirical results}

The theoretical results in Section 2 suggest that the covariance between agricultural productivity, $\ln A_{i}$, and the domestic share of expenditure, $\ln \lambda_{i i}$, should be lower when productivities are more spatially correlated. This section examines this relationship using exogenous temperatureand ENSO-driven changes in productivities and their global spatial correlation. We describe our estimation strategy in Section 4.1, present the main empirical results in Section 4.2, examine a series of robustness checks in Section 4.3, and corroborate our results using terms-of-trade changes in Section 4.4. Appendix B details our data sources.

\subsection{Estimation strategy}

To estimate equation (3), we employ an instrumental-variables (IV) strategy that exploits plausibly exogenous variation in local yields and the global spatial correlation of yields. To drive local yields, we use country-level crop-area-weighted annual temperature, $T_{i t}$, constructed using data from Willmott and Matsuura (2001) (see Appendix B). As described in Section 3, global spatial correlation of yields is driven by contemporaneous and lagged ENSO.

Equation (3), our second-stage equation, has two endogenous variables, $\ln A_{i t}$ and $I_{t} \ln A_{i t}$. We instrument for them using the following first-stage equations:

$$
\begin{aligned}
\ln A_{i t} & =\alpha_{11}^{\prime} f\left(T_{i t}\right)+\alpha_{12}^{\prime} f\left(T_{i t}\right) g\left(E N S O_{t}+E N S O_{t-1}\right)+\Gamma_{1}^{\prime} \mathbb{Z}_{i t}+v_{1 i t} \\
I_{t} \ln A_{i t} & =\alpha_{21}^{\prime} f\left(T_{i t}\right)+\alpha_{22}^{\prime} f\left(T_{i t}\right) g\left(E N S O_{t}+E N S O_{t-1}\right)+\Gamma_{2}^{\prime} \mathbb{Z}_{i t}+v_{2 i t}
\end{aligned}
$$

where the vector of semi-parametric controls, $\mathbb{Z}_{i t}$, includes the same variables as equation (3). $\alpha_{11}^{\prime}, \alpha_{12}^{\prime}, \alpha_{21}^{\prime}$, and $\alpha_{22}^{\prime}$ are vectors of first-stage coefficients. $f()$ captures the relationship between local temperature and yield; nonlinearity in $f()$ is well documented (Schlenker and Roberts, 2009; Schlenker and Lobell, 2010; Welch et al., 2010; Moore and Lobell, 2015; Proctor et al., 2018). In particular, we model $f()$ as a restricted cubic spline of local temperature; the choice of the number of splines is detailed below. $g()$ captures the relationship between ENSO and the global spatial correlation of yields. Following the model-selection results in Table $1, g()$ is a quadratic function of $\left(E N S O_{t}+E N S O_{t-1}\right)$. $v_{1 i t}$ and $v_{2 i t}$ are error terms.

Nonlinear functional forms for $f()$ and $g()$ are necessary to capture nonlinearities in our firststage equations, but this means that we have more than two instruments for the two endogenous variables. Two-stage least squares (2SLS) estimation in such over-identified IV settings can exacerbate issues with biased point estimates and incorrectly sized inference. These issues worsen if the many instruments are also weak (Bound, Jaeger and Baker, 1995). ${ }^{24}$

We address this concern using several weak-instrument diagnostics. First, we employ the limited

\footnotetext{
${ }^{24}$ Indeed, the use of local temperature in first-stage equations (4) and (5) is intended to ameliorate the overidentification problem. One could alternatively predict $\ln A_{i t}$ and $I_{t} \ln A_{i t}$ using flexible functions of country-specific ENSO effects. However, that approach would involve many more instruments as our sample has over 130 countries. Our benchmark specification for equations (4) and (5) employs 12 instruments.
} 
information maximum likelihood (LIML) IV estimator, which is approximately median-unbiased for over-identified models (Mariano, 2001). Second, we conduct tests to detect weak instruments in our LIML estimator. Third, we conduct inference that is robust to the presence of weak instruments.

\subsection{Main results}

To begin, consider OLS estimates of $\beta_{0}$ and $\beta_{1}$ from equation (3), reported in column 1 of Table 2 . The OLS estimate of $\beta_{0}$ has the expected sign and is statistically distinct from zero, but the OLS estimate of $\beta_{1}$ is indistinct from zero and, in fact, positive.

Columns 2 through 6 of Table 2 report IV estimates that address the potential bias of the OLS estimates. Across columns, we vary the number of spline terms in the temperature function $f()$. Column 2 has two spline terms, the minimum needed to capture nonlinearity in $f()$. Each subsequent column adds another spline term in $f() .{ }^{25}$ Because all models include a quadratic function of the sum of contemporaneous and lagged ENSO, this corresponds to 6, 9, 12, 15, and 18 instruments used jointly across the first-stage equations (4) and (5). ${ }^{26}$ Panel A shows 2SLS estimates, while panel B shows LIML estimates. Because ENSO varies only in the time dimension, we cluster standard errors by year to allow arbitrary forms of spatial correlation and heteroskedasticity across countries within a given year. In robustness checks, we consider other error structures, including the Bekker (1994) adjustment that accounts for LIML standard errors being potentially too small in the presence of many weak instruments.

The OLS estimate of $\beta_{0}$ appears to be biased downward relative to the IV estimates, suggesting that $\ln A_{i t}$ and $\mu_{i t}$ are negatively correlated. One potential source of such OLS bias would be demand shocks for domestic output, as a positive shock would raise the value of the dependent variable and lower the average-productivity regressor if domestic production exhibited decreasing returns. Similarly, an exogenous increase in trade costs could increase the value of the dependent variable and decrease cereal yields if production employs imported inputs.

The 2SLS estimates reported in panel A of Table 2 show $\widehat{\beta}_{0}>0$ and $\widehat{\beta}_{1}<0$, with little variation in the point estimates across columns 2 to 6 . The 2SLS estimates of both parameters are also statistically different from the OLS estimates, suggesting that the 2SLS estimates do not exhibit the same bias as the OLS estimates and thus are not the result of completely uninformative instruments. However, in over-identified IV settings, 2SLS estimates are still biased and incorrectly sized. This is evident in that the Cragg and Donald (1993) joint F-statistic for both first-stage regressions is well below the Stock and Yogo (2005) critical values for 10\% maximal 2SLS bias and

\footnotetext{
${ }^{25}$ Two to six spline terms correspond to three to seven knots. Knots are placed between equally spaced percentiles of the temperature empirical distribution according to Harrell (2001).

${ }^{26}$ Columns $1-5$ of Table F.1 show first-stage statistics for $\alpha_{11}^{\prime}$ and $\alpha_{12}^{\prime}$ from equation (4) and $\alpha_{21}^{\prime}$ and $\alpha_{22}^{\prime}$ from equation (5), corresponding to the IV specifications shown in columns $2-6$ of Table 2 . They show p-values from F-tests examining the joint significance of elements in each vector of first-stage coefficients. As expected, uninteracted local temperature is consistently a strong predictor of local cereal yields in first-stage equation (4). For the interaction between local yields and the global spatial correlation of yields in first-stage equation (5), both uninteracted local temperature (i.e., $0^{\text {th }}$ order ENSO) and local temperature interacted with ENSO (i.e., $1^{\text {st }}$ and $2^{\text {nd }}$ order ENSO) are strong predictors.
} 
Table 2: Domestic shares of expenditure and the spatial correlation of productivities Outcome is $\log$ domestic share of expenditure

\begin{tabular}{|c|c|c|c|c|c|c|}
\hline & $\begin{array}{l}(1) \\
\text { OLS }\end{array}$ & $\begin{array}{l}(2) \\
\text { IV }\end{array}$ & $\begin{array}{l}(3) \\
\text { IV }\end{array}$ & $\begin{array}{l}(4) \\
\text { IV }\end{array}$ & $\begin{array}{l}(5) \\
\text { IV } \\
\end{array}$ & $\begin{array}{l}\text { (6) } \\
\text { IV }\end{array}$ \\
\hline \multirow{3}{*}{$\ln A_{i t}\left(\beta_{0}\right)$} & & \multicolumn{5}{|c|}{ Panel A: 2SLS estimates } \\
\hline & $\begin{array}{c}0.284 \\
(0.119)\end{array}$ & $\begin{array}{c}1.541 \\
(0.515)\end{array}$ & $\begin{array}{c}1.746 \\
(0.542)\end{array}$ & $\begin{array}{l}1.696 \\
(0.412)\end{array}$ & $\begin{array}{c}1.701 \\
(0.425)\end{array}$ & $\begin{array}{c}1.654 \\
(0.431)\end{array}$ \\
\hline & {$[0.021]$} & {$[0.004]$} & {$[0.002]$} & {$[0.000]$} & {$[0.000]$} & {$[0.000]$} \\
\hline \multirow[t]{3}{*}{$\ln A_{i t} \times I_{t}\left(\beta_{1}\right)$} & 0.758 & -3.321 & -3.440 & -3.391 & -3.350 & -3.290 \\
\hline & $(0.487)$ & $(2.071)$ & $(2.148)$ & $(1.476)$ & $(1.493)$ & $(1.555)$ \\
\hline & {$[0.126]$} & {$[0.115]$} & {$[0.115]$} & {$[0.026]$} & {$[0.029]$} & {$[0.039]$} \\
\hline \multirow{4}{*}{$\begin{array}{l}\text { Pct. change in welfare variance } \\
\text { from } 1 \text { s.d. increase in } I_{t}\end{array}$} & -0.353 & 1.536 & 1.591 & 1.568 & 1.549 & 1.521 \\
\hline & $(0.226)$ & $(0.976)$ & $(1.023)$ & $(0.716)$ & $(0.728)$ & $(0.754)$ \\
\hline & {$[0.119]$} & {$[0.116]$} & {$[0.120]$} & {$[0.029]$} & {$[0.033]$} & {$[0.044]$} \\
\hline & & \multicolumn{5}{|c|}{ Panel B: LIML estimates } \\
\hline \multirow[t]{3}{*}{$\ln A_{i t}\left(\beta_{0}\right)$} & & 2.110 & 2.380 & 2.114 & 2.196 & 2.308 \\
\hline & & $(0.837)$ & $(0.847)$ & $(0.604)$ & $(0.669)$ & $(0.771)$ \\
\hline & & {$[0.015]$} & {$[0.007]$} & {$[0.001]$} & {$[0.002]$} & {$[0.004]$} \\
\hline \multirow[t]{3}{*}{$\ln A_{i t} \times I_{t}\left(\beta_{1}\right)$} & & -4.530 & -4.907 & -4.144 & -4.218 & -4.463 \\
\hline & & $(2.752)$ & $(2.937)$ & $(1.834)$ & $(1.949)$ & $(2.194)$ \\
\hline & & {$[0.106]$} & {$[0.101]$} & {$[0.028]$} & {$[0.035]$} & {$[0.047]$} \\
\hline \multirow{3}{*}{$\begin{array}{l}\text { Pct. change in welfare variance } \\
\text { from } 1 \text { s.d. increase in } I_{t}\end{array}$} & & 2.091 & 2.264 & 1.914 & 1.948 & 2.060 \\
\hline & & $(1.407)$ & $(1.497)$ & $(0.954)$ & $(1.035)$ & $(1.191)$ \\
\hline & & {$[0.137]$} & {$[0.131]$} & {$[0.045]$} & {$[0.060]$} & {$[0.084]$} \\
\hline \multicolumn{2}{|l|}{ Number of temperature splines in $f()$} & 2 & 3 & 4 & 5 & 6 \\
\hline \multicolumn{2}{|l|}{ ENSO polynomial order in $g()$} & 2 & 2 & 2 & 2 & 2 \\
\hline \multicolumn{2}{|l|}{ Number of instruments } & 6 & 9 & 12 & 15 & 18 \\
\hline \multicolumn{2}{|l|}{ Cragg-Donald F-stat } & 7.052 & 5.832 & 5.174 & 4.324 & 3.801 \\
\hline \multicolumn{2}{|l|}{ Stock-Yogo crit. value: $10 \% \max 2$ SLS bias } & 9.480 & 10.430 & 10.780 & 10.930 & 11.000 \\
\hline \multicolumn{2}{|l|}{ Stock-Yogo crit. value: $10 \% \max 2$ SLS size } & 21.680 & 27.510 & 32.880 & 38.080 & 43.220 \\
\hline \multicolumn{2}{|l|}{ Stock-Yogo crit. value: $10 \% \max$ LIML size } & 4.060 & 3.700 & 3.580 & 3.540 & 3.560 \\
\hline \multicolumn{2}{|l|}{ Kleibergen-Paap F-stat } & 6.100 & 5.664 & 3.963 & 3.332 & 3.069 \\
\hline \multicolumn{2}{|l|}{ Anderson-Rubin weak-id robust joint p-value } & 0.000 & 0.000 & 0.000 & 0.000 & 0.000 \\
\hline \multicolumn{2}{|l|}{ BIC for first stage equations } & -30933.7 & -30917.4 & -31134.0 & -31120.2 & -31091.8 \\
\hline Observations & 5452 & 5452 & 5452 & 5452 & 5452 & 5452 \\
\hline \multicolumn{7}{|c|}{$\begin{array}{l}\text { NoTES: This table reports estimates of } \beta_{0} \text { and } \beta_{1} \text { from equation (3). Column } 1 \text { shows OLS estimates. Columns } \\
2-6 \text { show IV estimates that vary by the number of temperature spline terms in } f() \text {. Panel A (B) shows } 2 S L S \\
\text { (LIML) IV estimates. All models include quadratic } E N S O_{t}+E N S O_{t-1} \text { terms and incorporate country fixed } \\
\text { effects, year fixed effects, and country-specific linear trends as included instruments. Standard errors, clustered } \\
\text { by year, in parentheses; p-values in brackets. Appendix D. } 1 \text { describes how we compute the percentage change in } \\
\text { the variance of welfare for a one-standard-deviation increase in Moran's } I \text { relative to the historical mean assuming } \\
\epsilon=8.59, \text { with those standard errors calculated using the delta method. }\end{array}$} \\
\hline
\end{tabular}

size across columns 2 to 6 of Panel A.

As an alternative to 2SLS, panel B of Table 2 presents LIML estimates. Again, we find very similar point estimates for $\widehat{\beta}_{0}>0$ and $\widehat{\beta}_{1}<0$ across the varying number of temperature splines in columns 2 to 6 . The LIML estimates are even farther away from the OLS estimates than the 2SLS estimates, suggesting that the LIML estimator mitigates biases in our 2SLS estimates.

LIML is an approximately median-unbiased estimator in over-identified settings, but its stan- 
dard errors may still be incorrectly sized in the presence of weak instruments. We report two tests to assess whether weak instruments are a concern. First, across columns 2 to 6 , the Cragg-Donald joint F-statistic for both first-stage regressions is above the Stock-Yogo critical values for $10 \%$ maximal LIML size, which rejects the presence of weak instruments. However, the Stock-Yogo critical values are only valid for iid errors. While we also report the Kleibergen-Paap F-statistic, which is more appropriate given our clustered error structure (Kleibergen and Paap, 2006), there are no established critical values for non-iid errors. We therefore cannot entirely rule out the presence of weak instruments solely by looking at first-stage F-statistics. Second, we turn to inference methods that are robust to the presence of weak instruments. For each IV model in columns 2 to 6 , we present the $\mathrm{p}$-value from the Anderson-Rubin test of the null hypothesis that $\beta_{0}$ and $\beta_{1}$ in equation (3) are jointly zero (Anderson and Rubin, 1949). This null hypothesis is strongly rejected. The combined evidence from these various diagnostics suggests that weak instruments are not a concern. This gives us confidence that our LIML estimates are unbiased and correctly sized.

Which number of spline terms in the temperature function $f()$ yields the most informative estimates of our parameters of interest? Note that this model selection is not crucial to our conclusions: across columns 2 through 6 , the point estimates of $\beta_{0}$ and $\beta_{1}$ do not vary much. All the estimates of $\beta_{0}$ have $\mathrm{p}$-values near or below 0.01 , and the LIML estimates of $\beta_{1}$ have p-values ranging from 0.03 to 0.11. To select one specification, we employ the Bayesian Information Criterion (BIC) statistic from a joint seemingly unrelated regression of first-stage equations (4) and (5) to address the trade-off between capturing nonlinearities in $f()$ and having too many spline terms in $f()$. Table 2 shows that the BIC statistic is minimized with four temperature spline terms in column 4 . This corresponds to the specification with the most precise LIML estimates of $\beta_{0}$ and $\beta_{1}$, with p-values of 0.001 and 0.03 , respectively, and will serve as our benchmark model moving forward.

Per the theoretical framework in Section 2, our empirical estimates suggest that the spatial distribution of productivity affects a country's terms of trade, as revealed by its domestic share of expenditure. The positive relationship between its own productivity and domestic share of expenditure $\left(\hat{\beta}_{0}>0\right)$ reveals that higher productivity worsens the terms of trade. This deterioration is dampened when productivities are more spatially correlated $\left(\hat{\beta}_{1}<0\right)$ since higher productivity in neighboring countries improves a country's terms of trade. ${ }^{27}$ We corroborate this terms-of-trade interpretation using observed changes in unit values in Section 4.4.

For the class of models introduced in Section 2, these estimated effects imply an increase in the global variance of welfare. Suppose that the cross-sectional global spatial correlation of agricultural productivity were to increase by one standard deviation relative to the historical mean. Applying the expression for the variance of welfare in equation (2) to our benchmark LIML estimates in column 4, panel B of Table 2, we find that a one-standard-deviation increase in the spatial correlation of productivities leads to a statistically significant $2 \%$ increase in the global variance of welfare. ${ }^{28}$

\footnotetext{
${ }^{27}$ At empirically observed levels of spatial correlation, this does not reverse the positive relationship between $\ln A_{i t}$ and $\ln \lambda_{i i t}$. As shown in Figure 7, the spatial correlation of cereal yields lies between 0.17 and 0.25 in our estimation sample. Thus, $\hat{\beta}_{0}+\hat{\beta}_{1} \times I_{t}>0$ at all historical values of $I_{t}$ for the estimates reported in Table 2 .

${ }^{28}$ See Appendix D.1 for details. As a point of comparison, Kopczuk, Saez and Song (2010) find that the annual
} 


\subsection{Additional robustness checks}

This section presents several robustness checks of our main empirical result. They are designed to test the validity of our statistical assumptions, the interpretation of our results, and the consequences of our data-construction choices. Our benchmark model throughout is that shown in column 4, panel B of Table 2.

Randomization inference Our main source of identifying variation is time-series fluctuations in the global ENSO cycle, shown in Figure 4. While it is plausible that ENSO is uncorrelated with unobserved determinants of domestic shares of expenditure over a large sample of years, spurious correlations could occur within a 53-year sample.

To examine the relevance of this small-sample concern, we conduct a placebo test by randomly reshuffling years (i.e., drawn without replacement) of our panel data, breaking the time-series link between domestic shares of expenditure and ENSO-driven changes in country-level cereal yields and the global spatial correlation of yields. This allows us to obtain an empirical distribution of our estimated reduced-form coefficients, $\widehat{\beta}_{0}$ and $\widehat{\beta}_{1}$, under placebo conditions and compute the probability of observing our benchmark estimates if years were randomly assigned.

The left and right panels of Figure 9 show the empirical distribution for $\widehat{\beta}_{0}$ and $\widehat{\beta}_{1}$, respectively, for 10,000 samples. The vertical lines show the location of our estimated $\widehat{\beta}_{0}$ and $\widehat{\beta}_{1}$ from the observed data. It is highly unlikely that our main result is due to small-sample bias.

Figure 9: Randomization inference
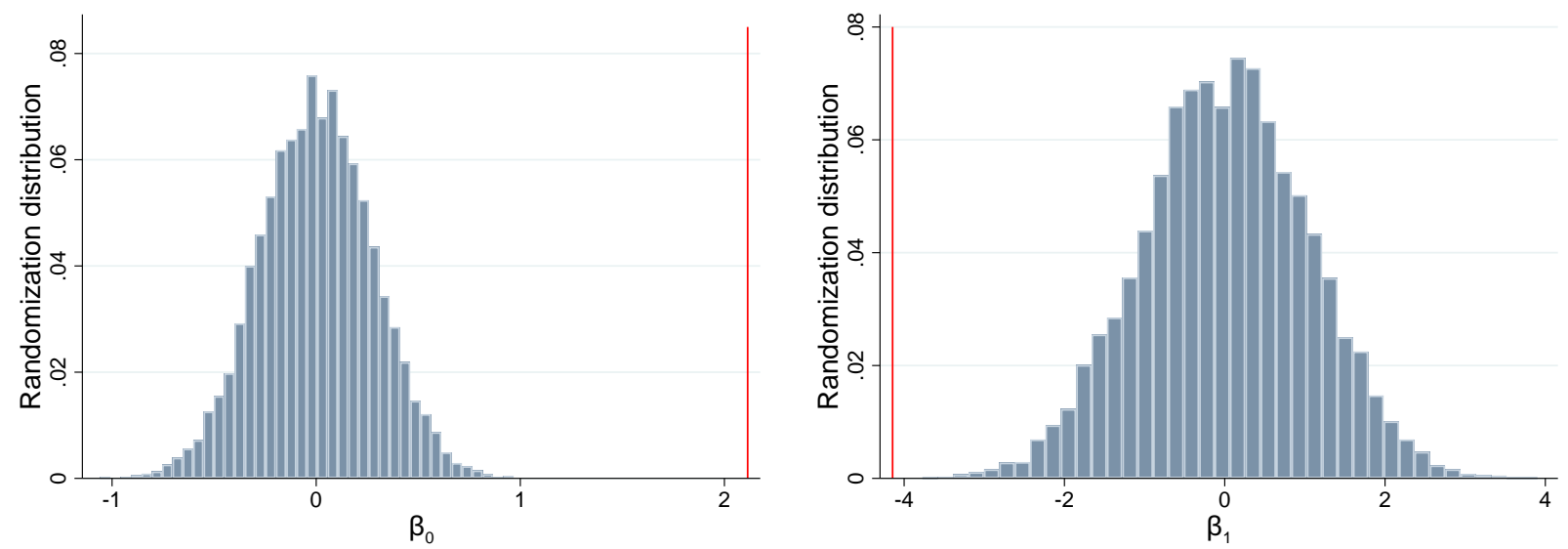

Notes: Empirical distributions of $\widehat{\beta}_{0}$ (left panel) and $\widehat{\beta}_{1}$ (right panel) from 10,000 samples of 53 years drawn from the original data without replacement. Vertical lines show $\widehat{\beta}_{0}$ and $\widehat{\beta}_{1}$ from observed data estimated using benchmark model in column 4, panel B of Table 2.

Standard errors Standard errors are clustered by year in our benchmark model because ENSO varies in the time dimension. Table F.2 considers alternative error structures. Column 1 reproduces our benchmark results. To account for serial correlation, column 2 allows year-level clustering and variance of log earnings across U.S. workers increased on average by $2 \%$ per year between 1970-2003. 
common serial correlation across countries within a 20-year rolling window following Driscoll and Kraay (1998). Column 3 allows differential serial correlation and heteroskedasticity across countries over our entire sample period by clustering standard errors by both year and country. Allowing both forms of serial correlation has little effect on standard errors. Finally, if instruments are weak, standard errors from the LIML estimator may be too small (Hansen, Hausman and Newey, 2008). Column 4 applies the Bekker (1994) adjustment to our benchmark LIML estimates. This only slightly inflates our standard errors, which is unsurprising given that the various tests in Table 2 do not suggest the instrumental variables are weak.

Controlling for time-varying trade costs Our IV model correctly identifies $\beta_{0}$ and $\beta_{1}$ when ENSO conditions influence a country's domestic share of cereal expenditure only through its effects on local yields and the global spatial correlation of yields. ${ }^{29}$ While it is unlikely that ENSO, as a naturally occurring climatic phenomenon, is affected by economic activity, the exclusion restriction could be violated if ENSO affects domestic cereal expenditure outside of its influence on cereal yields. For example, a violation would occur if ENSO directly affected trade costs.

To address this potential violation of the exclusion restriction, Table F.3 augments our benchmark model with additional controls designed to capture time-and-country-varying trade costs. Column 1 replicates our benchmark result. In column 2, we add a proxy for country-year-specific trade costs by interacting the global annual crude oil price with the country's average log domestic share of expenditure over our sample period. Column 3 uses an alternative measure of crosssectional trade openness by interacting the global oil price with a country's centrality, measured as the average of its inverse distance to every other country weighted by that trading partner's longrun average log agricultural output. In both cases, these proxies for time-varying trade costs do not meaningfully alter our estimates of $\beta_{0}$ and $\beta_{1}$. Columns 4 and 5 provide more flexible specifications by interacting year fixed effects with the two cross-sectional measures of trade openness used in columns 2 and 3. Again, our coefficients of interest are relatively unaffected by the inclusion of these controls, suggesting that unobserved shocks to trade costs are not correlated with our ENSOdriven instruments. Cereals may be subject to export restrictions that are imposed in response to productivity shocks. In column 6 , we include a dummy variable that indicates if a country imposed a new export restriction on cereals that year, using data from the UNCTAD TRAINS database. Controlling for such export restrictions does not alter our result. ENSO also alters local precipitation. If precipitation is also a determinant of trade costs, there may be an exclusion restriction

\footnotetext{
${ }^{29}$ For example, Hsiang, Meng and Cane (2011) show that warmer ENSO conditions increase the likelihood of civil conflicts in the tropics over the same period. This relationship, however, need not imply an exclusion-restriction violation. Suppose ENSO increases civil conflicts in the tropics only through lowered cereal yields. In that scenario, civil conflict would serve as a "bad control" in our IV specification, potentially biasing our coefficients of interest (see Angrist and Pischke 2009, p. 64-68). Our exclusion-restriction assumption is invalid only if ENSO increases civil conflicts partially through non-agricultural channels and if civil conflicts affect domestic share of expenditure by, for example, raising international trade costs relative to internal trade costs. Because the current climate-conflict literature currently supports both agricultural and non-agricultural channels (Hsiang, Burke and Miguel, 2013), the inclusion of conflict as a control would not deliver a unique interpretation: it would either jeopardize a valid identification strategy or suggest that our instrumental-variables strategy is invalid.
} 
violation. In column 7 , we include quadratic terms for total annual precipitation for each country and find that it does not affect our result.

Large economies Our estimate of $\hat{\beta}_{0}>0$ implies that a positive productivity shock worsens an economy's terms of trade. This is at odds with the small-open-economy assumption that the terms of trade are exogenous to local conditions. ${ }^{30}$ Of course, some economies must influence world prices, but since our estimating equation treats each country as an informative observation without weighting by size, our results suggest that the "typical" economy is not small. To examine this more explicitly, column 2 of Table F.4 excludes the ten largest economies that account for more than half of world cereal production from our estimation sample. The resulting estimates of $\hat{\beta}_{0}$ and $\hat{\beta}_{1}$ are very similar to our benchmark estimates. This finding is consistent with the idea that trade costs make all markets "local", so that no exporter is a price taker.

Dynamic effects Table F.5 estimates dynamic responses that the static model presented in Section 2 necessarily omits. Column 1 replicates our benchmark contemporaneous-productivity specification for a sample in which $t$ is restricted to 1962-2012, the sample period that allows for both lead and lagged yields. Before discussing these results, it is important to note that because current productivity is affected by $E N S O_{t}$ and $E N S O_{t-1}$, we would not expect lead productivity, driven in part by $E N S O_{t}$, or lagged productivity, driven in part by $E N S O_{t-1}$, to have zero effect on current domestic share of expenditure. Rather, the absence of dynamics would produce lead and lagged effects that are muted compared with the contemporaneous effect.

Improvements since the 1980s in the forecasting of strong ENSO events (Chen et al., 2004; Shrader, 2017) could allow the domestic share of expenditure to respond to future ENSO-driven cereal yields. To examine whether agricultural trade anticipates future ENSO events, column 2 tests for the effects of lead log yields, as instrumented by ENSO in years $t+1$ and $t$ and local temperature in year $t+1$. Lead effects are much smaller in magnitude than contemporaneous effects and are not statistically significant.

Past yields might influence the domestic share of expenditure if past productivity affects contemporary productivity through intertemporal channels such as depletion of soil nutrients or if past output is stored to facilitate current consumption. Cereal storage, in particular, has been shown to facilitate consumption smoothing in many settings (Williams and Wright, 2005; Roberts and Schlenker, 2013). We address this in two ways. Column 3 examines the effects of lagged log yields generally, as instrumented by ENSO in years $t-1$ and $t-2$ and local temperature in year $t-1$. Compared with contemporaneous effects, lagged effects are smaller in magnitude and not significant at conventional levels. Our measure of domestic expenditure is contemporaneous output minus exports; this includes potential changes in stored cereal inventories. In column 4, we use a

\footnotetext{
${ }^{30}$ Prior empirical work, which "typically assumes that countries are small and that the terms of trade are exogenous" (Debaere and Lee, 2003, 1), has primarily focused on the consequences of external shocks to countries' commodity terms of trade. Notable exceptions are Acemoglu and Ventura (2002) and Debaere and Lee (2003), which study the effects of capital accumulation on the terms of trade.
} 
measure of domestic expenditure that removes changes in cereal inventory using cereal storage data from the FAO. ${ }^{31}$ The estimated coefficients are smaller in absolute magnitude than our benchmark estimates; however, they are not statistically different.

The static model of Section 2 assumes that trade is balanced. To verify the plausibility of this assumption, we have estimated a variant of the regression specification in equation (3) in which the dependent variable is instead country $i$ 's aggregate goods trade deficit in year $t$. Neither instrumented cereal productivity nor its interaction with Moran's $I$ for cereal productivities have statistically significant effects on the trade deficit.

Sample split One may wonder if $\beta_{0}$ and $\beta_{1}$ vary over the sample, particularly given improvements in ENSO forecasts since the 1980s. Table F.4 reports separate estimates for the two halves of our estimation sample, 1961-1987 and 1988-2013. While the estimated coefficients for the second half are smaller in absolute magnitude than those for the first half, these differences are not statistically significant.

ENSO and local temperature definitions Table F.6 considers alternative definitions of ENSO and country-level local temperatures. Column 1, panel A reproduces our benchmark results using the NINO4 measure as our ENSO index and crop-area-weighted country-level temperatures. In columns 2, 3 and 4, we use the NINO3, NINO34, and NINO12 indices, alternative measures of ENSO that differ by the spatial area over which average sea-surface temperature is calculated (see Figure E.2). In panel B, we construct country-level temperatures from pixel-level temperature data by taking the average across the total area of each country rather than across crop areas. ${ }^{32}$ Our results are largely unaffected by these two data-construction choices.

Our identification strategy need not require ENSO per se. Rather, one needs an exogenous driver of the global spatial correlation of cereal yields that exhibits a sufficiently strong first stage. In Table F.7, we report estimates produced by replacing $g\left(E N S O_{t}+E N S O_{t-1}\right)$ in equations (4) and (5) with the annual global spatial correlation of temperature, $I_{t}\left(T_{i t}\right) .{ }^{33}$ While the point estimates in Table F.7 do not differ drastically from the corresponding estimates in panel B of Table 2, the first-stage regressions are generally weaker. This is consistent with Table 1 , which shows that $I_{t}\left(T_{i t}\right)$ does not predict the global spatial correlation of cereal yields as strongly as ENSO. In short, based on the strength of the first-stage relationship, we prefer to use ENSO as the source of exogenous

\footnotetext{
${ }^{31}$ This measure is contemporaneous output minus exports minus change in cereal inventory, where the latter is defined as the difference in stored cereals in year $t$ minus stored cereals in year $t-1$. This implicitly assumes that all stored cereals are domestically produced. The sample is smaller due to observations with missing storage data.

${ }^{32}$ Our sample of countries increases slightly when using total-area-weighted temperature compared with using croparea-weighted temperature because a handful of small-sized countries have no agricultural activity in the Ramankutty et al. (2008) dataset.

${ }^{33}$ When considering temperature-driven only variation, instead of using $I_{t}\left(T_{i t}\right)$ in equations (4) and (5), one could alternatively use the vector of country-specific local temperature-predicted productivity to construct a predicted Moran's I statistic. Such an approach, however, implicitly assumes that $I_{t}\left(\left\{\widehat{\ln A_{i t}}\left(T_{i t}\right)\right\}\right)$ is the correct functional relationship between local temperature and the global spatial correlation in yields. Our approach, which follows Kelejian (1971) and Amemiya (1974), allows for more flexible estimation and in general produces a more efficient IV estimator.
} 
variation in the global spatial correlation of cereal yields rather than the spatial correlation of an intermediate local weather variable.

Domestic expenditure share construction As detailed in Appendix B, we do not observe cereal prices for all cereal-country-year observations with positive cereal output. Our benchmark measure of domestic share of expenditure imputes missing cereal-level prices using the average export-volume-weighted cereal export unit value for that country and year. While this imputation increases the number of observations in our estimation sample, this procedure could bias our estimates if it introduces measurement error into the outcome variable that is correlated with the instrumented regressors.

Table F.8 presents alternative approximations for the domestic expenditure share. Column 1 reproduces our benchmark result. Columns 2 through 4 employ alternative price imputations. Column 2 imputes missing export unit values using producer prices. ${ }^{34}$ Columns 3 and 4 impute missing cereal prices using the lowest and highest observed export unit values, rather than the average, for a given country and year. All three alternative imputation methods yield estimates of $\beta_{0}$ and $\beta_{1}$ that are statistically indistinguishable from the benchmark estimate in column 1 . To see if our benchmark result is sensitive to the source of trade data, in column 5 we compute domestic expenditure shares using trade data from Comtrade instead of FAO. Finally, in column 6 we drop observations where our benchmark measure of log domestic expenditure share is in the bottom and top $1 \%$ of its unconditional distribution. Neither robustness check alters our conclusions.

\subsection{Estimates using terms-of-trade outcomes}

Thus far, the outcome variable in our empirical investigation has been the domestic share of expenditure, a sufficient statistic for welfare under the modeling assumptions described in Section 2.1. That theoretical result leverages assumptions that restrict admissible combinations of consumer preferences, production technologies, and market structure. While widely used, this class of models may be regarded as narrow.

We now investigate how the spatial correlation of productivities affects the gain from trade using an outcome variable that captures welfare changes under much weaker assumptions. We examine changes in the terms of trade as measured by the product of price changes and the previous period's traded quantities. Appendix B describes how we construct this variable using trade data. This measure identifies whether a country's terms of trade locally improve or deteriorate under the relatively weak assumptions required for the revealed-preference argument of Dixit and Norman (1980).

Since this outcome variable is defined in terms of changes from the previous year, we timedifference our estimating equations so that we relate changes in the terms of trade to changes in log productivity and changes in the product of spatial correlation and log productivity. In particular, we employ first-differenced versions of the second-stage and first-stage equations $(3,4,5)$. The

\footnotetext{
${ }^{34}$ See discussion in Appendix B regarding concerns with using FAO's producer prices.
} 
second-stage equation is now

$$
\operatorname{arcsinh}\left(\Delta \mathrm{ToT}_{i t}\right)=\varsigma_{0}\left(\ln A_{i t}-\ln A_{i t-1}\right)+\varsigma_{1}\left(I_{t} \ln A_{i t}-I_{t-1} \ln A_{i t-1}\right)+\zeta_{i}+\xi_{t}+\varepsilon_{i t},
$$

where $\zeta_{i}$ and $\xi_{t}$ are country and year fixed effects that correspond to the country-specific trends and differences in year fixed effects in the levels second-stage equation (3), respectively. ${ }^{35} \varepsilon_{i t}$ is an error term that we cluster by year. To facilitate interpretation of $\varsigma_{0}$ and $\varsigma_{1}$ as elasticities (as with $\beta_{0}$ and $\beta_{1}$ ), we use an inverse hyperbolic sine transformation of $\Delta \mathrm{ToT}_{i t}$ on the left side of equation (6) (Bellemare and Wichman, 2020). ${ }^{36}$ The terms-of-trade interpretation of our main empirical results predicts that $\varsigma_{0}<0$ and $\varsigma_{1}>0$. The two first-stage equations are:

$$
\begin{aligned}
\ln A_{i t}-\ln A_{i t-1} & =\varrho_{11}^{\prime}\left(f\left(T_{i t}\right)-f\left(T_{i t-1}\right)\right) \\
& +\varrho_{12}^{\prime}\left(f\left(T_{i t}\right) g\left(E N S O_{t}+E N S O_{t-1}\right)-f\left(T_{i t-1}\right) g\left(E N S O_{t-1}+E N S O_{t-2}\right)\right) \\
& +\zeta_{1 i}+\xi_{1 t}+\varphi_{1 i t} \\
I_{t} \ln A_{i t}-I_{t-1} \ln A_{i t-1} & =\varrho_{21}^{\prime}\left(f\left(T_{i t}\right)-f\left(T_{i t-t}\right)\right) \\
& +\varrho_{22}^{\prime}\left(f\left(T_{i t}\right) g\left(E N S O_{t}+E N S O_{t-1}\right)-f\left(T_{i t-1}\right) g\left(E N S O_{t-1}+E N S O_{t-2}\right)\right) \\
& +\zeta_{2 i}+\xi_{2 t}+\varphi_{2 i t}
\end{aligned}
$$

where $\varphi_{1 i t}$ and $\varphi_{2 i t}$ are error terms. Consistent with the benchmark expenditure share specification in column 4, panel B of Table $2, f(\cdot)$ is a restricted cubic spline function with four terms and $g(\cdot)$ is a quadratic function.

Table 3 reports LIML IV estimates of equation (6). Column 1 examines changes in the terms of trade for cereals. An increase in productivity worsens a country's terms of trade $\left(\hat{\varsigma}_{0}<0\right)$, but this effect is dampened when productivities are more spatially correlated $\left(\hat{\varsigma}_{1}>0\right)$. This corroborates the interpretation of our expenditure-share results as reflecting terms-of-trade effects. To broaden the economic scope, Column 2 examines changes in the terms of trade for all commodities in the commodity section "food and live animals," which includes cereals. Consistent with the discussion of multi-sector models in Appendix Section A.3, these welfare effects are somewhat dampened when we incorporate a broader set of goods. The standard errors in column 2 are also larger than in column 1, perhaps unsurprisingly given that the dependent variable uses a broader set of unit values, which are noisy proxies for prices, and cereal imports are only $25 \%$ of food imports for the average observation. The dampened coefficients and larger standard errors render these estimates statistically insignificant at conventional thresholds. We therefore find that countries' terms of trade in cereals respond in the predicted manner to greater spatial correlation of cereal productivities, but we lack the statistical power to trace these effects through to economy-wide changes in the terms of trade. ${ }^{37}$

\footnotetext{
${ }^{35}$ The country fixed effects of equation (3) are eliminated by taking the difference.

${ }^{36}$ Since changes in the terms of trade can be positive or negative, a log transformation is infeasible.

${ }^{37}$ Estimates of the coefficients $\varsigma_{0}$ and $\varsigma_{1}$ for other 1-digit commodity sections are not statistically significant and often have the opposite sign of those found for the "food and live animals" section.
} 
Table 3: Changes in terms of trade

Outcome is asinh(change in terms of trade)

\begin{tabular}{|c|c|c|}
\hline & $\begin{array}{c}(1) \\
\text { Cereals }\end{array}$ & $\begin{array}{c}(2) \\
\text { Food }\end{array}$ \\
\hline \multirow[t]{3}{*}{$\Delta \ln A_{i t}\left(\varsigma_{0}\right)$} & -1.886 & -1.354 \\
\hline & $(1.015)$ & $(1.273)$ \\
\hline & {$[0.069]$} & {$[0.292]$} \\
\hline \multirow[t]{3}{*}{$\Delta \ln A_{i t} \times I_{t}\left(\varsigma_{1}\right)$} & 8.756 & 6.625 \\
\hline & $(5.058)$ & $(6.643)$ \\
\hline & {$[0.089]$} & {$[0.323]$} \\
\hline Cragg-Donald F-stat & 10.054 & 10.054 \\
\hline Stock-Yogo crit. value: $10 \%$ max LIML size & 3.580 & 3.580 \\
\hline Kleibergen-Paap F-stat & 3.347 & 3.347 \\
\hline Observations & 5747 & 5747 \\
\hline \multicolumn{3}{|c|}{$\begin{array}{l}\text { NOTES: This table reports estimates of equation (6). Column } 1 \text { examines } \\
\text { change in the terms of trade for cereals. Column } 2 \text { examines change in the } \\
\text { terms of trade for all commodities in Standard International Trade Classifi- } \\
\text { cation (SITC) section } 0 \text { (food and live animals). Standard errors are reported } \\
\text { in parentheses; p-values in brackets. }\end{array}$} \\
\hline
\end{tabular}

\section{Application: Inequality under future climate change}

In this section, we demonstrate how to incorporate the role of spatial interdependence via trade into projections of economic outcomes when the spatial correlation of productivities changes. Recent reviews of quasi-experimental studies that inform climate-change impact projections emphasize the need to consider spatial linkages (Dell, Jones and Olken, 2014; Hsiang, 2016; Auffhammer, 2018; Deschênes and Meng, 2018). In this growing literature, the effect of local temperature on an economic outcome is first estimated using quasi-experimental variation that implicitly holds temperatures in other locations fixed. These estimates are then used to compute the local consequences of anticipated future warming and the sum of these projected local impacts is used to quantify climate change's global impact. However, by using estimates that hold fixed the spatial structure of temperature, these projections amount to considering many scenarios in which each scenario has only a single location experiencing warming. This exercise misses the global nature of climate change, in which all locations experience warming simultaneously.

To that end, we amend this approach to incorporate changes in the spatial correlation of productivities due to climate change. ${ }^{38}$ By allowing the expenditure-productivity relationship to depend on spatial correlation, this approach incorporates spatial interdependence without imposing the full structure of quantitative trade models. This strategy is similar to that of Monte, Redding and Rossi-Hansberg (2018), who use observables to account for heterogeneous local employment

\footnotetext{
${ }^{38}$ There is currently no scientific consensus on how ENSO will be affected by anthropogenic climate change (Stocker et al., 2013). Our projection exercise therefore assumes ENSO is stationary over the twenty-first century and does not contribute to long-run changes in the global spatial correlation of cereal productivities.
} 
elasticities implied by a quantitative model of commuting flows. More broadly, we posit that this approach can be applied to studying other determinants of productivity, provided that the researcher observes exogenous variation in that determinant that also alters its global spatial correlation.

Because this exercise serves only to highlight the implications of incorporating this particular mechanism, we emphasize that it omits other potential general-equilibrium effects of climate change. First, these projections study changes in cereal productivity due to climate-driven changes in local temperatures over the twenty-first century in isolation. We fix all other variables, such as the spatial pattern of comparative advantage within cereals, at recent historical values. Thus, we do not take into account important trends such as technological change. Second, we apply estimates based on past exogenous annual changes in cereal productivity to future long-term productivity changes due to climate change. This implies that we omit possible adaptations in anticipation of future climate change (Deschênes and Greenstone, 2007c; Hsiang, 2016). Third, we do not consider other potential adjustments such as factor reallocation across sectors and across crops within the agricultural sector. All three practices are standard in this climate-impacts literature, due to the absence of credible estimates of the relevant mechanism, and these assumptions may ultimately cause these projections to differ from realized climate impacts. Our objective is merely to demonstrate how the economic consequences of spatial correlation, estimated using quasi-experimental variation, can be incorporated into projections of climate impacts. As such, this exercise helps bridge the gap between quasi-experimental approaches and structural models of climate impacts (Brock, Engström and Xepapadeas, 2014; Desmet and Rossi-Hansberg, 2015; Costinot, Donaldson and Smith, 2016; Krusell and Smith, 2022).

We first report climate change's projected effects on the global variance and spatial correlation of cereal productivity. We then show how incorporating these changes in the spatial correlation of productivities alters welfare projections.

\subsection{Cereal productivity under climate change}

To examine how climate change will affect cereal productivity, we estimate a nonlinear log cereal yield response function using historical variation in annual temperatures across countries and years. Specifically, for the period 1961-2013, we estimate:

$$
\ln A_{i t}=k\left(T_{i t}\right)+\Psi^{\prime} \mathbb{X}_{i t}+\nu_{i t}
$$

where $k()$ is a restricted cubic spline function and the benchmark set of controls in $\mathbb{X}_{i t}$ include country fixed effects, year fixed effects, and country-specific quadratic trends. Figure 10 shows the estimated cubic spline response function, $k()$, using four temperature spline terms. It also shows two cross-sectional temperature distributions: observed temperatures in 2013 and the forecast for 2099 under a business-as-usual (Representative Concentration Pathway 8.5) climate scenario obtained from the Coupled Model Intercomparison Project (CMIP5) multi-model ensemble mean. ${ }^{39}$

\footnotetext{
${ }^{39}$ CMIP5 is a coordinated effort by the climate-science community to harmonize model runs across various climate models. The average climate projection across CMIP5 models is known as the multi-model ensemble mean. CMIP5
} 
Column 1 of Table F.9 shows that the coefficients of $k()$ shown in Figure 10 are jointly statistically significant with a productivity-maximizing temperature around $9^{\circ} \mathrm{C}{ }^{40}$ Table F.9 also indicates that the predicted optimal temperature is relatively insensitive to the number of knots in the spline function and to the inclusion of precipitation controls. Next, we combine the estimated coefficients in equation (9) with local temperature projections under a business-as-usual climate scenario to project log cereal yields in the 2014-2099 period. All other variables in equation (9) are fixed at 2013 levels (see Appendix D.2 for details).

Figure 10: Estimated temperature response function for log cereal yields

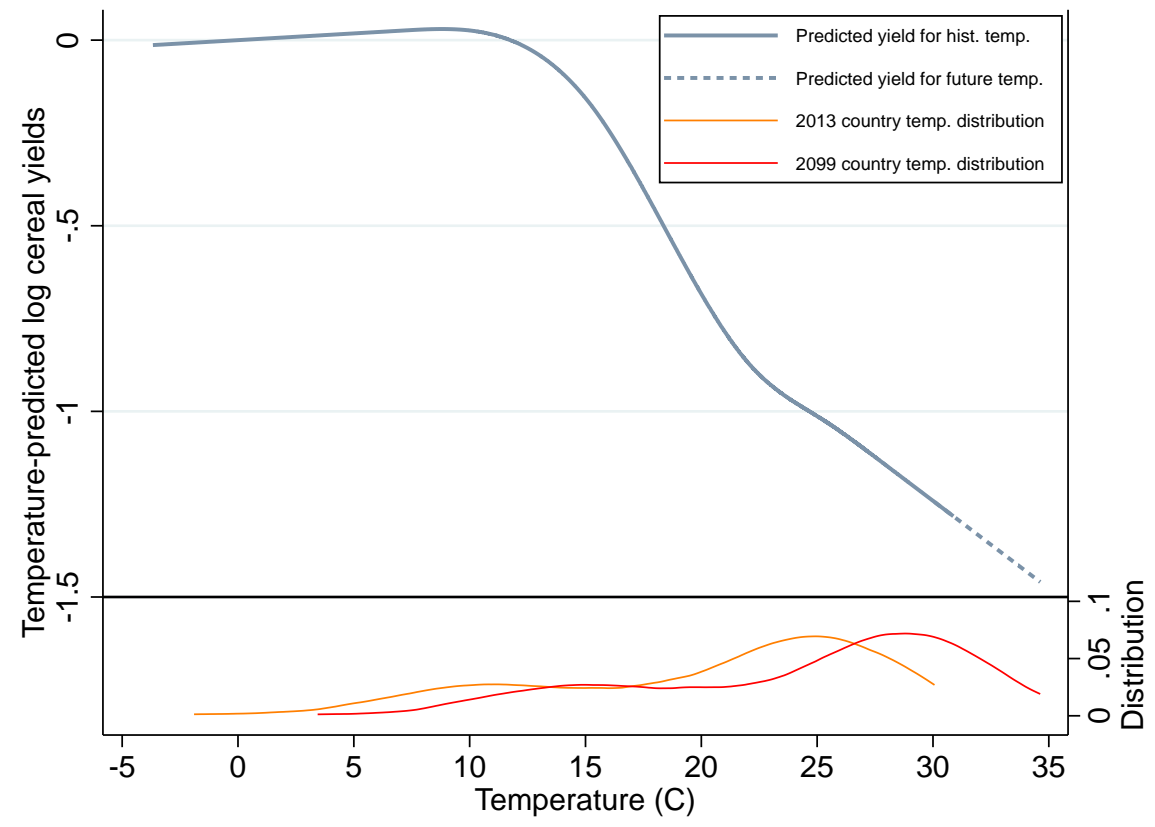

Notes: Gray solid line shows $k()$ in equation (9), the predicted relationship between crop-area-weighted countrylevel temperature and log cereal yields, estimated during 1961-2013. Restricted cubic spline function is estimated using four spline terms with knot placements according to Harrell (2001). Gray dashed line shows predicted log cereal yields using extrapolated temperature in 2099. Estimated model corresponds to column 1 of Table F.9. Orange line shows distribution of observed country-level temperatures in 2013. Red line shows distribution of projected country-level temperature in 2099 from CMIP5 ensemble mean under a business-as-usual (RCP 8.5) scenario.

Climate change alters two important moments of the cross-country cereal productivity distribution. First, the variance of cereal productivity increases. In 2013, 10 of the 12 countries with temperatures below the global productivity-maximizing temperature had productivities above the cross-sectional mean (see Figure E.4). ${ }^{41}$ As climate change raises temperatures, these more produc-

was used to inform the Fifth Assessment Report of the Intergovernmental Panel on Climate Change (see Taylor, Stouffer and Meehl (2012) for details).

${ }^{40}$ Using similar country-by-year-level data but for the 1983-2009 period, Proctor et al. (2018) find a similar productivity-maximizing temperature.

${ }^{41}$ Figure E.4 shows that the unconditional relationship between log productivity and temperature is very similar to the conditional relationship depicted in Figure 10, $k\left(T_{i t}\right)$. Thus, we can describe how climate change alters the variance and spatial correlation of productivities in terms of the nonlinear shape of $k\left(T_{i t}\right)$, even though productivity incorporates other determinants contained in controls $\Psi^{\prime} \mathbb{X}_{i t}$ and residual $\nu_{i t}$ from equation (9). 
tive countries will gain further by moving towards the productivity-maximizing temperature shown in Figure 10. Concurrently nearly all other countries will experience productivity losses as they move away from the optimal temperature. Because the gains from climate change will be experienced almost exclusively by more productive countries, the cross-country variance of productivity will rise, as depicted by the black line in the left panel of Figure 11.

Figure 11: Variance in climate-driven welfare over the $21^{\text {st }}$ century
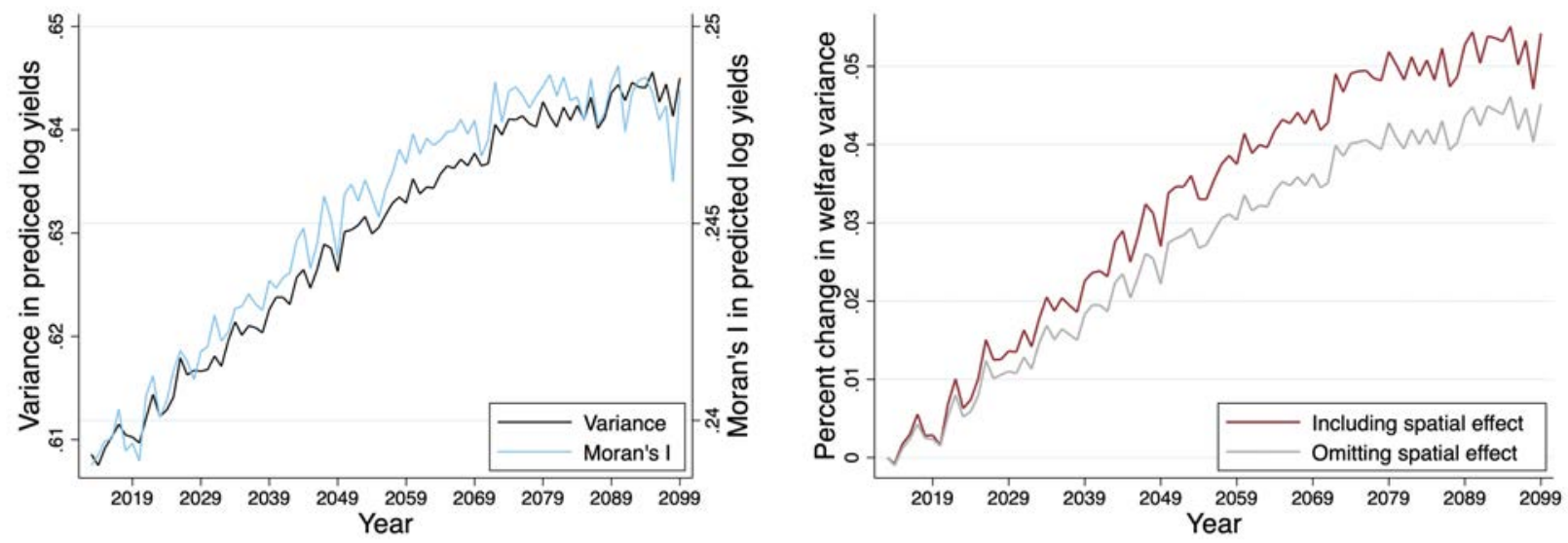

Notes: The left panel shows the change in the global variance (black line) and Moran's I (blue line) of log cereal yields over the twenty-first century under climate change. The right panel shows the percent change in the variance of welfare omitting (gray line) and including (red line) changes in the spatial correlation of log cereal yields over the same period. Climate projections are from CMIP5 ensemble mean under a business-as-usual (RCP 8.5) scenario. Appendix D.2 describes the welfare calculations assuming $\epsilon=8.59$.

Second, as temperatures increase across the planet, the spatial correlation of cereal productivities increases. This is again due to the non-monotone yield response function shown in Figure 10 and the fact that surface temperatures are generally decreasing in distance to the equator. Absent climate change, mid-latitude locations experience the productivity-maximizing temperature. Locations closer to and farther from the equator both generally exhibit lower yields. As climate change increases temperatures, latitudes closer to the poles will experience the productivity-maximizing temperature, and less productive countries will be more bunched around the equator. This bifurcation of global agriculture into high-productivity poles and a low-productivity band around the equator would increase the spatial correlation of cereal productivity. ${ }^{42}$ The resulting increase in Moran's I for cereal productivity under climate change is depicted by the blue series in the left panel of Figure 11.

\footnotetext{
${ }^{42}$ Additionally, the country-specific shift in temperature due to climate change is not spatially uniform. Because of surface albedo changes due to polar ice melt, there will be greater warming near the poles. However, this latitudedependent gradient is relatively small compared to the average global temperature change and thus plays a secondorder role in determining changes in the spatial correlation of productivities. For example, the projected temperature change over the twenty-first century for Gabon, the country located closest to the equator, is $3.4^{\circ} \mathrm{C}$. For Finland, the country located closest to the north pole, the projected temperature change is $2.9^{\circ} \mathrm{C}$.
} 


\subsection{Welfare projections and changes in spatial structure}

Greater spatial correlation of cereal productivity due to climate change matters for global welfare inequality. To demonstrate this, we combine projected local cereal productivity under climate change with the estimates of $\widehat{\beta}_{0}$ and $\widehat{\beta}_{1}$ from Section 4 to project future domestic shares of expenditure via equation (3) and welfare variance via equation (2) (see Appendix D.2 for details). We consider two scenarios with different terms-of-trade effects. ${ }^{43}$ In the first scenario, we fix the spatial correlation of temperature-predicted cereal productivities to its 2013 value. In the second scenario, we allow climate change to increase the spatial correlation of productivities as depicted by the blue series in the left panel of Figure 11.

The projected change in the variance of welfare over the twenty-first century is shown in the right panel of Figure 11. The gray line shows the projection that omits changes in spatial correlation and the red line shows the projection that include such changes. Omitting changes in spatial correlation, the projected increase in the variance of cereal productivity generates a projected increase in the variance of welfare. The projection that incorporates increases in the spatial correlation of cereal productivity due to climate change predicts a $20 \%$ greater increase in welfare inequality between 2013-2099 compared to the projection that holds spatial correlation fixed.

How do the projections differ across countries? Figure 12 maps the difference between the two projections. ${ }^{44}$ Including an increase in the spatial correlation of productivities causes the gains from trade to be lower in less productive countries and higher in more productive countries than in a projection that holds spatial correlation fixed. In particular, Figure 12 shows that most countries in Africa, and a few in Asia and South America have lower gains from trade in the projection that incorporates changes in spatial correlation. This is because the relatively high local temperatures that drive yield losses in these countries are compounded by similar temperatures simultaneously experienced by neighboring countries. In the simplest terms, a key feature of climate change is that it makes Ethiopia and Kenya less productive at the same time, lowering the gains from trade compared to a scenario in which each country warms independently. By the same logic, parts of Europe and North American have higher gains from trade when the projection includes increases in spatial correlation. The relatively milder temperatures experienced by these countries are accompanied by similar temperatures over neighboring locations.

Figure 13 depicts climate-change forecasts for each country in terms of the predicted change in cereal productivity and the difference in projected welfare from omitting the change in spatial correlation shown in Figure 12 on the vertical axis. The vast majority of countries suffer a decrease in cereal productivity as a result of increased temperature. As in Figure 12, the strongest contrast in Figure 13 is between outcomes for African and European economies. While there is substantial heterogeneity in the productivity declines across countries within each continent, most economies in Africa, and a few in South America and Asia, experience productivity losses that would be

\footnotetext{
${ }^{43}$ In autarky, the variance of welfare would be proportionate to the variance of productivity. Since a productivity increase is associated with worse terms of trade, an increase in the variance of productivity causes a smaller increase in the variance of welfare when there is international trade.

${ }^{44}$ See equation (D.12) at the end of Appendix D.2.
} 
Figure 12: Differences in projected welfare changes due to change in spatial correlation (2013-2099)

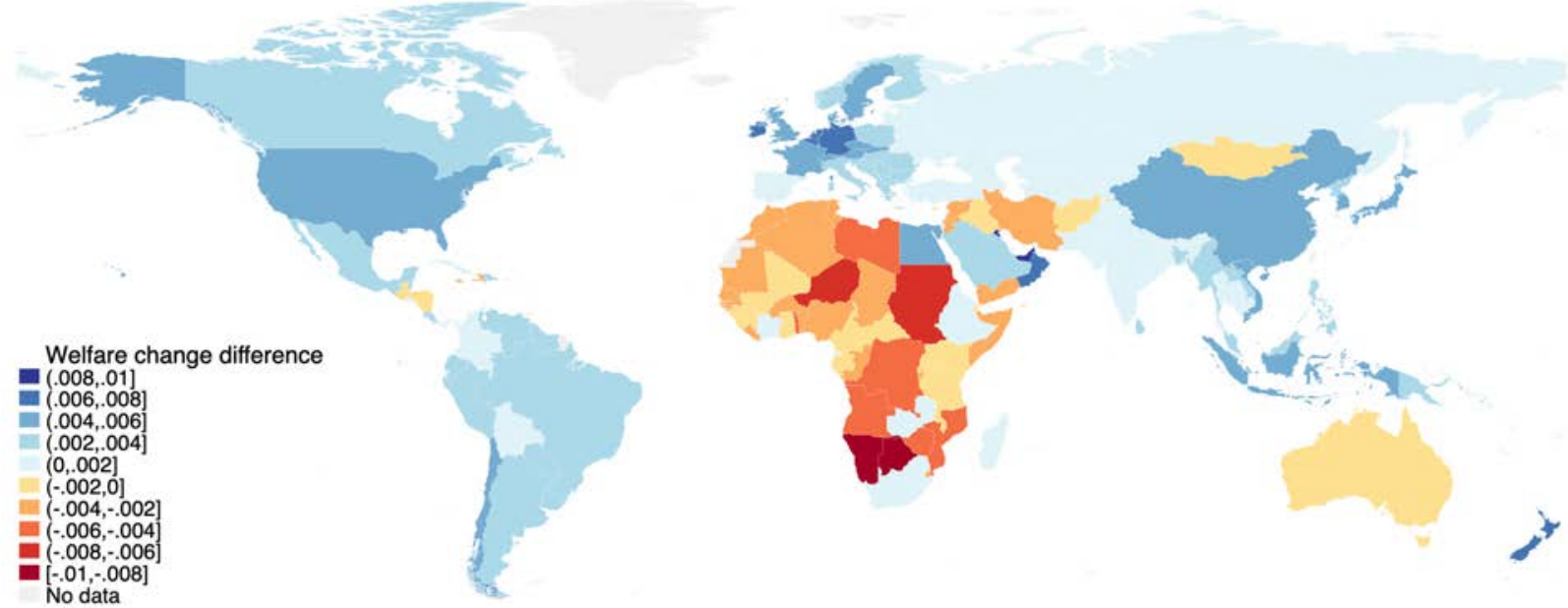

Notes: Map shows the difference in projected country-level welfare change over 2013-2099 between projections that include and omit changes in spatial correlation. Climate projections from CMIP5 ensemble mean under a business-as-usual (RCP 8.5) scenario. Appendix D.2 describes welfare calculations assuming $\epsilon=8.59$.

Figure 13: Differences in welfare projections from projected changes in spatial correlation and yields

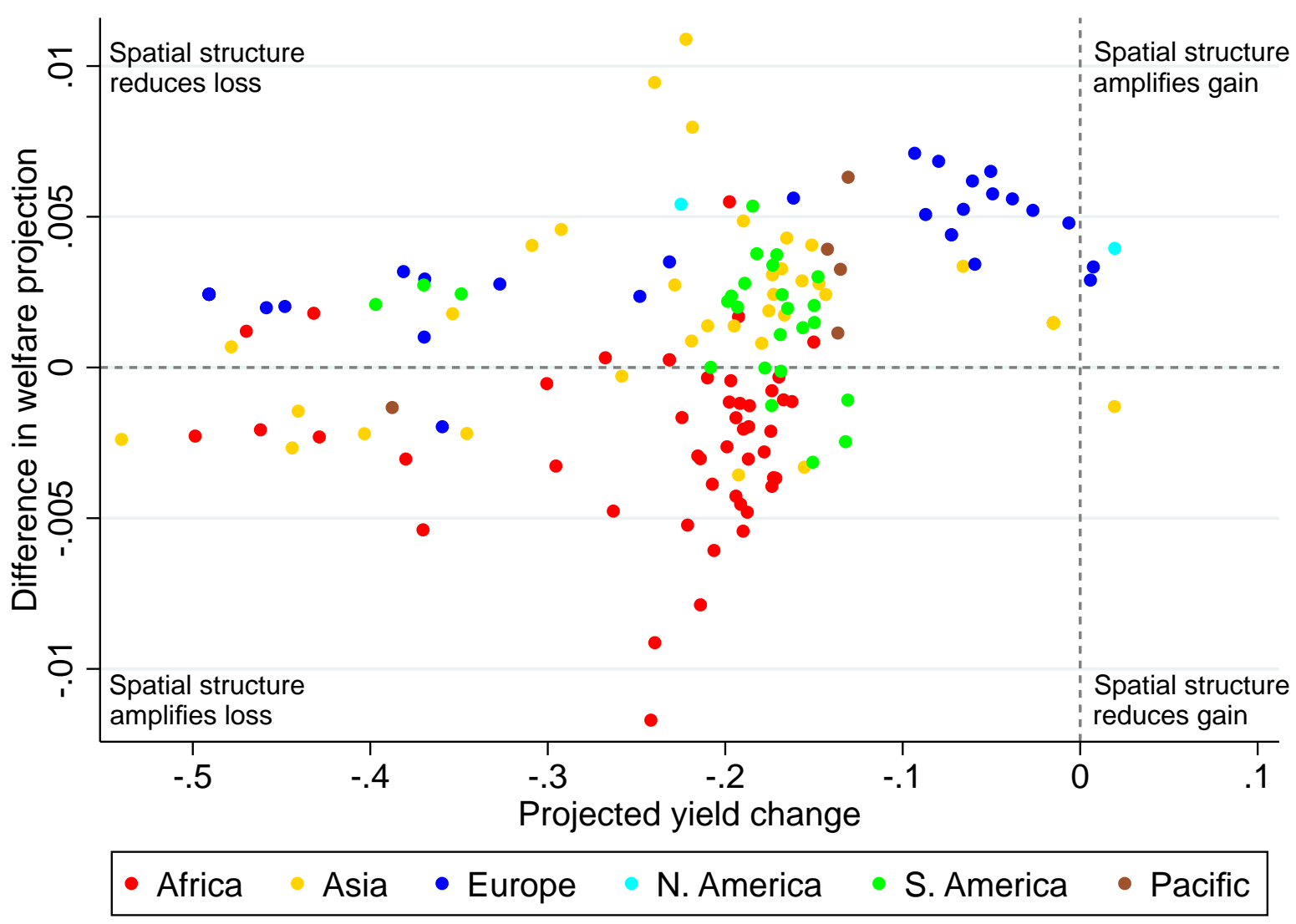

Notes: Scatter shows the difference in projected country-level welfare change between projections that include and omit changes in spatial correlation (from Figure 12) plotted against change in log cereal yields over 20132099 under climate change. Countries are color-coded by continent. See Figure E.5 for the same plot with country identifiers. Appendix D.2 describes welfare calculations assuming $\epsilon=8.59$. 
considerably amplified by changes in spatial correlation. By contrast, most European economies have reduced projected welfare losses when the change in spatial correlation is incorporated. For the few economies with increased productivity under climate change, the differences across projections are close to zero.

\section{Conclusion}

This paper studies how the spatial structure of the global productivity distribution shapes the distribution of welfare across countries. In particular, we use a benchmark trade model with distance-related trade costs to show that, all else equal, greater spatial correlation of productivities can increase welfare inequality. The increase in spatial correlation causes high-productivity locations to enjoy larger gains from trade than they would if productivity were spatially uncorrelated. In settings in which welfare differences are arbitraged away by mobile factors of production, greater spatial correlation of productivities would make population density, rather than welfare per capita, more unequal across locations. ${ }^{45}$

To investigate the empirical relationship between the spatial correlation of productivities and the distribution of gains from trade, we exploit a global natural experiment. Specifically, we use the El Niño-Southern Oscillation, a naturally occurring global climatic phenomenon, which exogenously alters the annual spatial correlation of cereal productivity around the planet. We examine how the spatial correlation of cereal productivity governs the response of the domestic share of expenditure, a sufficient statistic for the gains from trade in a broad class of trade models, to local productivity. Using data from the past five decades of cereal trade, we find that high-productivity countries enjoy larger gains from trade when cereal productivities are more spatially correlated, as predicted. More broadly, our empirical approach advances the use of causal-inference techniques to estimate general-equilibrium predictions.

In our application, we demonstrate that incorporating changes in the spatial correlation of productivities substantially alters predictions about global welfare inequality when forecasting the consequences of anthropogenic climate change. This interplay between the spatial structure of productivity and welfare inequality is potentially important in many other domains. Many determinants of productivity - such as demographics, political institutions, and natural endowments - tend to exhibit substantial spatial correlation. For natural endowments in particular, spatial correlation may change following the relocation of existing endowments (e.g., migrating wildlife stocks), the discovery of new uses for them (e.g., solar and wind availability), or the discovery of new endowments (e.g., fossil fuel deposits). This paper provides a framework for analyzing the welfare consequences of such widespread productivity changes.

\footnotetext{
${ }^{45}$ Appendix A.5 proves that this is the case for a symmetric geography with four locations.
} 


\section{References}

Acemoglu, Daron, and Jaume Ventura. 2002. "The World Income Distribution." The Quarterly Journal of Economics, 117(2): 659-694.

Agcaoili-Sombilla, Mercedita C, and Mark W Rosegrant. 1994. "International trade in a differentiated good: Trade elasticities in the world rice market." Agricultural Economics, 10(3): 257-267.

Allen, Treb, and Costas Arkolakis. 2014. "Trade and the Topography of the Spatial Economy." The Quarterly Journal of Economics, 129(3): 1085-1140.

Allen, Treb, Costas Arkolakis, and Yuta Takahashi. 2020. "Universal Gravity." Journal of Political Economy, 128(2): 393-433.

Amemiya, Takeshi. 1974. "The nonlinear two-stage least-squares estimator." Journal of Econometrics, 2(2): 105-110.

Anderson, James E., and Eric van Wincoop. 2003. "Gravity with Gravitas: A Solution to the Border Puzzle." American Economic Review, 93(1): 170-192.

Anderson, T. W., and Herman Rubin. 1949. "Estimation of the Parameters of a Single Equation in a Complete System of Stochastic Equations." The Annals of Mathematical Statistics, 20(1): 46-63.

Angrist, Joshua D., and Jörn-Steffen Pischke. 2009. Mostly Harmless Econometrics: An Empiricist's Companion. Princeton University Press.

Arkolakis, Costas, Arnaud Costinot, and Andrés Rodríguez-Clare. 2012. "New Trade Models, Same Old Gains?" American Economic Review, 102(1): 94-130.

Armington, Paul S. 1969. "A theory of demand for products distinguished by place of production." Staff Papers, 16(1): 159-178.

Auffhammer, Maximilian. 2018. "Quantifying Economic Damages from Climate Change." Journal of Economic Perspectives, 32(4): 33-52.

Barro, Robert J, José F Ursúa, and Joanna Weng. 2020. "The Coronavirus and the Great Influenza Pandemic: Lessons from the "Spanish Flu" for the Coronavirus's Potential Effects on Mortality and Economic Activity." National Bureau of Economic Research Working Paper 26866.

Bekker, Paul A. 1994. "Alternative Approximations to the Distributions of Instrumental Variable Estimators." Econometrica, 62(3): 657-681.

Bellemare, Marc F, and Casey J Wichman. 2020. "Elasticities and the inverse hyperbolic sine transformation." Oxford Bulletin of Economics and Statistics, 82(1): 50-61.

Bleakley, Hoyt. 2007. "Disease and Development: Evidence from Hookworm Eradication in the American South." The Quarterly Journal of Economics, 122(1): 73-117. 
Bloom, David E., and Jeffrey D. Sachs. 1998. "Geography, Demography, and Economic Growth in Africa." Brookings Papers on Economic Activity, 29(2): 207-296.

Bound, John, David A. Jaeger, and Regina M. Baker. 1995. "Problems with Instrumental Variables Estimation When the Correlation Between the Instruments and the Endogeneous Explanatory Variable is Weak." Journal of the American Statistical Association, 90(430): 443-450.

Brock, William, Gustav Engström, and Anastasios Xepapadeas. 2014. "Spatial climate-economic models in the design of optimal climate policies across locations." European Economic Review, 69: $78-103$.

Burke, Marshall, Solomon M. Hsiang, and Edward Miguel. 2015. "Global non-linear effect of temperature on economic production." Nature, 527(7577): 235-239.

Caliendo, Lorenzo, and Fernando Parro. 2015. "Estimates of the Trade and Welfare Effects of NAFTA." The Review of Economic Studies, 82(1): 1-44.

Cane, Mark A., and Stephen E. Zebiak. 1985. "A Theory for El Niño and the Southern Oscillation." Science, 228(4703): 1085-1087.

Carleton, Tamma A, Amir Jina, Michael T Delgado, Michael Greenstone, Trevor Houser, Solomon M Hsiang, Andrew Hultgren, Robert E Kopp, Kelly E McCusker, Ishan B Nath, James Rising, Ashwin Rode, Hee Kwon Seo, Arvid Viaene, Jiacan Yuan, and Alice Tianbo Zhang. 2020. "Valuing the Global Mortality Consequences of Climate Change Accounting for Adaptation Costs and Benefits." National Bureau of Economic Research Working Paper 27599.

Chen, Dake, Mark A. Cane, Alexey Kaplan, Stephen E. Zebiak, and Daji Huang. 2004. "Predictability of El Nino over the past 148 years." Nature, 428(6984): 733-736.

Chiang, John C.H., and Adam H. Sobel. 2002. "Tropical Tropospheric Temperature Variations Caused by ENSO and Their Influence on the Remote Tropical Climate." Journal of Climate, 15(18): 2616-2631.

Costinot, Arnaud, and Andrés Rodríguez-Clare. 2014. "Trade Theory with Numbers: Quantifying the Consequences of Globalization." Vol. 4 of Handbook of International Economics, Chapter 4, 197-261. Elsevier.

Costinot, Arnaud, Dave Donaldson, and Cory Smith. 2016. "Evolving Comparative Advantage and the Impact of Climate Change in Agricultural Markets: Evidence from 1.7 Million Fields around the World." Journal of Political Economy, 124(1): 205-248.

Cragg, John G., and Stephen G. Donald. 1993. "Testing Identifiability and Specification in Instrumental Variable Models." Econometric Theory, 9(2): 222-240.

Debaere, Peter, and Hongshik Lee. 2003. "The Real-Side Determinants of Countries' Terms of Trade." mimeo. 
Dell, Melissa, Benjamin F. Jones, and Benjamin A. Olken. 2012. "Temperature Shocks and Economic Growth: Evidence from the Last Half Century." American Economic Journal: Macroeconomics, 4(3): 66-95.

Dell, Melissa, Benjamin F. Jones, and Benjamin A. Olken. 2014. "What Do We Learn from the Weather? The New Climate-Economy Literature." Journal of Economic Literature, 52(3): 74098.

Deschênes, Olivier, and Kyle C Meng. 2018. "Quasi-experimental methods in environmental economics: Opportunities and challenges." Handbook of Environmental Economics, 4: 285.

Deschênes, Olivier, and Michael Greenstone. 2007a. "Climate change, mortality, and adaptation: Evidence from the annual fluctuations in weather in the US." NBER Working Paper No. 13178.

Deschênes, Olivier, and Michael Greenstone. 2007b. "The economic impacts of climate change: evidence from agricultural output and random fluctuations in weather." American Economic Review, 97(1): 354-385.

Deschênes, Olivier, and Michael Greenstone. 2007c. "The Economic Impacts of Climate Change: Evidence from Agricultural Output and Random Fluctuations in Weather." American Economic Review, 97(1): 354-385.

Desmet, Klaus, and Esteban Rossi-Hansberg. 2015. "On the spatial economic impact of global warming." Journal of Urban Economics, 88: 16 - 37.

Disdier, Anne-Célia, and Keith Head. 2008. "The Puzzling Persistence of the Distance Effect on Bilateral Trade." The Review of Economics and Statistics, 90(1): 37-48.

Dixit, Avinash, and Victor Norman. 1980. Theory of international trade: A dual, general equilibrium approach. Cambridge University Press.

Donaldson, Dave. 2015. "The Gains from Market Integration." Annual Review of Economics, $7(1): 619-647$.

Dong, Ensheng, Hongru Du, and Lauren Gardner. 2020. "An interactive web-based dashboard to track COVID-19 in real time." The Lancet infectious diseases, 20(5): 533-534.

Driscoll, John C., and Aart C. Kraay. 1998. "Consistent Covariance Matrix Estimation with Spatially Dependent Panel Data." The Review of Economics and Statistics, 80(4): 549-560.

Easterly, William, and Ross Levine. 2003. "Tropics, Germs, and Crops: How Endowments Influence Economic Development." Journal of Monetary Economics, 50(1): 3-39.

Eaton, Jonathan, and Samuel Kortum. 2002. "Technology, Geography, and Trade." Econometrica, 70(5): 1741-1779. 
Fuchs-Schündeln, Nicola, and Tarek A. Hassan. 2016. "Natural Experiments in Macroeconomics." In . Vol. 2 of Handbook of Macroeconomics, , ed. John B. Taylor and Harald Uhlig, 923 - 1012. Elsevier.

Hansen, Christian, Jerry Hausman, and Whitney Newey. 2008. "Estimation With Many Instrumental Variables." Journal of Business ES Economic Statistics, 26(4): 398-422.

Harrell, Frank. 2001. Regression Modeling Strategies: With Applications to Linear Models, Logistic Regression, and Survival Analysis. Springer.

Head, Keith, and Thierry Mayer. 2004. "The Empirics of Agglomeration and Trade." , ed. J. V. Henderson and J. F. Thisse Vol. 4 of Handbook of Regional and Urban Economics, Chapter 59, 2609-2669. Elsevier.

Head, Keith, and Thierry Mayer. 2014. "Gravity Equations: Workhorse,Toolkit, and Cookbook." Vol. 4 of Handbook of International Economics, Chapter 3, 131-195. Elsevier.

Hsiang, Solomon. 2016. "Climate Econometrics." Annual Review of Resource Economics, 8(1): 4375.

Hsiang, Solomon M., and Kyle C. Meng. 2015. "Tropical Economics." American Economic Review: Papers and Proceedings, 105(5): 257-61.

Hsiang, Solomon M, Kyle C Meng, and Mark A Cane. 2011. "Civil conflicts are associated with the global climate." Nature, 476(7361): 438-441.

Hsiang, Solomon M., Marshall Burke, and Edward Miguel. 2013. "Quantifying the Influence of Climate on Human Conflict." Science, 341(6151).

Jameson, G. J. O. 2006. "Counting Zeros of Generalised Polynomials: Descartes' Rule of Signs and Laguerre's Extensions." The Mathematical Gazette, 90(518): 223-234.

Kaplan, A., M. Cane, Y. Kushnir, A. Clement, M. Blumenthal, and B. Rajagopalan. 1998. "Analyses of global sea surface temperature 1856-1991." Journal of Geophysical Research, 103: 18,56718,589 .

Kelejian, Harry H. 1971. "Two-Stage Least Squares and Econometric Systems Linear in Parameters but Nonlinear in the Endogenous Variables." Journal of the American Statistical Association, 66(334): 373-374.

Kleibergen, Frank, and Richard Paap. 2006. "Generalized reduced rank tests using the singular value decomposition." Journal of Econometrics, 133(1): 97 - 126.

Kopczuk, Wojciech, Emmanuel Saez, and Jae Song. 2010. "Earnings inequality and mobility in the United States: evidence from social security data since 1937." The Quarterly Journal of Economics, 125(1): 91-128. 
Krugman, Paul. 1980. "Scale Economies, Product Differentiation, and the Pattern of Trade." American Economic Review, 70(5): 950-59.

Krusell, Per, and Jr. Smith, Anthony A. 2022. "Climate Change Around the World." National Bureau of Economic Research Working Paper 30338.

Lind, Nelson, and Natalia Ramondo. 2019. "Trade with Correlation."

Mariano, Roberto S. 2001. "Simultaneous Equation Model Estimators: Statistical Properties and Practical implications." A Companion to Theoretical Econometrics, , ed. B. Baltagi, 122-143. Blackwell: Oxford, UK.

McGuirk, Eoin, and Marshall Burke. 2020. "The Economic Origins of Conflict in Africa." Journal of Political Economy, 128(10): 3940-3997.

Melitz, Marc J. 2003. "The Impact of Trade on Intra-Industry Reallocations and Aggregate Industry Productivity." Econometrica, 71(6): 1695-1725.

Monte, Ferdinando, Stephen J. Redding, and Esteban Rossi-Hansberg. 2018. "Commuting, Migration, and Local Employment Elasticities." American Economic Review, 108(12): 3855-90.

Moore, Frances C., and David B. Lobell. 2015. "The fingerprint of climate trends on European crop yields." Proceedings of the National Academy of Sciences, 112(9): 2670-2675.

Nakamura, Emi, and Jón Steinsson. 2018. "Identification in Macroeconomics." The Journal of Economic Perspectives, 32(3): 59-86.

Newey, Whitney K., and Kenneth D. West. 1987. "A Simple, Positive Semi-Definite, Heteroskedasticity and Autocorrelation Consistent Covariance Matrix." Econometrica, 55(3): 703-708.

Nordhaus, William D. 2006. "Geography and macroeconomics: New data and new findings." Proceedings of the National Academy of Sciences of the United States of America, 103(10): 3510-3517.

Nunn, Nathan, and Diego Puga. 2012. "Ruggedness: The Blessing of Bad Geography in Africa." Review of Economics and Statistics, 94(1): 20-36.

Piskorski, Tomasz, and Amit Seru. 2018. "Debt Relief and Slow Recovery: A Decade after Lehman." National Bureau of Economic Research Working Paper 25403.

Proctor, Jonathan, Solomon Hsiang, Jennifer Burney, Marshall Burke, and Wolfram Schlenker. 2018. "Estimating global agricultural effects of geoengineering using volcanic eruptions." Nature, 560(7719): 480-483.

Ramankutty, Navin, Amato T. Evan, Chad Monfreda, and Jonathan A. Foley. 2008. "Farming the planet: 1. Geographic distribution of global agricultural lands in the year 2000." Global Biogeochemical Cycles, 22. 
Ramey, Valerie A. 2019. "Ten Years after the Financial Crisis: What Have We Learned from the Renaissance in Fiscal Research?" Journal of Economic Perspectives, 33(2): 89-114.

Redding, Stephen, and Anthony J. Venables. 2004. "Economic geography and international inequality." Journal of International Economics, 62(1): 53-82.

Roberts, Michael J., and Wolfram Schlenker. 2013. "Identifying Supply and Demand Elasticities of Agricultural Commodities: Implications for the US Ethanol Mandate." American Economic Review, 103(6): 2265-95.

Ropelewski, C. F., and M. S. Halpert. 1987. "Global and Regional Scale Precipitation Patterns Associated with the El Niño/Southern Oscillation." Monthly Weather Review, 115(8): 1606-1626.

Sarachik, Edward S., and Mark A. Cane. 2010. The El Niño-Southern Oscillation Phenomenon. Cambridge University Press.

Schlenker, Wolfram, and David B Lobell. 2010. "Robust negative impacts of climate change on African agriculture." Environmental Research Letters, 5(1): 014010.

Schlenker, Wolfram, and Michael J Roberts. 2009. "Nonlinear temperature effects indicate severe damages to U.S. crop yields under climate change." Proceedings from the National Academy of Science, 106(37): 15594-8.

Shrader, Jeffrey. 2017. "Expectations and adaptation to environmental risks." mimeo.

Silva, JMC Santos, and Silvana Tenreyro. 2006. "The log of gravity." The Review of Economics and statistics, 88(4): 641-658.

Stock, James, and Motohiro Yogo. 2005. "Testing for Weak Instruments in Linear IV Regression." Identification and Inference for Econometric Models, , ed. Donald W.K. Andrews, 80-108. New York:Cambridge University Press.

Stocker, T.F., D. Qin, G.-K. Plattner, L.V. Alexander, S.K. Allen, N.L. Bindoff, F.-M. Bréon, J.A. Church, U. Cubasch, S. Emori, P. Forster, P. Friedlingstein, N. Gillett, J.M. Gregory, D.L. Hartmann, E. Jansen, B. Kirtman, R. Knutti, K. Krishna Kumar, P. Lemke, J. Marotzke, V. Masson-Delmotte, G.A. Meehl, I.I. Mokhov, S. Piao, V. Ramaswamy, D. Randall, M. Rhein, M. Rojas, C. Sabine, D. Shindell, L.D. Talley, D.G. Vaughan, and S.-P. Xie. 2013. "Technical Summary." Climate Change 2013: The Physical Science Basis. Contribution of Working Group I to the Fifth Assessment Report of the Intergovernmental Panel on Climate Change, , ed. T.F. Stocker, D. Qin, G.-K. Plattner, M. Tignor, S.K. Allen, J. Boschung, A. Nauels, Y. Xia, V. Bex and P.M. Midgley, Chapter TS, 33-115. Cambridge, United Kingdom and New York, NY, USA:Cambridge University Press.

Taylor, Karl E., Ronald J. Stouffer, and Gerald A. Meehl. 2012. "An Overview of CMIP5 and the Experiment Design." Bulletin of the American Meteorological Society, 93(4): 485-498. 
Tobler, Waldo R. 1970. "A computer movie simulating urban growth in the Detroit region." Economic geography, 46(sup1): 234-240.

Welch, Jarrod R., Jeffrey R. Vincent, Maximilian Auffhammer, Piedad F. Moya, Achim Dobermann, and David Dawe. 2010. "Rice yields in tropical/subtropical Asia exhibit large but opposing sensitivities to minimum and maximum temperatures." Proceedings of the National Academy of Sciences, 107(33): 14562-14567.

Williams, Jeffrey C, and Brian D Wright. 2005. Storage and Commodity Markets. Cambridge University Press.

Willmott, C. J., and K. Matsuura. 2001. "Terrestrial Air Temperature and Precipitation: Monthly and Annual Time Series (1950 - 1999).”

Wright, Philip G. 1928. Tariff on animal and vegetable oils. Macmillan Company, New York. 


\section{Appendix - For Online Publication}

\section{A Theory appendix}

\section{A.1 General economic environment}

This appendix section provides details of the perfect-competition results presented in Section 2 and extends them to the Krugman (1980) model of monopolistic competition.

Preferences. Individuals in country $j$ have constant-elasticity-of-substitution preferences over goods indexed by $\omega$. The accompanying price index is

$$
P_{j}=\left(\int_{\omega} p_{j}(\omega)^{1-\sigma} d \omega\right)^{1 /(1-\sigma)} .
$$

\section{A.1.1 Perfect-competition microfoundations}

Production. Productivity $A_{j}$ has a model-specific microeconomic interpretation. In the Armington model, each country $i$ produces a distinct variety using a linear production technology such that one unit of labor yields $A_{i}$ units of output. Under perfect competition, its price is $w_{i} / A_{i}$ and thus the Dixit-Stigliz price index is $P_{j}=\left(\sum_{i=1}^{N}\left(w_{i} \tau_{i j} / A_{i}\right)^{1-\sigma}\right)^{1 /(1-\sigma)}$. In the Eaton and Kortum (2002) model, there is a continuum of varieties, and each country's efficiency in producing them follows a Fréchet distribution with location parameter $T_{i}$ and dispersion parameter $\vartheta$. The equivalence with the Armington model requires $T_{i}=A_{i}^{\epsilon}$.

Gravity equation. Written in terms of expenditure shares, the gravity equation is

$$
\lambda_{i j}=\frac{X_{i j}}{X_{j}}=\frac{\chi_{i}\left(\tau_{i j} w_{i}\right)^{-\epsilon}}{\sum_{l=1}^{N} \chi_{l}\left(\tau_{l j} w_{l}\right)^{-\epsilon}}=\frac{\chi_{i}\left(\tau_{i j} w_{i}\right)^{-\epsilon}}{\Phi_{j}},
$$

where $\chi_{i}$ is a function of $A_{i}$ and other structural parameters that are not trade costs, $\epsilon$ is the "trade elasticity", and $\Phi_{j} \equiv \sum_{l=1}^{N} \chi_{l}\left(\tau_{l j} w_{l}\right)^{-\epsilon}$ is the "inward multilateral resistance" term (Head and Mayer, 2014). $\Phi_{j}$ is a (decreasing) transformation of $j$ 's price index that summarizes consumers' access to goods from every source. In the Armington model, $\epsilon=\sigma-1$ and $\chi_{i}=A_{i}^{\epsilon}$. In the EatonKortum model without intermediate inputs, $\epsilon=\vartheta$ and $\chi_{i}=T_{i}$. Thus, the equilibrium trade flows associated with a productivity distribution $\left\{A_{i}\right\}_{i}$ and trade elasticity $\epsilon$ in the Armington model are equal to the equilibrium trade flows for an Eaton-Kortum model in which efficiency distributions have location parameters $T_{i}=A_{i}^{\epsilon}$. As a result, we can replace $\chi_{i}$ in the gravity equation by $A_{i}^{\epsilon}$, as done in the main text.

Welfare. Equation (1) is an immediate consequence of the main result in Arkolakis, Costinot and Rodríguez-Clare (2012). They show that, in a broad class of models, the gains from trade relative to autarky are equal to $-\frac{1}{\epsilon} \ln \lambda_{i i}$. In our theoretical environment, autarky welfare is equal to $\ln A_{i}+\gamma$, as implied by equation (1). $\gamma$ is a function of structural parameters. In the Armington model with symmetric preferences, $\gamma$ is zero. In the Eaton and Kortum (2002) model, 
$\gamma=\left[\Gamma\left(1+\frac{1-\sigma}{\theta}\right)\right]^{1 /(1-\sigma)}$, where $\Gamma$ is the gamma function.

Spatial correlation and welfare. To examine the role of spatial correlation, consider two productivity distributions, a correlated state $c$ and an uncorrelated state $u$, with the same unconditional variance of productivities, $\operatorname{var}\left(\ln A_{i}^{c}\right)=\operatorname{var}\left(\ln A_{i}^{u}\right)$. The difference in welfare dispersion between these states is

$$
\begin{aligned}
\operatorname{var}\left(\ln \left(C_{i}^{c} / L_{i}\right)\right)-\operatorname{var}\left(\ln \left(C_{i}^{u} / L_{i}\right)\right)= & -\frac{2}{\epsilon}\left[\operatorname{cov}\left(\ln A_{i}^{c}, \ln \lambda_{i i}^{c}\right)-\operatorname{cov}\left(\ln A_{i}^{u}, \ln \lambda_{i i}^{u}\right)\right] \\
& +\frac{1}{\epsilon^{2}}\left[\operatorname{var}\left(\ln \lambda_{i i}^{c}\right)-\operatorname{var}\left(\ln \lambda_{i i}^{u}\right)\right] .
\end{aligned}
$$

The latter term should make only a second-order contribution to the difference in welfare dispersion, since $\frac{1}{\epsilon^{2}}$ is an order of magnitude smaller than $\frac{2}{\epsilon}$ for empirically relevant values of the trade elasticity. ${ }^{46}$

\section{A.1.2 Krugman (1980) microfoundations}

We now discuss the case of monopolistic competition with homogeneous firms, in which the measure of varieties available in equilibrium is endogenously determined. Consider a many-country version of the Krugman (1980) model in which costs may vary across countries. Denote the equilibrium number of homogeneous firms producing in country $j$ by $n_{j}$.

Production function. Homogeneous firms produce differentiated varieties under monopolistic competition. Denote their fixed costs by $f_{j}$ and constant marginal costs by $c_{j}$. Productivity $A_{j}$ may be a shifter of fixed costs or marginal costs for all firms.

Gravity equation. In the free-entry equilibrium, the gravity equation (A.1) holds with $\epsilon=$ $\sigma-1, n_{i}=L_{i} /\left(\sigma f_{i}\right)$, and $\chi_{i}=n_{i} c_{i}^{-\epsilon}$.

Welfare. In this setting, real per capita consumption is

$$
\ln \left(C_{i} / L_{i}\right)=\frac{1}{\epsilon} \ln n_{i}-\ln c_{i}+\ln \left(\frac{\sigma-1}{\sigma}\right)-\frac{1}{\epsilon} \ln \lambda_{i i}
$$

If population size $L_{i}$ and fixed costs $f_{i}$ are country-invariant $\left(n_{i}=n \forall j\right)$ and we interpret productivity as shifting marginal costs, $A_{i}=c_{i}^{-1}$, then this is equivalent to equation (1) with $\gamma=\frac{1}{\epsilon} \ln n+\ln \left(\frac{\sigma-1}{\sigma}\right)$. If population size $L_{i}$ and marginal costs $c_{i}$ are country-invariant and we interpret productivity as shifting fixed costs, $A_{i}=f_{i}^{-1 / \epsilon}$, then this is equivalent to equation (1) with $\gamma=\frac{1}{\epsilon} \ln (L / \sigma)+\ln \left(\frac{\sigma-1}{\sigma c}\right)$.

In the case of countries with heterogeneous population sizes, equation (1) must be extended to

\footnotetext{
${ }^{46}$ Typical estimates of the aggregate trade elasticity are between 4 and 8. Caliendo and Parro (2015) estimate that the trade elasticity for agricultural goods is between 8 and 17. Provided that $\operatorname{var}\left(\ln \lambda_{i i}^{c}\right)-\operatorname{var}\left(\ln \lambda_{i i}^{u}\right)$ is the same order of magnitude or smaller than $\operatorname{cov}\left(\ln A_{i}^{c}, \ln \lambda_{i i}^{c}\right)-\operatorname{cov}\left(\ln A_{i}^{u}, \ln \lambda_{i i}^{u}\right)$, this means that the second term on the right side of equation (A.2) is an order of magnitude smaller than the first term. Appendix A.1.3 shows that $\operatorname{cov}\left(\ln A_{i}^{c}, \ln \lambda_{i i}^{c}\right)-\operatorname{cov}\left(\ln A_{i}^{u}, \ln \lambda_{i i}^{u}\right)$ is the same order of magnitude as $\operatorname{var}\left(\ln \lambda_{i i}^{c}\right)-\operatorname{var}\left(\ln \lambda_{i i}^{u}\right)$ if trade costs are symmetric $\left(\tau_{i j}=\tau_{j i}\right)$ and countries equal sized $\left(L_{i}=L \forall i\right)$. This is also overwhelmingly true in numerical simulations featuring countries of different sizes reported in Appendix Figure E.1. Nonetheless, our welfare calculations, laid out in Appendix D, incorporate $\frac{1}{\epsilon^{2}}\left[\operatorname{var}\left(\ln \lambda_{i i}^{c}\right)-\operatorname{var}\left(\ln \lambda_{i i}^{u}\right)\right]$.
} 
replace $\gamma$ with a location-specific $\gamma_{i}$ that depends on structural parameters other than productivity. For example, if productivity shifts marginal costs, $A_{i}=c_{i}^{-1}$, then we obtain

$$
\ln \left(\frac{C_{i}}{L_{i}}\right)=\ln A_{i}+\gamma_{i}-\frac{1}{\epsilon} \ln \lambda_{i i}
$$

where $\gamma_{i}=\frac{1}{\epsilon} \ln n_{i}+\ln \left(\frac{\sigma-1}{\sigma}\right)$.

Spatial correlation and welfare. If we assume that $\operatorname{cov}\left(\ln A_{i}^{u}, \gamma_{i}\right)=\operatorname{cov}\left(\ln A_{i}^{c}, \gamma_{i}\right)$, we obtain an extension of equation (A.2):

$$
\begin{aligned}
\operatorname{var}\left(\ln C_{i}^{c} / L_{i}\right)-\operatorname{var}\left(\ln C_{i}^{u} / L_{i}\right)= & -\frac{2}{\epsilon}\left[\operatorname{cov}\left(\ln A_{i}^{c}, \ln \lambda_{i i}^{c}\right)-\operatorname{cov}\left(\ln A_{i}^{u}, \ln \lambda_{i i}^{u}\right)\right] \\
& -\frac{2}{\epsilon}\left[\operatorname{cov}\left(\gamma_{i}, \ln \lambda_{i i}^{c}\right)-\operatorname{cov}\left(\gamma_{i}, \ln \lambda_{i i}^{u}\right)\right] \\
& +\frac{1}{\epsilon^{2}}\left[\operatorname{var}\left(\ln \lambda_{i i}^{c}\right)-\operatorname{var}\left(\ln \lambda_{i i}^{u}\right)\right] .
\end{aligned}
$$

Similar results hold for the Melitz (2003) model of heterogeneous firms under monopolistic competition when the productivity distribution of country $j$ is a Pareto distribution with location parameter $A_{j}$.

\section{A.1.3 The case of symmetric trade costs}

The case of symmetric trade $\operatorname{costs}\left(\tau_{i j}=\tau_{j i} \forall i, j\right)$ is illuminating because it allows us to define the equilibrium in terms of one vector of endogenous outcomes $\left(\Phi_{i}\right)$ and relevant because it connects more closely with measures of spatial correlation, which use symmetric spatial weights. Starting from the equilibrium system of equations and using the assumption of symmetric trade costs:

$$
\begin{aligned}
Y_{i}=w_{i} L_{i} & =\sum_{j}\left(\frac{w_{i}}{A_{i}}\right)^{-\epsilon} \tau_{i j}^{-\epsilon} \frac{w_{j} L_{j}}{\Phi_{j}}=\left(\frac{w_{i}}{A_{i}}\right)^{-\epsilon} \Omega_{i} \\
\Rightarrow \frac{w_{i}}{A_{i}} & =\left(\frac{\Omega_{i}}{A_{i} L_{i}}\right)^{\frac{1}{\epsilon+1}} \\
\Rightarrow \Phi_{i} & =\sum_{j} \tau_{j i}^{-\epsilon}\left(\frac{w_{j}}{A_{j}}\right)^{-\epsilon}=\sum_{j} \tau_{j i}^{-\epsilon}\left(A_{j} L_{j} / \Omega_{j}\right)^{\frac{\epsilon}{\epsilon+1}} \\
& =\sum_{j} \tau_{j i}^{-\epsilon}\left(A_{j} L_{j} / \Phi_{j}\right)^{\frac{\epsilon}{\epsilon+1}}
\end{aligned}
$$

The last equality exploits the fact that we can normalize incomes such that $\Phi_{i}=\Omega_{i}$ when trade is balanced and $\tau_{i j}^{-\epsilon}$ is symmetric, as established in Anderson and van Wincoop (2003) and Head and Mayer (2014).

Combining $\lambda_{i i}=\frac{\left(w_{i} / A_{i}\right)^{-\epsilon}}{\Phi_{i}}$, the above expression for $w_{i} / A_{i}$, and the assumption of symmetric 
trade costs yields the result that

$$
\lambda_{i i}=\frac{\left(\Omega_{i} /\left(A_{i} L_{i}\right)\right)^{\frac{-\epsilon}{\epsilon+1}}}{\Phi_{i}}=\left(A_{i} L_{i}\right)^{\frac{\epsilon}{\epsilon+1}} \Phi_{i}^{-\frac{2 \epsilon+1}{\epsilon+1}} .
$$

Thus, in the case in which $L_{i}=L \forall i, \operatorname{var}\left(\ln \lambda_{i i}\right)=\frac{\epsilon}{\epsilon+1} \operatorname{cov}\left(\ln A_{i}, \ln \lambda_{i i}\right)-\frac{1+2 \epsilon}{1+\epsilon} \operatorname{cov}\left(\ln \Phi_{i}, \ln \lambda_{i i}\right)$. Comparing these outcomes for productivity distributions $A^{c}$ and $A^{u}$ in the case in which $L_{i}=L \forall i$,

$$
\begin{aligned}
\operatorname{var}\left(\ln \lambda_{i i}^{c}\right)-\operatorname{var}\left(\ln \lambda_{i i}^{u}\right)= & \frac{\epsilon}{\epsilon+1}\left[\operatorname{cov}\left(\ln A_{i}^{c}, \ln \lambda_{i i}^{c}\right)-\operatorname{cov}\left(\ln A_{i}^{u}, \ln \lambda_{i i}^{u}\right)\right] \\
& -\frac{1+2 \epsilon}{1+\epsilon}\left[\operatorname{cov}\left(\ln \Phi_{i}^{c}, \ln \lambda_{i i}^{c}\right)-\operatorname{cov}\left(\ln \Phi_{i}^{u}, \ln \lambda_{i i}^{u}\right)\right] .
\end{aligned}
$$

Heuristically, the latter term is of smaller magnitude, since $\Phi_{i}$ is a price-index term that is a weighted sum of all other countries' prices. Thus, $\operatorname{var}\left(\ln \lambda_{i i}^{c}\right)-\operatorname{var}\left(\ln \lambda_{i i}^{u}\right)$ is the same order of magnitude as $\operatorname{cov}\left(\ln A_{i}^{c}, \ln \lambda_{i i}^{c}\right)-\operatorname{cov}\left(\ln A_{i}^{u}, \ln \lambda_{i i}^{u}\right)$.

\section{A.2 Spatial correlation and the covariance of productivity and gains from trade}

This appendix section theoretically illustrates how the spatial correlation of productivities may affect welfare inequality by altering the covariance between productivity and gains from trade. We do so by a series of steps. First, we use a local approximation to show that the change in the covariance of productivities and domestic shares of expenditure resulting from an infinitesimal change in countries' productivities depends on the change in a term akin to the Moran's $I$ spatialcorrelation statistic for productivity. Second, we allow for large productivity changes by proving our theoretical prediction in a symmetric four-country model and showing that it holds in numerical simulations with more countries. Third, we examine how to identify this ceteris paribus prediction in asymmetric environments in which countries differ by other, potentially confounding, determinants of equilibrium trade flows, as well as allowing for realistic geography, productivities and trade costs. These simulations motivate our use of panel data in our empirical investigation. Finally, we show implications for our predictions for trade models with multiple sectors, spatial correlation in comparative advantage, and mobile labor.

\section{A.2.1 A local approximation}

A partial-equilibrium local approximation suggests that an increase in the spatial correlation of productivities should decrease the covariance of productivities and domestic shares of expenditure and that Moran's I captures part of this spatial interdependence. A general-equilibrium local approximation that exploits the assumption of symmetric trade costs $\left(\tau_{i j}=\tau_{j i}\right)$ delivers a very similar result, as shown below. We can regress $\ln \lambda_{i i}$ on the interaction of $\log$ productivity and Moran's $I$ to estimate this relationship.

We first consider the effect of an infinitesimal change in countries' productivities on the covariance of productivities and domestic shares of expenditure. Let $\left\{\mathrm{d} \ln A_{i}\right\}_{i}$ denote a set of local 
productivity changes that do not alter the distribution's variance $\left(\mathrm{d} \operatorname{var}\left(\ln A_{i}\right)=0\right)$. The resulting change in $\operatorname{cov}\left(\ln \lambda_{i i}, \ln A_{i}\right)$ can be written as the sum of four terms:

$$
\mathrm{d} \operatorname{cov}\left(\ln \lambda_{i i}, \ln A_{i}\right)=\epsilon \underbrace{\mathrm{d} v a r\left(\ln A_{i}\right)}_{=0}-\epsilon \underbrace{\operatorname{cov}\left(\mathrm{d} \ln w_{i}, \ln A_{i}\right)}_{=0 \text { by P.E. }}-\underbrace{\operatorname{cov}\left(\mathrm{d} \ln \Phi_{i}, \ln A_{i}\right)}_{\approx \mathrm{d} I \text { by P.E. }}+\operatorname{cov}\left(\ln \lambda_{i i}, \mathrm{~d} \ln A_{i}\right)
$$

The first term is zero by the assumption that the distribution's variance is unchanged. If we take a partial-equilibrium perspective by assuming $\mathrm{d} \ln w_{i}=0 \forall i$, the second term is also zero. Furthermore, in partial equilibrium the third term is closely related to the spatial correlation of productivities. The following subsection shows that, if wages are unchanged, $\operatorname{cov}\left(\mathrm{d} \ln \Phi_{i}, \ln A_{i}\right)$ is akin to the change in Moran's $I$ if we set spatial weights equal to initial expenditure shares $\omega_{j i}=\lambda_{j i}$ for $j \neq i .{ }^{47}$ The fourth term, while not taking the form of a change in Moran's $I$, is also intuitively linked to spatial correlation. Conditional on $A_{i}$ and $L_{i}, \lambda_{i i}$ will be lower in countries where neighboring countries are larger and more productive. An increase in spatial correlation will tend to raise productivity in countries with more productive neighbors, so the fourth term should also be negative when spatial correlation increases.

\section{Partial-equilibrium case}

Using the facts that $\ln \lambda_{i i}=\epsilon \ln A_{i}-\epsilon \ln w_{i}-\ln \Phi_{i}$ and $\mathrm{d} \operatorname{cov}\left(y_{i}, x_{i}\right)=\operatorname{cov}\left(\mathrm{d} y_{i}, x_{i}\right)+\operatorname{cov}\left(y_{i}, \mathrm{~d} x_{i}\right)$, we can derive the following

$$
\begin{aligned}
\mathrm{d} \operatorname{cov} & \left(\ln \lambda_{i i}, \ln A_{i}\right)=\epsilon \mathrm{d} \operatorname{cov}\left(\ln A_{i}, \ln A_{i}\right)-\epsilon \mathrm{d} \operatorname{cov}\left(\ln w_{i}, \ln A_{i}\right)-\mathrm{d} \operatorname{cov}\left(\ln \Phi_{i}, \ln A_{i}\right) \\
& =\epsilon \mathrm{d} v \operatorname{var}\left(\ln A_{i}\right)-\epsilon \operatorname{cov}\left(\mathrm{d} \ln w_{i}, \ln A_{i}\right)-\epsilon \operatorname{cov}\left(\ln w_{i}, \mathrm{~d} \ln A_{i}\right)-\operatorname{cov}\left(\mathrm{d} \ln \Phi_{i}, \ln A_{i}\right)-\operatorname{cov}\left(\ln \Phi_{i}, \mathrm{~d} \ln A_{i}\right) \\
& =\epsilon \underbrace{\mathrm{d} v a r\left(\ln A_{i}\right)}_{=0}-\epsilon \underbrace{\operatorname{cov}\left(\mathrm{d} \ln w_{i}, \ln A_{i}\right)}_{=0 \text { by P.E. }}-\underbrace{\operatorname{cov}\left(\mathrm{d} \ln \Phi_{i}, \ln A_{i}\right)}_{\approx \mathrm{d} I \text { by P.E. }}-\underbrace{\operatorname{cov}\left(\epsilon \ln w_{i}+\ln \Phi_{i}, \mathrm{~d} \ln A_{i}\right)}_{=\operatorname{cov}\left(\ln \lambda_{i i}, \mathrm{~d} \ln A_{i}\right)},
\end{aligned}
$$

which yields equation (A.3). The first two terms are zero by the assumptions of unchanged variance and partial equilibrium, respectively. The fourth term is equivalent to $\operatorname{cov}\left(\ln \lambda_{i i}, \mathrm{~d} \ln A_{i}\right)$ because $\ln \lambda_{i i}=\epsilon \ln A_{i}-\epsilon \ln w_{i}-\ln \Phi_{i}$ and $\mathrm{d} \operatorname{var}\left(\ln A_{i}\right)=2 \operatorname{cov}\left(\ln A_{i}, \mathrm{~d} \ln A_{i}\right)=0$. We proceed to show why the third term is related to the change in Moran's $I, d I$.

Starting from the definition of Moran's $I$ for productivity, we can write changes in Moran's $I$

\footnotetext{
${ }^{47}$ Moran's $I$ is a commonly used measure of global spatial correlation that can be computed for any geography endowed with a distance metric. It takes values between -1 and 1 . Moran's $I$ for productivity $\ln A_{i}$ is defined by

$$
I \equiv \frac{N}{\sum_{i} \sum_{j \neq i} \omega_{i j}} \frac{\sum_{i} \sum_{j \neq i} \omega_{i j}\left(\ln A_{i}-\overline{\ln A}\right)\left(\ln A_{j}-\overline{\ln A}\right)}{\sum_{\ell}\left(\ln A_{\ell}-\overline{\ln A}\right)^{2}}
$$

where $N$ is the number of countries, $\omega_{i j}=\omega_{j i}$ is a symmetric spatial weight, and $\overline{\ln A}$ is the cross-sectional average.
} 
as a covariance of $\ln A_{i}$ and a weighted sum of $\mathrm{d} \ln A_{j}$.

$$
\begin{array}{rlrl}
I & \equiv \underbrace{\frac{N}{\sum_{i} \sum_{j \neq i} \omega_{i j}} \frac{1}{\sum_{\ell}\left(\ln A_{\ell}-\overline{\ln A}\right)^{2}} \sum_{i} \sum_{j \neq i} \omega_{i j}\left(\ln A_{i}-\overline{\ln A}\right)\left(\ln A_{j}-\overline{\ln A}\right)}_{\equiv \Omega} \\
\mathrm{d} I & =\Omega \sum_{i} \sum_{j \neq i} \omega_{i j}\left[\mathrm{~d} \ln A_{i}\left(\ln A_{j}-\overline{\ln A}\right)+\left(\ln A_{i}-\overline{\ln A}\right) \mathrm{d} \ln A_{j}\right] & \text { by } \mathrm{d} v a r(\ln A)=0 \\
& =2 \Omega \sum_{i} \sum_{j \neq i} \omega_{i j}\left(\ln A_{j}-\overline{\ln A}\right) \mathrm{d} \ln A_{i} & \text { by } \omega_{i j}=\omega_{j i} \forall i, j \\
& =2 \Omega \operatorname{cov}\left(\sum_{j} \omega_{j i} \mathrm{~d} \ln A_{j}, \ln A_{i}\right) & \text { by } \omega_{i i}=0 \forall i
\end{array}
$$

The third term in equation (A.3) evaluated at fixed wages is a covariance of $\ln A_{i}$ and a weighted sum of d $\ln A_{j}$.

$$
\begin{aligned}
\Phi_{i} & =\sum_{j} A_{j}^{\epsilon} \tau_{j i}^{-\epsilon} w_{j}^{-\epsilon} \\
\mathrm{d} \ln \Phi_{i} & =\frac{1}{\Phi_{i}} \sum_{j} \epsilon A_{j}^{\epsilon} \tau_{j i}^{-\epsilon} w_{j}^{-\epsilon}\left(\frac{1}{A_{j}} \mathrm{~d} A_{j}-\frac{1}{w_{j}} \mathrm{~d} w_{j}\right) \\
& =\epsilon \sum_{j} \lambda_{j i}\left(\mathrm{~d} \ln A_{j}-\mathrm{d} \ln w_{j}\right) \\
\operatorname{cov}\left(\mathrm{d} \ln \Phi,\left.\ln A_{i}\right|_{\mathrm{d} \ln w_{i}=0 \forall i}\right) & =\epsilon \operatorname{cov}\left(\sum_{j} \lambda_{j i} \mathrm{~d} \ln A_{j}, \ln A_{i}\right)
\end{aligned}
$$

As a result, this covariance would be proportionate to the expression for $\mathrm{d} I$ above if $\omega_{j i}=\lambda_{j i}$. It is not identical to the change in Moran's $I$ because $\omega_{i i}=0$ and while spatial weights are symmetric, $\omega_{j i}=\omega_{i j}$, the initial equilibrium's expenditures shares need not be.

\section{General-equilibrium case with symmetric trade costs}

Assume that $\tau_{i j}=\tau_{j i} \forall i, j$. Using the two previously noted facts that $\mathrm{d} \operatorname{cov}\left(y_{i}, x_{i}\right)=\operatorname{cov}\left(\mathrm{d} y_{i}, x_{i}\right)+$ $\operatorname{cov}\left(y_{i}, \mathrm{~d} x_{i}\right)$, and symmetric trade costs imply $\lambda_{i i}=\left(A_{i} L_{i}\right)^{\frac{\epsilon}{\epsilon+1}} \Phi_{i}^{-\frac{2 \epsilon+1}{\epsilon+1}}$, we obtain the following expression for $\mathrm{d} \operatorname{cov}\left(\ln \lambda_{i i}, \ln A_{i}\right)$ :

$$
\begin{aligned}
\mathrm{d} \operatorname{cov}\left(\ln \lambda_{i i}, \ln A_{i}\right) & =\operatorname{cov}\left(\mathrm{d} \ln \lambda_{i i}, \ln A_{i}\right)+\operatorname{cov}\left(\ln \lambda_{i i}, \mathrm{~d} \ln A_{i}\right) \\
& =\frac{\epsilon}{\epsilon+1}[\frac{1}{2} \underbrace{\mathrm{d} v a r\left(\ln A_{i}\right)}_{=0}+\underbrace{\operatorname{cov}\left(\mathrm{d} \ln L_{i}, \ln A_{i}\right)}_{=0}]-\frac{2 \epsilon+1}{\epsilon+1} \operatorname{cov}\left(\mathrm{d} \ln \Phi_{i}, \ln A_{i}\right)+\operatorname{cov}\left(\ln \lambda_{i i}, \mathrm{~d} \ln A_{i}\right)
\end{aligned}
$$


Section A.1.3 showed that when $\tau_{i j}=\tau_{j i} \forall i, j$, we can characterize equilibria in terms of $\left\{\Phi_{i}\right\}_{i}$ and exogenous variables. We therefore obtain an expression for $\mathrm{d} \ln \Phi_{i}$.

$$
\begin{aligned}
\Phi_{i} & =\sum_{j} \tau_{j i}^{-\epsilon} A_{j}^{\epsilon} w_{j}^{-\epsilon}=\sum_{j} \tau_{j i}^{-\epsilon}\left(A_{j} L_{j} / \Phi_{j}\right)^{\frac{\epsilon}{\epsilon+1}} \\
\mathrm{~d} \ln \Phi_{i} & =\frac{1}{\Phi_{i}} \frac{\epsilon}{\epsilon+1} \sum_{j} \tau_{j i}^{-\epsilon}\left(A_{j} L_{j} / \Phi_{j}\right)^{\frac{\epsilon}{\epsilon+1}}\left(\frac{1}{A_{j}} \mathrm{~d} A_{j}-\frac{1}{\Phi_{j}} \mathrm{~d} \Phi_{j}\right) \\
& =\frac{\epsilon}{\epsilon+1} \sum_{j} \lambda_{j i}\left(\mathrm{~d} \ln A_{j}-\mathrm{d} \ln \Phi_{j}\right)
\end{aligned}
$$

To establish the connection between $\operatorname{cov}\left(\mathrm{d} \ln \Phi_{i}, \ln A_{i}\right)$ and the change in Moran's $I$, we switch to matrix notation. Define the following matrices:

$$
\begin{array}{rlrl}
\ln \tilde{\mathbf{A}} & \equiv\left\{\ln A_{i}-\overline{\ln A}\right\}_{i} & n \text {-element vector } \\
\mathrm{d} \ln \mathbf{A} & \equiv\left\{\mathrm{d} \ln A_{i}\right\}_{i} & n \text {-element vector } \\
\mathbf{W} & \equiv\left\{\omega_{i j}\right\}_{i, j} & n \text {-by- } n \text { matrix }
\end{array}
$$

Using these matrices, we can write the change in Moran's $I$ as

$$
\mathrm{d} I=2 \Omega \sum_{i} \sum_{j} \omega_{i j}\left(\ln A_{j}-\overline{\ln A}\right) \mathrm{d} \ln A_{i}=2 \Omega \cdot \ln \tilde{\mathbf{A}}^{\prime} \mathbf{W} \mathrm{d} \ln \mathbf{A} .
$$

If we define $\mathbf{B}$ as the matrix whose $i j$ element is $\frac{\epsilon}{\epsilon+1} \lambda_{j i}$, then equation (A.4) can be written as

$$
\begin{aligned}
\mathrm{d} \ln \boldsymbol{\Phi} & =\mathbf{B}(\mathrm{d} \ln \mathbf{A}-\mathrm{d} \ln \boldsymbol{\Phi}) \\
\Rightarrow \mathrm{d} \ln \boldsymbol{\Phi} & =(\mathbf{I}+\mathbf{B})^{-1} \mathbf{B} \mathrm{d} \ln \mathbf{A},
\end{aligned}
$$

where the inverse exists because $\mathbf{I}+\mathbf{B}$ is diagonal-dominant. As a result

$$
\operatorname{cov}\left(\ln A_{i}, \mathrm{~d} \ln \Phi_{i}\right)=\frac{1}{N}\left[\ln \tilde{\mathbf{A}}^{\prime}(\mathbf{I}+\mathbf{B})^{-1} \mathbf{B} \mathrm{d} \ln \mathbf{A}\right] .
$$

This covariance would be proportionate to the change in the Moran's $I$ spatial-correlation statistic for $\left\{\ln A_{i}\right\}_{i}$ if we were to use the spatial weight matrix $\mathbf{W}=(\mathbf{I}+\mathbf{B})^{-1} \mathbf{B}=\sum_{n=1}^{\infty}(-1)^{n+1} \mathbf{B}^{n}$. That is, if the spatial weights were equal to the infinite sum of expenditure-share interactions that summarize the entire trading network, the change in Moran's $I$ would capture $\operatorname{cov}\left(\mathrm{d} \ln \Phi_{i}, \ln A_{i}\right)$. The first term in this infinite sum, $\mathbf{B}$, is the "direct effect" in which productivity changes are simply weighted by their expenditure share. Since the gravity equation relates expenditure shares to bilateral distances, we thus expect the change in spatial correlation to affect $\mathrm{d} \operatorname{cov}\left(\ln \lambda_{i i}, \ln A_{i}\right)$. 
Figure A.1: Four-country example: Productivity distributions

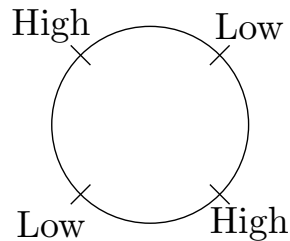

"Alternating" arrangement

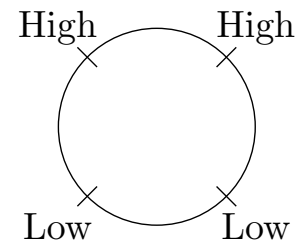

"Regional" arrangement

\section{A.2.2 Four-country case}

A symmetric four-country model is the simplest possible environment in which one can demonstrate our result for large productivity changes. Consider four countries of equal size evenly spaced on a symmetric geography. Each country is "near" two neighbors and farther from the remaining country. Thus, the trade cost matrix is

$$
\tau \equiv\left[\begin{array}{cccc}
1 & d_{1} & d_{2} & d_{1} \\
d_{1} & 1 & d_{1} & d_{2} \\
d_{2} & d_{1} & 1 & d_{1} \\
d_{1} & d_{2} & d_{1} & 1
\end{array}\right], \quad 1<d_{1}<d_{2}<d_{1}^{2}
$$

where the trade costs $d_{2}>d_{1}$, a mnemonic for distance, obey the triangle inequality: $d_{2}<d_{1}^{2}$.

For these four countries, consider a mirror-image productivity distribution in which two countries have high productivity and the other two countries have low productivity. These productivities might alternate - high, low, high, low - or the world may be divided into a high-productivity region and a low-productivity region. Figure A.1 depicts the two possible spatial arrangements. What are the consequences for trade and welfare?

Proposition 1 shows that the "regional" arrangement of productivities exhibits greater spatial correlation, as measured by Moran's $I$. As a result, the covariance of productivity and the domestic share of expenditure is lower when productivities are distributed this way. That makes the variance of welfare across countries greater. The proof of Proposition 1 follows below.

Proposition 1 (Four-country case). Consider an economy in which $N=4, L_{i}=L \forall i, \epsilon \geq 1$, and trade costs $\tau_{i j}$ are given by condition (A.5). Comparing the productivity distributions $A^{c}=$ $(\tilde{a}, \tilde{a}, 1,1)$ and $A^{u}=(\tilde{a}, 1, \tilde{a}, 1)$, where $\tilde{a}>1$,

- $A^{c}$ is more spatially correlated than $A^{u}$ in the sense that the value of Moran's I for $\ln A^{c}$ is greater for any spatial weight matrix that is a one-to-one mapping between $\omega_{i j}$ and $\tau_{i j}$ and assigns a higher weight to the pairs with $\tau_{i j}=d_{1}$ than pairs with $\tau_{i j}=d_{2}$.

- Equilibrium income inequality, given by $Y_{1} / Y_{4}$, is greater for the more spatially correlated productivity distribution, $A^{c}$. Equivalently, the more productive economies' equilibrium double- 
factoral terms of trade are greater for the more spatially correlated productivity distribution.

- The covariance of productivity and the domestic share of expenditure is lower for the more spatially correlated productivity distribution: $\operatorname{cov}\left(\ln A_{i}^{c}, \ln \lambda_{i i}^{c}\right)<\operatorname{cov}\left(\ln A_{i}^{u}, \ln \lambda_{i i}^{u}\right)$.

- The variance of welfare across countries is greater for the more spatially correlated productivity distribution: $\operatorname{var}\left(\ln \left(C_{i}^{c} / L\right)\right)>\operatorname{var}\left(\ln \left(C_{i}^{u} / L\right)\right)$.

This four-country case illustrates our prediction linking the spatial correlation of productivities to welfare inequality.

\section{$A^{c}$ is more spatially correlated than $A^{u}$}

Proof. Recall that Moran's I is given by

$$
I(\ln A, W)=\frac{N}{\sum_{i} \sum_{j} \omega_{i j}} \frac{\sum_{i}\left(\ln A_{i}-\overline{\ln A}\right) \sum_{j} \omega_{i j}\left(\ln A_{j}-\overline{\ln A}\right)}{\sum_{i}\left(\ln A_{i}-\overline{\ln A}\right)^{2}},
$$

where $\omega_{i j}$ are spatial weights. Define the spatial weight matrix

$$
\left\{\omega_{i j}\right\}=\left[\begin{array}{cccc}
\omega_{0} & \omega_{1} & \omega_{2} & \omega_{1} \\
\omega_{1} & \omega_{0} & \omega_{1} & \omega_{2} \\
\omega_{2} & \omega_{1} & \omega_{0} & \omega_{1} \\
\omega_{1} & \omega_{2} & \omega_{1} & \omega_{0}
\end{array}\right] .
$$

Thus, there is a one-to-one mapping between $\omega_{i j}$ and $\tau_{i j} . \omega_{1}$ is the spatial weight associated with trade cost $d_{1} ; \omega_{2}$ is the spatial weight associated with trade cost $d_{2}$.

The average $\log$ productivity is given by $\overline{\ln A}=\frac{1}{2} \ln \tilde{a}$. For the correlated state, $\ln A^{c}=$ $(\ln \tilde{a}, \ln \tilde{a}, 0,0)$, so the demeaned $\log$ productivity vector is equal to $\widehat{\ln A^{c}}=\left(\frac{1}{2} \ln \tilde{a}, \frac{1}{2} \ln \tilde{a},-\frac{1}{2} \ln \tilde{a},-\frac{1}{2} \ln \tilde{a}\right)$. For the uncorrelated state, $\ln A^{u}=(\ln \tilde{a}, 0, \ln \tilde{a}, 0)$ and $\widehat{\ln A^{u}}=\left(\frac{1}{2} \ln \tilde{a},-\frac{1}{2} \ln \tilde{a}, \frac{1}{2} \ln \tilde{a},-\frac{1}{2} \ln \tilde{a}\right)$.

$\ln A^{c}$ is more spatially correlated than $\ln A^{u}$ if and only if $I\left(\ln A^{c}, W\right)>I\left(\ln A^{u}, W\right) \Longleftrightarrow$ $\sum_{i} \widehat{\ln A_{i}^{c}} \sum_{j} \omega_{i j} \widehat{\ln A_{j}^{c}}>\sum_{i} \widehat{\ln A_{i}^{u}} \sum_{j} \omega_{i j} \widehat{\ln A_{j}^{u}}$.

The relevant terms are as follows:

$$
\begin{gathered}
\sum_{j} \omega_{i j} \widehat{\ln A_{j}^{c}}=\left\{\begin{array}{c}
\frac{1}{2}\left(\omega_{0}-\omega_{2}\right) \ln \tilde{a} \quad \text { for } i=1,2 \\
-\frac{1}{2}\left(\omega_{0}-\omega_{2}\right) \ln \tilde{a} \quad \text { for } i=3,4
\end{array}\right. \\
\sum_{i} \widehat{\ln A_{i}^{c}} \sum_{j} \omega_{i j} \widehat{\ln A_{j}^{c}}=\left(\omega_{0}-\omega_{2}\right)(\ln \tilde{a})^{2} \\
\sum_{j} \omega_{i j} \widehat{\ln A_{j}^{u}}=\left\{\begin{array}{c}
\frac{1}{2}\left(\omega_{0}-2 \omega_{1}+\omega_{2}\right) \ln \tilde{a} \quad \text { for } i=1,3 \\
-\frac{1}{2}\left(\omega_{0}-2 \omega_{1}+\omega_{2}\right) \ln \tilde{a} \quad \text { for } i=2,4
\end{array}\right. \\
\sum_{i} \widehat{\ln A_{i}^{u}} \sum_{j} \omega_{i j} \widehat{\ln A_{j}^{u}}=\left(\omega_{0}-2 \omega_{1}+\omega_{2}\right)(\ln \tilde{a})^{2}
\end{gathered}
$$

$I\left(\ln A^{c}, W\right)>I\left(\ln A^{u}, W\right) \Longleftrightarrow \omega_{0}-\omega_{2}>\omega_{0}-2 \omega_{1}+\omega_{2} \Longleftrightarrow \omega_{1}>\omega_{2}$. 
Equilibrium for the correlated state: $A^{c}=(\tilde{a}, \tilde{a}, 1,1)$

By symmetry, the equilibrium incomes and market access of countries 1 and 2 are identical, $Y_{1}=Y_{2}$ and $\Phi_{1}=\Phi_{2}$. Similarly, countries 3 and 4 have identical outcomes: $Y_{3}=Y_{4}$ and $\Phi_{3}=\Phi_{4}$. As a result, the equilibrium incomes that solve $Y_{i}=\sum_{j=1}^{N} \lambda_{i j} Y_{j}$ can without loss of generality be characterized by the scalar $x \equiv Y_{1} / Y_{4}$, the relative income levels.

$$
Y_{1}=\lambda_{11} Y_{1}+\lambda_{12} Y_{2}+\lambda_{13} Y_{3}+\lambda_{14} Y_{4} \Rightarrow x=\frac{\lambda_{13}+\lambda_{14}}{1-\lambda_{11}-\lambda_{12}}
$$

Equilibrium expenditure shares can be expressed as $\lambda_{i j}=A_{i}^{\epsilon} Y_{i}^{-\epsilon} \tau_{i j}^{-\epsilon} / \Phi_{j}$. Thus $\lambda_{i j} A_{i}^{-\epsilon} Y_{i}^{\epsilon}=$ $\tau_{i j}^{-\epsilon} / \Phi_{j}$ and

$$
x=\frac{\tau_{13}^{-\epsilon} / \Phi_{3}+\tau_{14}^{-\epsilon} / \Phi_{4}}{\tilde{a}^{-\epsilon} Y_{1}^{\epsilon}-\tau_{11}^{-\epsilon} / \Phi_{1}-\tau_{12}^{-\epsilon} / \Phi_{2}} .
$$

Using the facts that $\Phi_{1}=\Phi_{2}=Y_{1}^{-\epsilon} \tilde{a}^{\epsilon}\left(1+d_{1}^{-\epsilon}\right)+Y_{3}^{-\epsilon}\left(d_{2}^{-\epsilon}+d_{1}^{-\epsilon}\right)$ and $\Phi_{3}=\Phi_{4}=Y_{1}^{-\epsilon} \tilde{a}^{\epsilon}\left(d_{2}^{-\epsilon}+\right.$ $\left.d_{1}^{-\epsilon}\right)+Y_{3}^{-\epsilon}\left(1+d_{1}^{-\epsilon}\right)$, it can be shown that the equilibrium value of $x$ is the solution to the equation

$$
x^{2 \epsilon+1}+\underbrace{\frac{d_{2}^{-\epsilon}+d_{1}^{-\epsilon}}{1+d_{1}^{-\epsilon}}}_{\equiv r^{c}} \tilde{a}^{\epsilon}\left(x^{\epsilon+1}-x^{\epsilon}\right)-\tilde{a}^{2 \epsilon}=0 .
$$

Equilibrium for the uncorrelated state: $A^{u}=(\tilde{a}, 1, \tilde{a}, 1)$

Analogous to the correlated state, this case can be solved by exploiting the facts that countries 1 and 3 have identical outcomes, $Y_{1}=Y_{3}$ and $\Phi_{1}=\Phi_{3}$, and countries 2 and 4 have identical outcomes: $Y_{2}=Y_{4}$ and $\Phi_{2}=\Phi_{4}$. The equation that characterizes equilibrium relative income $x$ is

$$
x^{2 \epsilon+1}+\underbrace{\frac{d_{1}^{-\epsilon}+d_{1}^{-\epsilon}}{1+d_{2}^{-\epsilon}}}_{\equiv r^{u}} \tilde{a}^{\epsilon}\left(x^{\epsilon+1}-x^{\epsilon}\right)-\tilde{a}^{2 \epsilon}=0 .
$$

Note that $0<r^{c}<r^{u}<1$ since $d_{1}^{2}>d_{2}>d_{1}>0$.

\section{Comparing equilibria}

Equations (A.6) and (A.7) show that relative income in each equilibrium is given by the zeros of the following generalized polynomial

$$
R(x ; r)=x^{2 \epsilon+1}+r \tilde{a}^{\epsilon}\left(x^{\epsilon+1}-x^{\epsilon}\right)-\tilde{a}^{2 \epsilon}
$$

when $r>0$ is evaluated at $r^{c}$ and $r^{u}$, respectively. By Descartes' rule of signs, $R(x ; r)$ has exactly one real positive zero (for a given value of $r$ ) (Jameson, 2006). ${ }^{48}$ Denote this zero of $R(x ; r)$ by $x^{*}(r)$.

\footnotetext{
${ }^{48}$ It also has either 0 or 2 negative zeros that are obviously not of interest.
} 
We prove that $x^{*}(r)$ is decreasing by contradiction. Let $r_{1}<r_{2}$ and denote by $x_{1}^{*}$ and $x_{2}^{*}$ their respective unique positive zeros. Suppose that $x_{1}^{*}<x_{2}^{*}$. Consider the function $F(x)=$ $R\left(x ; r_{2}\right)-R\left(x ; r_{1}\right)=\left(r_{2}-r_{1}\right) \tilde{a}^{\epsilon} x^{\epsilon}(x-1)$. It is evident that $F(0)=F(1)=0, F(x)<0 \forall x \in(0,1)$, and $F(x)>0 \forall x>1$. When evaluated at $x_{1}^{*}, F\left(x_{1}^{*}\right)=R\left(x_{1}^{*} ; r_{2}\right)-R\left(x_{1}^{*} ; r_{1}\right)=R\left(x_{1}^{*} ; r_{2}\right)$, since $x_{1}^{*}$ is a zero of $R\left(x ; r_{1}\right)$.

Note that $R(x ; r)$ is continuous in $x$ and that $R(0 ; r)<0$. Therefore, $R\left(x ; r_{2}\right)<0 \forall x \in\left(0, x_{2}^{*}\right)$. Since $x_{1}^{*} \in\left(0, x_{2}^{*}\right)$ by assumption, $F\left(x_{1}^{*}\right)=R\left(x_{1}^{*} ; r_{2}\right)<0$. Since $F(x)>0 \forall x>1$, we conclude that $x_{1}^{*} \in(0,1)$. We also know that $\forall x>x_{1}^{*}, R\left(x ; r_{1}\right)>0$ since $R\left(x_{1}^{*} ; r_{1}\right)=0$ and $\lim _{x \rightarrow+\infty} R\left(x ; r_{1}\right)=$ $+\infty$. Together, these results imply that $R\left(1 ; r_{1}\right)>0$. Yet, $R\left(1 ; r_{1}\right)=1-\tilde{a}^{2 \epsilon}<0$ as $\tilde{a}>1$. Thus, we have a contradiction. We conclude that $r_{1}<r_{2} \Rightarrow x_{1}^{*}>x_{2}^{*}$.

Denote the equilibrium relative incomes by $x_{c}$ and $x_{u}$. Since $r^{u}>r^{c}, x_{u}<x_{c}$. The ratio of equilibrium incomes is greater in the correlated case. Since the countries are of equal size, the ratio of equilibrium incomes $x$ is also the more productive economy's "double-factoral terms of trade". Thus, the more productive economies' double-factoral terms of trade are greater in the correlated case.

$\operatorname{cov}\left(\ln A_{i}, \ln \lambda_{i i}\right)$ is lower in the spatially correlated case

Proof. Equilibrium domestic shares of expenditure can be expressed as $\lambda_{i i}=A_{i}^{\epsilon} Y_{i}^{-\epsilon} / \Phi_{i}$. For the correlated state $A^{c}, \Phi_{1}=\Phi_{2}=Y_{1}^{-\epsilon} \tilde{a}^{\epsilon}\left(1+d_{1}^{-\epsilon}\right)+Y_{3}^{-\epsilon}\left(d_{2}^{-\epsilon}+d_{1}^{-\epsilon}\right)$ and $\Phi_{3}=\Phi_{4}=Y_{1}^{-\epsilon} \tilde{a}^{\epsilon}\left(d_{2}^{-\epsilon}+\right.$ $\left.d_{1}^{-\epsilon}\right)+Y_{3}^{-\epsilon}\left(1+d_{1}^{-\epsilon}\right)$, so

$$
\begin{aligned}
& \lambda_{11}^{c}=\lambda_{22}^{c}=A_{1}^{\epsilon} Y_{1}^{-\epsilon} / \Phi_{1}=\frac{1}{1+d_{1}^{-\epsilon}+\tilde{a}^{-\epsilon} x_{c}^{\epsilon}\left(d_{2}^{-\epsilon}+d_{1}^{-\epsilon}\right)}=\frac{1}{\left(1+d_{1}^{-\epsilon}\right)\left(1+\tilde{a}^{-\epsilon} x_{c}^{\epsilon} r^{c}\right)} \\
& \lambda_{33}^{c}=\lambda_{44}^{c}=A_{3}^{\epsilon} Y_{3}^{-\epsilon} / \Phi_{3}=\frac{1}{1+d_{1}^{-\epsilon}+\tilde{a}^{\epsilon} x_{c}^{-\epsilon}\left(d_{2}^{-\epsilon}+d_{1}^{-\epsilon}\right)}=\frac{1}{\left(1+d_{1}^{-\epsilon}\right)\left(1+\tilde{a}^{\epsilon} x_{c}^{-\epsilon} r^{c}\right)}
\end{aligned}
$$

For the uncorrelated state $A^{u}, \Phi_{1}=\Phi_{3}=Y_{1}^{-\epsilon} \tilde{a}^{\epsilon}\left(1+d_{2}^{-\epsilon}\right)+2 Y_{2}^{-\epsilon} d_{1}^{-\epsilon}$ and $\Phi_{2}=\Phi_{4}=Y_{2}^{-\epsilon}(1+$ $\left.d_{2}^{-\epsilon}\right)+2 Y_{1}^{-\epsilon} \tilde{a}^{\epsilon} d_{1}^{-\epsilon}$, so

$$
\begin{aligned}
& \lambda_{11}^{u}=\lambda_{33}^{u}=A_{1}^{\epsilon} Y_{1}^{-\epsilon} / \Phi_{1}=\frac{1}{1+d_{2}^{-\epsilon}+2 \tilde{a}^{-\epsilon} x_{u}^{\epsilon} d_{1}^{-\epsilon}}=\frac{1}{\left(1+d_{2}^{-\epsilon}\right)\left(1+\tilde{a}^{-\epsilon} x_{u}^{\epsilon} r^{u}\right)} \\
& \lambda_{22}^{u}=\lambda_{44}^{u}=A_{2}^{\epsilon} Y_{2}^{-\epsilon} / \Phi_{2}=\frac{1}{1+d_{2}^{-\epsilon}+2 \tilde{a}^{\epsilon} x_{u}^{-\epsilon} d_{1}^{-\epsilon}}=\frac{1}{\left(1+d_{2}^{-\epsilon}\right)\left(1+\tilde{a}^{\epsilon} x_{u}^{-\epsilon} r^{u}\right)}
\end{aligned}
$$

Thus, we obtain the following demeaned values of the log domestic shares of expenditure

$$
\begin{aligned}
& \widehat{\ln \lambda_{11}}=-\frac{1}{2}\left[\ln \left(1+x^{\epsilon} \tilde{a}^{-\epsilon} r\right)-\ln \left(1+\tilde{a}^{\epsilon} x^{-\epsilon} r\right)\right] \\
& \widehat{\ln \lambda_{44}}=-\overline{\ln \lambda_{11}}
\end{aligned}
$$

when evaluated at $\left(r^{c}, x_{c}\right)$ and $\left(r^{u}, x_{u}\right)$ for the two respective equilibria. 
The covariance of productivity and the domestic share of expenditure is therefore

$$
\operatorname{cov}\left(\ln A_{i}, \ln \lambda_{i i}\right)=\frac{-1}{4} \ln \tilde{a}\left[\ln \left(1+x^{\epsilon} \tilde{a}^{-\epsilon} r\right)-\ln \left(1+\tilde{a}^{\epsilon} x^{-\epsilon} r\right)\right]
$$

Recall that $\epsilon$ and $\tilde{a}$ are fixed parameters while $x$ is a function of $r$. This covariance is positive because $\tilde{a}>x .^{49}$

It can be shown that $\operatorname{cov}\left(\ln A_{i}, \ln \lambda_{i i}\right)$ is increasing in $r$.

$$
\frac{\mathrm{d} \operatorname{cov}\left(\ln A_{i}, \ln \lambda_{i i}\right)}{\mathrm{d} r} \propto-\frac{\mathrm{d} \ln \left(\frac{1+x^{\epsilon^{-} \tilde{a}^{-\epsilon} r}}{1+\tilde{a}^{\epsilon} x^{-\epsilon}}\right)}{\mathrm{d} r} \propto \underbrace{\left(\frac{\tilde{a}}{x}\right)^{\epsilon}-\left(\frac{x}{\tilde{a}}\right)^{\epsilon}}_{>0}-\underbrace{\frac{r \epsilon}{x}\left[2+x^{\epsilon} \tilde{a}^{-\epsilon}+x^{-\epsilon} \tilde{a}^{\epsilon}\right]}_{>0} \underbrace{\frac{\mathrm{d} x}{\mathrm{~d} r}}_{<0}>0
$$

Since $r^{u}>r^{c}$, the covariance of productivity and the domestic share of expenditure is lower for $A^{c}$ than $A^{u}$. Thus, the covariance of productivity and the equilibrium gains from trade, $\operatorname{cov}\left(\ln A_{i}, \frac{-1}{\epsilon} \ln \lambda_{i i}\right)$, is greater for $A^{c}$ than $A^{u}$.

$\operatorname{var}\left(\ln \left(C_{i} / L\right)\right)$ is greater in the spatially correlated case

Proof. In both equilibria,

$$
\operatorname{var}\left(\ln \lambda_{i i}\right)=\frac{2}{4}\left(\widehat{\ln \lambda_{11}}\right)^{2}+\frac{2}{4}\left(\widehat{\ln \lambda_{44}}\right)^{2}=\left(\widehat{\ln \lambda_{11}}\right)^{2}=\frac{4 \epsilon^{2}}{(\ln \tilde{a})^{2}}\left(\operatorname{cov}\left(\ln A_{i},-\frac{1}{\epsilon} \ln \lambda_{i i}\right)\right)^{2} .
$$

Therefore

$$
\begin{aligned}
\operatorname{var}\left(\ln \left(C_{i} / L\right)\right) & =\operatorname{var}\left(A_{i}\right)+2 \operatorname{cov}\left(\ln A_{i}, \frac{-1}{\epsilon} \ln \lambda_{i i}\right)+\frac{1}{\epsilon^{2}} \operatorname{var}\left(\ln \lambda_{i i}\right) \\
& =\operatorname{var}\left(A_{i}\right)+2 \operatorname{cov}\left(\ln A_{i}, \frac{-1}{\epsilon} \ln \lambda_{i i}\right)+\frac{4}{(\ln \tilde{a})^{2}}\left(\operatorname{cov}\left(\ln A_{i},-\frac{1}{\epsilon} \ln \lambda_{i i}\right)\right)^{2}
\end{aligned}
$$

This is increasing in $\operatorname{cov}\left(\ln A_{i}, \frac{-1}{\epsilon} \ln \lambda_{i i}\right)$ if and only if

$$
2+\frac{8}{(\ln \tilde{a})^{2}} \operatorname{cov}\left(\ln A_{i},-\frac{1}{\epsilon} \ln \lambda_{i i}\right)>0 \Longleftrightarrow \ln \tilde{a}>\frac{1}{\epsilon} \ln \left(\frac{1+\tilde{a}^{\epsilon} x^{-\epsilon} r}{1+x^{\epsilon} \tilde{a}^{-\epsilon} r}\right)
$$

This inequality is true. The triangle inequality for trade costs, $d_{2}<d_{1}^{2}$, implies that $r^{u}<1$. If $r<1$ and $\epsilon \geq 1$, then $R(\sqrt{\tilde{a}} ; r) \leq 0 .{ }^{50}$ Thus, $x^{*}(r) \geq \sqrt{\tilde{a}} \forall r \in(0,1)$. That implies the following

\footnotetext{
${ }_{50}^{49} \tilde{a}>x$ because $x$ is the largest positive zero of $R(x ; r), R\left(x^{\prime} ; r\right)<0 \forall x^{\prime} \in(0, x)$, and $R(\tilde{a} ; r)=(1+r)(\tilde{a}-1) \tilde{a}^{2 \epsilon}>0$.
}

$$
\begin{aligned}
R(\sqrt{\tilde{a}} ; r) & =\tilde{a}^{\frac{2 \epsilon+1}{2}}+r \tilde{a}^{\epsilon}\left(\tilde{a}^{\frac{\epsilon+1}{2}}-\tilde{a}^{\frac{\epsilon}{2}}\right)-\tilde{a}^{2 \epsilon}=\tilde{a}^{\epsilon}\left(\tilde{a}^{\frac{1}{2}}+r \tilde{a}^{\frac{\epsilon}{2}}\left(\tilde{a}^{\frac{1}{2}}-1\right)-\tilde{a}^{\epsilon}\right) \\
& \leq \tilde{a}^{\epsilon}\left(\tilde{a}^{\frac{1}{2}}+\tilde{a}^{\frac{\epsilon}{2}}\left(\tilde{a}^{\frac{1}{2}}-1\right)-\tilde{a}^{\epsilon}\right)=-\tilde{a}^{\epsilon}\left(\tilde{a}^{\frac{\epsilon}{2}}-\tilde{a}^{\frac{1}{2}}\right)\left(1+\tilde{a}^{\frac{\epsilon}{2}}\right) \leq 0
\end{aligned}
$$


inequality:

$$
\frac{1+\tilde{a}^{\epsilon} x^{-\epsilon} r}{1+x^{\epsilon} \tilde{a}^{-\epsilon} r} \leq \frac{\tilde{a}^{\epsilon} x^{-\epsilon}(1+r)}{x^{\epsilon} \tilde{a}^{-\epsilon}(1+r)}=\left(\frac{\tilde{a}}{x}\right)^{2 \epsilon} \leq\left(\frac{\tilde{a}}{\sqrt{\tilde{a}}}\right)^{2 \epsilon}=\tilde{a}^{\epsilon}
$$

Thus, $\operatorname{var}\left(\ln \left(C_{i} / L\right)\right)$ is increasing in $\operatorname{cov}\left(\ln A_{i}, \frac{-1}{\epsilon} \ln \lambda_{i i}\right)$.

This completes the proof of Proposition 1.

\section{A.2.3 Circular geography}

Next, we investigate a symmetric geography with more than four countries and more than two productivity levels using numerical simulations. Figure 3 presents this illustrative example in which we parameterize $A_{i}$ and $\tau_{i j}$ on a circular geography. As stated in the main text, $N=50$, $\epsilon=1$, and $L_{i}=1 \forall i$. Countries have locations given by $l_{i}=\frac{\pi}{N}(2 i-1-N)$ for $i=1, \ldots, N$. Productivity $\ln A_{i}$ has a mean value of 10 and follows a sine wave with amplitude 1 and frequency $\theta .^{51}$ Bilateral trade costs are given by $\ln \tau_{i j}=.8 \ln \left(1+\left\|l_{i}-l_{j}\right\|\right)$, where $\left\|l_{i}-l_{j}\right\|$ is the distance between locations $i$ and $j$ on the circle. Moran's $I$ is computed using spatial weight $\omega_{i j}=\frac{1}{1+\left\|l_{i}-l_{j}\right\|}$ for $i \neq j$. Figure 3 depicts demeaned distributions. Table A.1 reports the means and variances of countries' welfare per capita under autarky and trade.

Table A.1: Outcomes for one-sector sine-wave economy

\begin{tabular}{lcccc}
\hline Frequency of $\ln A$ sine wave $(\theta)$ & 1 & 2 & 3 & 4 \\
\hline Autarky welfare $(\ln A)$ variance & 0.510204 & 0.510204 & 0.510204 & 0.510204 \\
Trading-equilbrium welfare $(\ln C / L)$ variance & 0.298203 & 0.226274 & 0.203006 & 0.184882 \\
\hline
\end{tabular}

Economic characteristics other than productivity that influence domestic shares of expenditure complicate bivariate plots like the right panel of Figure 3. A simple example is heterogeneity in country size $L_{i}$ : all else equal, larger economies have a larger domestic share of expenditure. Variation in size orthogonal to productivity simply adds noise to the bivariate plot. However, variation in size correlated with productivity also introduces omitted variable bias. This can be addressed by examining the covariance of the domestic share of expenditure and productivity conditional on size. More generally, any time-invariant country characteristics that influence the domestic share of expenditure and might be correlated with productivity can be absorbed by country fixed effects.

We illustrate this in Figure A.2, which depicts the relationship between $\ln \lambda_{i i}$ and $\ln A_{i}$ in an environment that extends the circular geography and sine-wave productivity parameterization used in Figure 3 to feature heterogeneous country sizes. In particular, size $\ln L_{i}$ is the sum of a sine

\footnotetext{
${ }^{51}$ The standard deviation of a sine wave is proportional to its amplitude and independent of its frequency. This is true for both the function and our $N$-point discretization.
} 
wave with mean value 10 , amplitude 1 , and frequency $\theta_{L}=1$ and Gaussian noise $\sim \mathcal{N}(0,1)$. Thus, country size $\ln L_{i}$ is positively correlated with productivity $\ln A_{i}$ in the $\theta=1$ state. The left panel depicts the covariance of $\ln \lambda_{i i}$ and $\ln A_{i}$ for the frequencies $\theta=1$ and $\theta=4$. The right panel depicts these covariances conditional on country fixed effects, which we estimated using the equilibrium outcomes of the five equilibria associated with $\theta=1,2,3,4,5$. While our ceteris paribus prediction is not evident in the left panel due to omitted variable bias, the right panel shows that the covariance of $\ln \lambda_{i i}$ and $\ln A_{i}$ is lower when $\theta$ is lower after country fixed effects absorb the consequences of heterogeneous country sizes.

Figure A.2: Circular geography with heterogeneous sizes and productivity sine wave

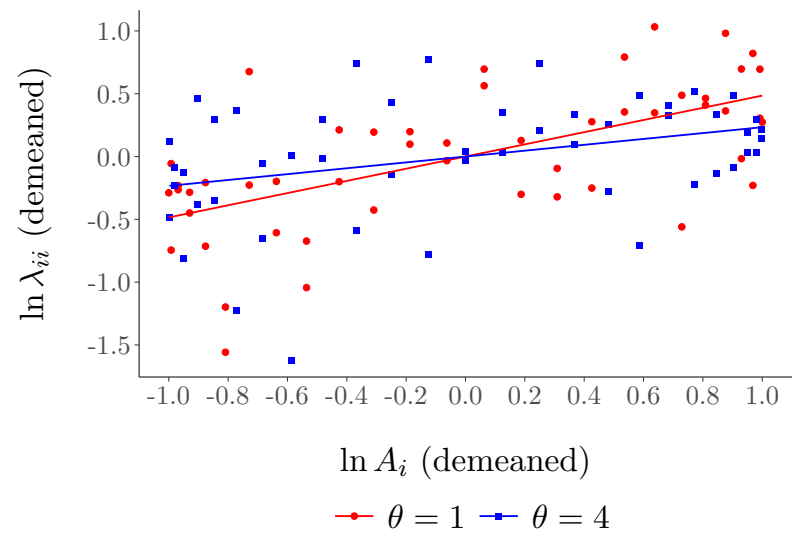

Unconditional relationship

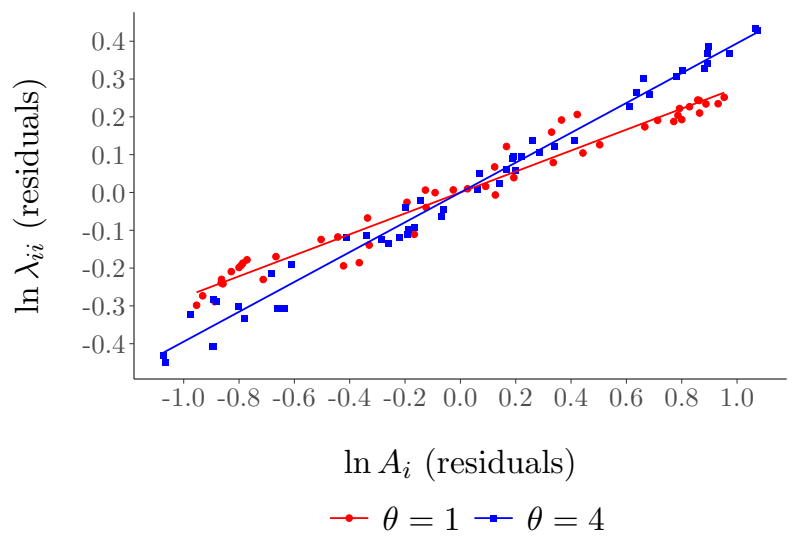

Relationship conditional on fixed effects

Notes: This figure depicts the $\lambda_{i i}-A_{i}$ relationship for an economy with a circular geography and a productivity distribution that follows a sine wave with frequency $\theta$. Geographic locations, trade costs, and the trade elasticity are the same as in Figure 3. Country sizes $L_{i}$ are positively correlated with $A_{i}$ in the $\theta=1$ state. The residuals in the right panel are obtained by subtracting the country-level mean values of $\ln \lambda_{i i}$ and $\ln A_{i}$ across the five equilibria associated with $\theta=1,2,3,4,5$. See Appendix A.2.3 for parameterization details.

The real world features productivities and trade costs that do not exhibit the symmetry of a sine wave on a circle. Departing from the sine-wave distribution, Figure A.3 depicts the expenditureproductivity relationship for the circular geography with equal-sized countries when we shuffle a productivity vector drawn from the normal distribution so as to vary its spatial correlation. They were generated by shuffling a vector $\ln A_{0}$ that was drawn from $\mathcal{N}(0,1)$. There is a clear negative relationship: as Moran's $I$ increases, the equilibrium domestic share of expenditure is less responsive to domestic productivity.

\section{A.2.4 Calibrated geography}

To examine our prediction with realistic geography, productivities and trade costs, we simulate a global economy made up of 158 countries whose geographic coordinates, cereal yields, and crop areas are their 1961-2013 averages in our data. We impose distance-related trade costs and swap pairs of countries' productivity levels in order to vary spatial correlation without altering the mean or variance of the productivity distribution. We recover the covariance of expenditure and productivity in each equilibrium by regressing the domestic share of expenditure for country $i$ at 
Figure A.3: Circular geography with equal-sized countries and arbitrary productivities

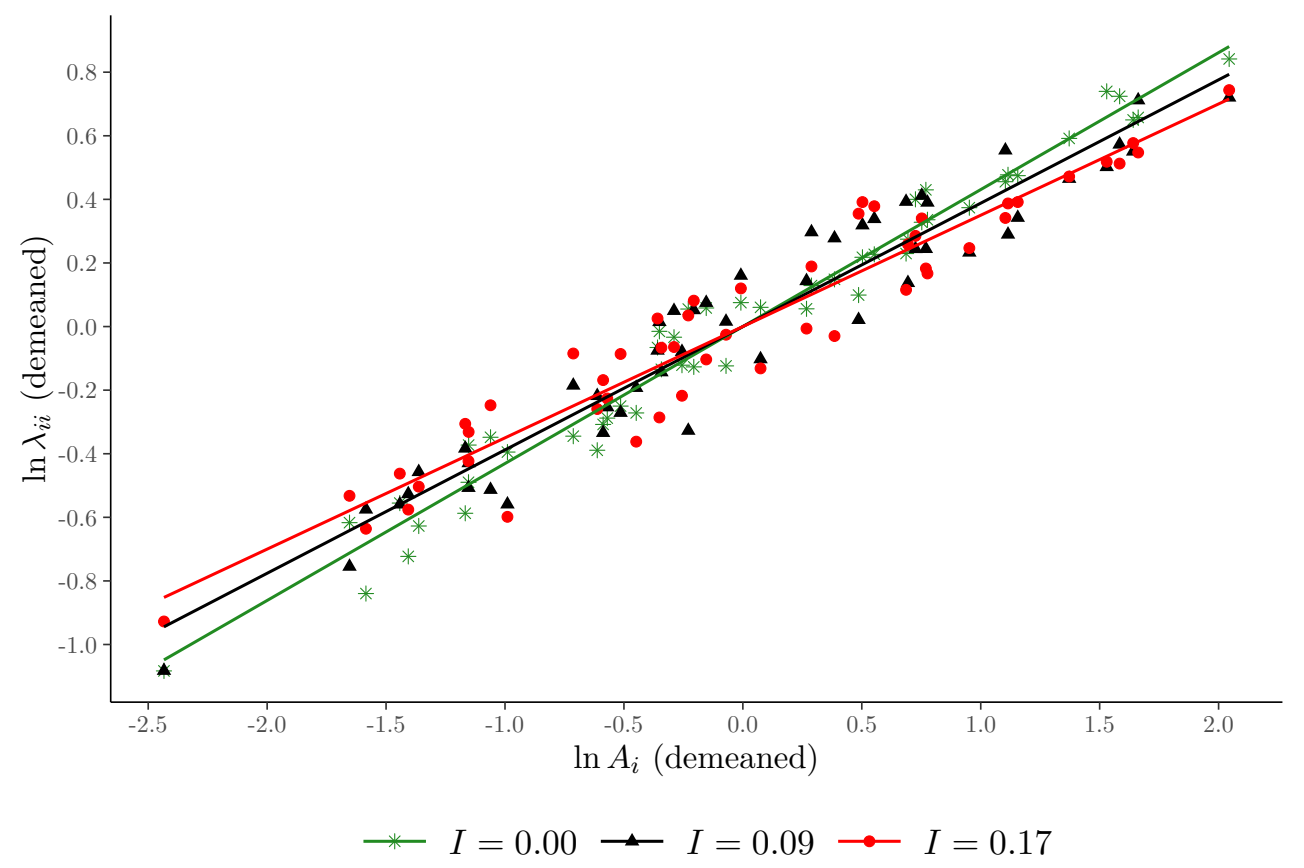

Notes: This figure depicts the $\lambda_{i i} A_{i}$ relationship in an economy with a circular geography for three randomly generated productivity distributions. Geography, equal-sized locations, and trade costs are the same as in Figure 3.

"time" $t$, where each $t$ denotes an equilibrium associated with a different productivity distribution, on its own productivity and fixed effects:

$$
\ln \lambda_{i i t}=\beta_{t} \ln A_{i t}+\pi_{i}^{I}+\pi_{t}^{T}+\mu_{i t}
$$

As in the right panel of Figure A.2, the country fixed effects $\pi_{i}^{I}$ control for differences in countries' time-invariant determinants of the domestic share of expenditure, such as size and remoteness. The "year" fixed effects $\pi_{t}^{T}$ control for differences in the average domestic shares of expenditure across different spatial distributions of productivity.

The coefficients $\beta_{t}$ in equation (A.8) characterize the conditional covariance of $\ln \lambda_{i i}$ and $\ln A_{i}$ in each equilibrium. Since the equilibrium value of $\ln \lambda_{i i}$ depends on the entire vector of productivities and not just $\ln A_{i}$, as shown by the gravity equation (2.1), this covariance differs across equilibria. $^{52}$ Relating the general-equilibrium elasticity $\beta_{t}$ to properties of the exogenous productivity vector shows how this covariance's contribution to welfare inequality depends on properties of the productivity vector. Figure A.4 shows that this covariance exhibits a negative and roughly linear relationship with Moran's I, a statistic that captures the spatial correlation of productivities. On this realistic geography, when productivities are less spatially correlated, the equilibrium covariance of $\ln \lambda_{i i}$ and $\ln A_{i}$ is more positive and thus welfare inequality is lower.

\footnotetext{
${ }^{52}$ For the same reason, we expect the elasticity $\frac{\partial \ln \lambda_{i i}}{\partial \ln A_{i}}$ to vary across $i$, so that $\beta_{t}$ is an average elasticity.
} 
Figure A.4: Real-world geography and bilateral productivity swaps

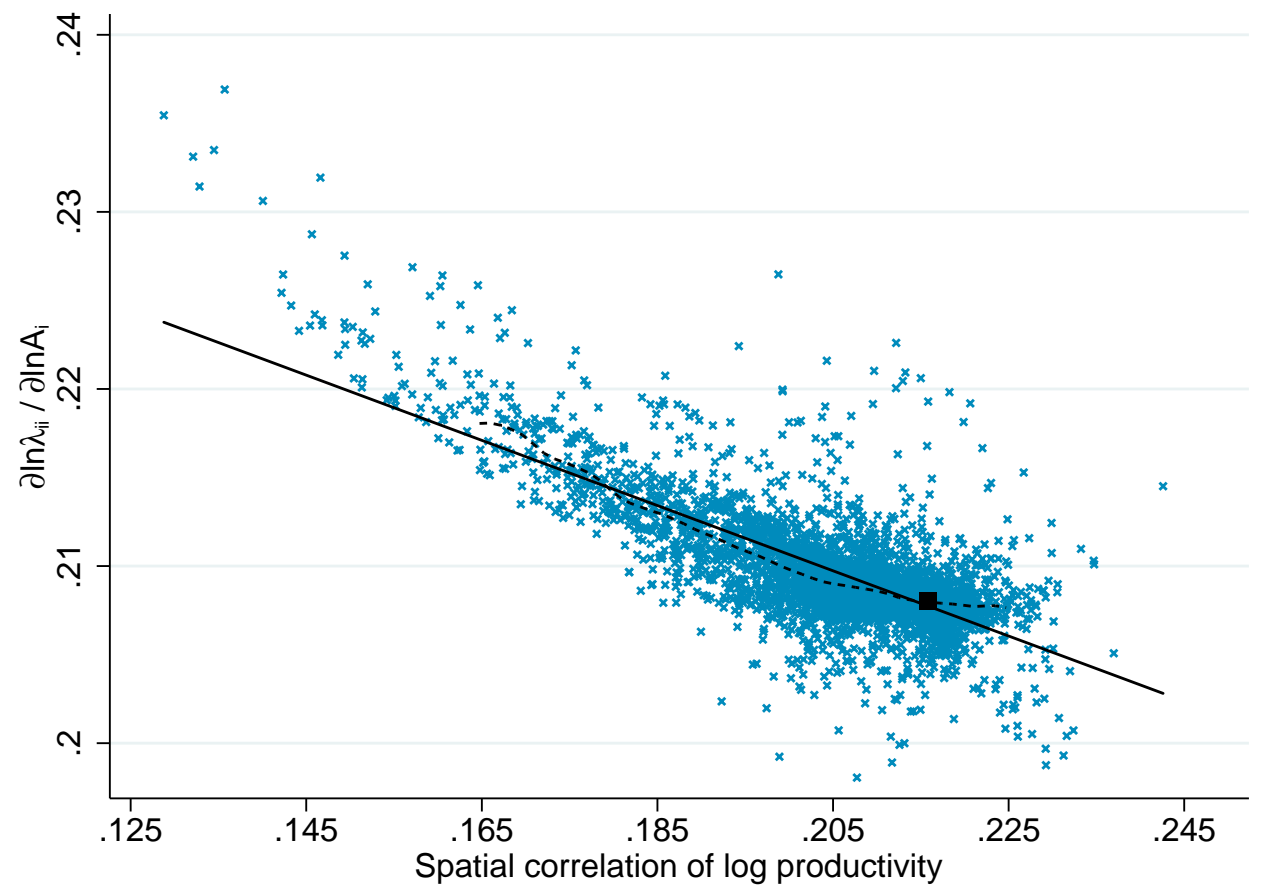

Notes: Each observation is the estimated productivity elasticity of domestic expenditure share and spatial correlation of productivities for the equilibrium resulting from a bilateral swap of two countries' productivity levels. Countries' productivities and factor endowments are set equal to their long-run averages of cereal yield and log crop area, respectively. Bilateral trade costs are proportionate to bilateral distances between countries' crop centroids. The trade elasticity is set to 8.59 and the scale of trade costs is set so that the distance elasticity of trade is 1.46 . Equilibria computed for 7499 bilateral swaps of productivities. Linear fit shown as solid line. Local polynomial fit for 1st through 99th percentiles of spatial correlation shown as dashed line. Equilibrium associated with long-run averages shown as square.

While the line of best fit in Figure A.4 is not perfect, the Moran's I statistic aptly summarizes how the spatial structure of productivity affects welfare inequality. In the model, the covariance of productivity and gains from trade is determined by the general-equilibrium solution of a system of non-linear equations. In Appendix Figure E.1, we examine how well relating this covariance to Moran's I for productivity captures changes in the variance of welfare per capita. For each of the equilibria depicted in Figure A.4, we compare the variance of welfare per capita in the model to that predicted by using the line of best fit. Regressing variance of welfare per capita in the model on its predicted value yields an $R^{2}$ of .93 . Thus, a log-linear specification employing Moran's $I$ aptly captures how welfare inequality determined by the general-equilibrium model depends on the spatial structure of productivity. Our empirical investigation will therefore estimate the expenditureproductivity relationship using a linear regression and exogenous variation in productivities without imposing the full structure of a quantitative trade model. ${ }^{53}$

\footnotetext{
${ }^{53}$ An alternative way to examine the predicted expenditure-productivity relationship would be to calibrate the trade model to rationalize the observed data from one year, introduce a change in the spatial correlation of productivities, and then examine how well the calibrated model's predicted expenditure responses align with observed changes.
} 


\section{A.3 Multiple-sector case}

We obtained predictions about the spatial correlation of absolute advantage $A_{i}$ using a theoretical framework that makes two important assumptions about the pattern of comparative advantage. First, there is only one sector. Second, the pattern of comparative advantage across varieties within that sector is symmetric across countries. This appendix section extends the model to multiple sectors. The following appendix section examines the case of correlated comparative advantage.

Our empirical investigation exploits exogenous variation in the spatial distribution of productivities in the agricultural sector, which constitutes a small share of global trade. What happens in an economy with multiple sectors? This appendix section shows that our prediction linking the spatial correlation of productivities and the productivity-expenditure relationship holds for each sector in a multi-sector gravity model of trade. When consumers have Cobb-Douglas preferences over sectors and CES preferences over varieties within sectors, there are multi-sector analogues of equations (1), (2), and (A.2) that sum over sectors using their expenditure shares. Thus, the previous section's predictions about trade in one sector can be investigated in a multi-sector world that introduces an additional dimension of comparative advantage.

Preferences. Individuals in country $i$ have preferences that are Cobb-Douglas over sectors $s=1, \ldots, S$ and constant elasticity of substitution (CES) within sectors. Thus, the relevant price indices are

$$
P_{i}=\prod_{s=1}^{S} P_{i s}^{\alpha_{i s}} \text { and } P_{i s}=\left(\int_{\omega_{s}} p_{i}\left(\omega_{s}\right)^{1-\sigma_{s}} d \omega_{s}\right)^{1 /\left(1-\sigma_{s}\right)}
$$

where $\alpha_{i s} \geq 0$ are expenditure shares $\left(\sum_{s=1}^{S} \alpha_{i s}=1\right)$ and $\sigma_{s}$ are sectoral elasticities of substitution across varieties.

Production. Productivity in country $j$ in sector $s$ is $A_{i s}$.

Trade costs. Selling one unit to $j$ from $i$ in sector $s$ requires producing $\tau_{i j s} \geq 1$ units, with $\tau_{\text {iis }}=1$.

Gravity equation. Denote sales from $i$ to $j$ in sector $s$ by $X_{i j s}$ and $j$ 's total expenditure by $X_{j} \equiv \sum_{i=1}^{N} \sum_{s=1}^{S} X_{i j s}$. Across sectors, Cobb-Douglas preferences cause optimizing consumers to spend $\alpha_{j s}$ of their total expenditure in sector $s, X_{j s}=\alpha_{j s} X_{j}$. Within each sector, CES preferences result in the share of expenditure by $j$ on goods from $i$ in sector $s$ taking the form of a gravity equation:

$$
\lambda_{i j s}=\frac{X_{i j s}}{X_{j s}}=\frac{\chi_{i s}\left(\tau_{i j s} w_{i}\right)^{-\epsilon_{s}}}{\sum_{l=1}^{N} \chi_{l s}\left(\tau_{l j s} w_{l}\right)^{-\epsilon_{s}}}=\frac{\chi_{i s}\left(\tau_{i j s} w_{i}\right)^{-\epsilon_{s}}}{\Phi_{j s}} .
$$

Equilibrium. In a competitive equilibrium, labor-market clearing, goods-market clearing, and

This approach would encounter two challenges. First, computing the spatial correlation of productivities requires productivity levels. Common calibration procedures, such as "exact hat algebra" (Costinot and Rodríguez-Clare, 2014), do not identify these productivity levels. One would therefore need to explicitly estimate many structural parameters to pursue this approach. Second, since other shocks affect both expenditure shares and productivities, this alternative approach would still require the researcher to select relevant exogenous variation and define a criterion for evaluating model fit. Our instrumental-variables approach employs standard statistical criteria to define appropriate exogenous variation and perform causal inference. 
budget constraints are satisfied such that total income $Y_{i}=w_{i} L_{i}$ and sectoral income $Y_{i s}=w_{i} L_{i s}$ satisfy $Y_{i s}=\sum_{j=1}^{N} X_{i j s}, Y_{i}=\sum_{s=1}^{S} Y_{i s}$, and $X_{i s}=\alpha_{i s} Y_{i}$ for all countries. The equilibrium system of equations is

$$
Y_{i s}=\sum_{j=1}^{N} \lambda_{i j s} \alpha_{j s} \sum_{s^{\prime}=1}^{S} Y_{j s^{\prime}}
$$

In this environment, real consumption per capita is

$$
\ln \left(\frac{C_{i}}{L_{i}}\right)=\sum_{s=1}^{S} \alpha_{i s}\left(\ln A_{i s}+\gamma_{s}-\frac{1}{\epsilon_{s}} \ln \lambda_{i i s}\right)
$$

The first two terms, $\sum_{s=1}^{S} \alpha_{i s}\left(\ln A_{i s}+\gamma_{s}\right)$, are per capita welfare in autarky, and the final term, $-\sum_{s=1}^{S} \frac{\alpha_{i s}}{\epsilon_{s}} \ln \lambda_{i i s}$, summarizes the gains from trade.

Dispersion in per capita welfare across countries thus depends on the exogenous variation in productivities $A_{i s}$ and the endogenous variation in domestic shares of expenditure $\lambda_{i i s}$. For the sake of expositional brevity, assume that expenditures shares are common across countries, $\alpha_{i s}=\alpha_{s} \forall i$ In that case, the variance of per capita welfare is

$\operatorname{var}\left(\ln \left(\frac{C_{i}}{L_{i}}\right)\right)=\operatorname{var}\left(\sum_{s=1}^{S} \alpha_{i s} \ln A_{i s}\right)+\operatorname{var}\left(\sum_{s=1}^{S} \frac{\alpha_{i s}}{\epsilon_{s}} \ln \lambda_{i i s}\right)-2 \sum_{s=1}^{S} \sum_{s^{\prime}=1}^{S} \frac{\alpha_{s} \alpha_{s^{\prime}}}{\epsilon_{s^{\prime}}} \operatorname{cov}\left(\ln A_{i s}, \ln \lambda_{i i s^{\prime}}\right)$

To examine the role of spatial correlation, consider two productivity distributions - a correlated state $c$ and an uncorrelated state $u$. Assume that unconditional variance of the productivity distributions is the same, $\operatorname{var}\left(\sum_{s=1}^{S} \alpha_{i s} \ln A_{i s}^{c}\right)=\operatorname{var}\left(\sum_{s=1}^{S} \alpha_{i s} \ln A_{i s}^{u}\right)$. The difference in welfare dispersion then depends on the covariance of productivities and domestic shares of expenditure, both within and across sectors, and between domestic shares of expenditure.

$$
\begin{aligned}
\operatorname{var}\left(\ln \left(C_{i}^{c} / L_{i}\right)\right)-\operatorname{var}\left(\ln \left(C_{i}^{u} / L_{i}\right)\right)= & 2 \sum_{s=1}^{S} \sum_{s^{\prime}=1}^{S} \frac{\alpha_{s} \alpha_{s^{\prime}}}{\epsilon_{s^{\prime}}}\left\{\operatorname{cov}\left(\ln A_{i s}^{u}, \ln \lambda_{i i s^{\prime}}^{u}\right)-\operatorname{cov}\left(\ln A_{i s}^{c}, \ln \lambda_{i i s^{\prime}}^{c}\right)\right\} \\
& -\sum_{s=1}^{S} \sum_{s^{\prime}=1}^{S} \frac{\alpha_{s} \alpha_{s^{\prime}}}{\epsilon_{s} \epsilon_{s^{\prime}}}\left\{\operatorname{cov}\left(\ln \lambda_{i i s}^{u}, \ln \lambda_{i i s^{\prime}}^{u}\right)-\operatorname{cov}\left(\ln \lambda_{i i s}^{c}, \ln \lambda_{i i s^{\prime}}^{c}\right)\right\}
\end{aligned}
$$

Just as in the single-sector case, for typical values of the sectoral trade elasticities, $2 \frac{\alpha_{s} \alpha_{s^{\prime}}}{\epsilon_{s^{\prime}}}$ is an order of magnitude larger than $\frac{\alpha_{s} \alpha_{s^{\prime}}}{\epsilon_{s} \epsilon_{s^{\prime}}}$. Thus, the difference in welfare dispersion is governed by the $\operatorname{cov}\left(\ln A_{i s}, \ln \lambda_{i i s^{\prime}}\right)$ terms, provided that the block of $\operatorname{cov}\left(\ln A_{i s}, \ln \lambda_{i i s^{\prime}}\right)$ terms is the same order of magnitude as the block of $\operatorname{cov}\left(\ln \lambda_{i i s}, \ln \lambda_{i i s^{\prime}}\right)$ terms.

Under what circumstances is studying differences in $\operatorname{cov}\left(\ln A_{i s}, \ln \lambda_{i i s}\right)$ in one sector alone informative about welfare dispersion? For simplicity, consider the two-sector case and three possible relationships between the two sectors: perfectly correlated productivities, perfectly anti-correlated 
Table A.2: Outcomes for two-sector sine-wave economy

\begin{tabular}{lcccc}
\hline Frequency of $\ln A_{1}$ sine wave $\left(\theta_{1}\right)$ & 1 & 2 & 3 & 4 \\
\hline Autarky welfare $\left(\frac{1}{2} \ln A_{1}+\frac{1}{2} \ln A_{2}\right)$ variance & 0.255102 & 0.255102 & 0.255102 & 0.255102 \\
Trading-equilbrium welfare $(\ln C / L)$ variance & 0.114255 & 0.097649 & 0.092189 & 0.087935 \\
\hline
\end{tabular}

productivities, and orthogonal productivities.

In the perfectly correlated case, there is little scope for adjustment across sectors, and thus outcomes are similar to those obtained in the one-sector environment. In fact, if all sectors have perfectly correlated productivities $\left(A_{i s} \propto A_{i} \forall s\right)$, perfectly correlated spatial linkages $\left(\tau_{i j s} \propto \tau_{i j} \forall s\right)$, and equal trade elasticities $\left(\epsilon_{s}=\epsilon \forall s\right)$, then expenditure shares are equal across sectors, $\lambda_{i j s}=\lambda_{i j}$, and the difference in welfare dispersion in equation (A.9) is exactly proportionate to the singlesector expression in equation (A.2).

If sectoral productivities are perfectly anti-correlated, then outcomes in one sector may be exactly offset by outcomes in another, leaving welfare unchanged. That is, it is possible to construct circumstances in which the sum of covariances of productivities and domestic shares of expenditure within sectors is exactly the opposite of the sum of cross-sector covariances. Consider the two-sector case with equal expenditure shares $\alpha_{1}=\alpha_{2}=\frac{1}{2} \forall j$ and equal trade elasticities $\epsilon_{1}=\epsilon_{2}=\epsilon$. If the two sectors' productivities are perfectly anti-correlated, such that $\ln A_{i 1}+\ln A_{i 2}$ is a constant, then it can be shown that $\sum_{s=1}^{S} \sum_{s^{\prime}=1}^{S} \frac{\alpha_{s} \alpha_{s^{\prime}}}{\epsilon_{s^{\prime}}} \operatorname{cov}\left(\ln A_{i s}, \ln \lambda_{i i s^{\prime}}\right)=0$. Thus, our predictions about trade flows are valid, but the welfare consequences of these changes are fully offset by the non-agricultural sector's anti-correlated changes.

What about the orthogonal case? Figure A.5 depicts a two-sector sine-wave economy with two symmetric sectors that differ only in their sine-wave frequency. Table A.2 reports the means and variances of countries' welfare per capita under autarky and trade. Compared to Table A.1, the variance of autarky welfare is lower because autarky welfare is the simple average of two sectors' (orthogonal) productivities with the same mean and variance. The mean trading-equilibrium welfare is higher (the gains from trade are larger) in the multi-sector case due to gains from specialization according to comparative advantage. This additional margin of adjustment also dampens the degree to which greater spatial correlation of productivities in one of the two sectors affects the variance of welfare in the trading equilibrium, but our main prediction still holds in this multi-sector setting with orthogonal productivities.

\section{A.4 Spatial correlation of comparative advantage}

This appendix section addresses how the spatial correlation of comparative advantage interacts with the spatial correlation of absolute advantage. Introducing spatially correlated comparative advantage could reverse how the expenditure-productivity relationship varies with the spatial correlation of absolute advantage. 
Figure A.5: Two-sector sine-wave economy: $\operatorname{cov}\left(\ln \lambda_{i i 1}, \ln A_{i 1}\right)$

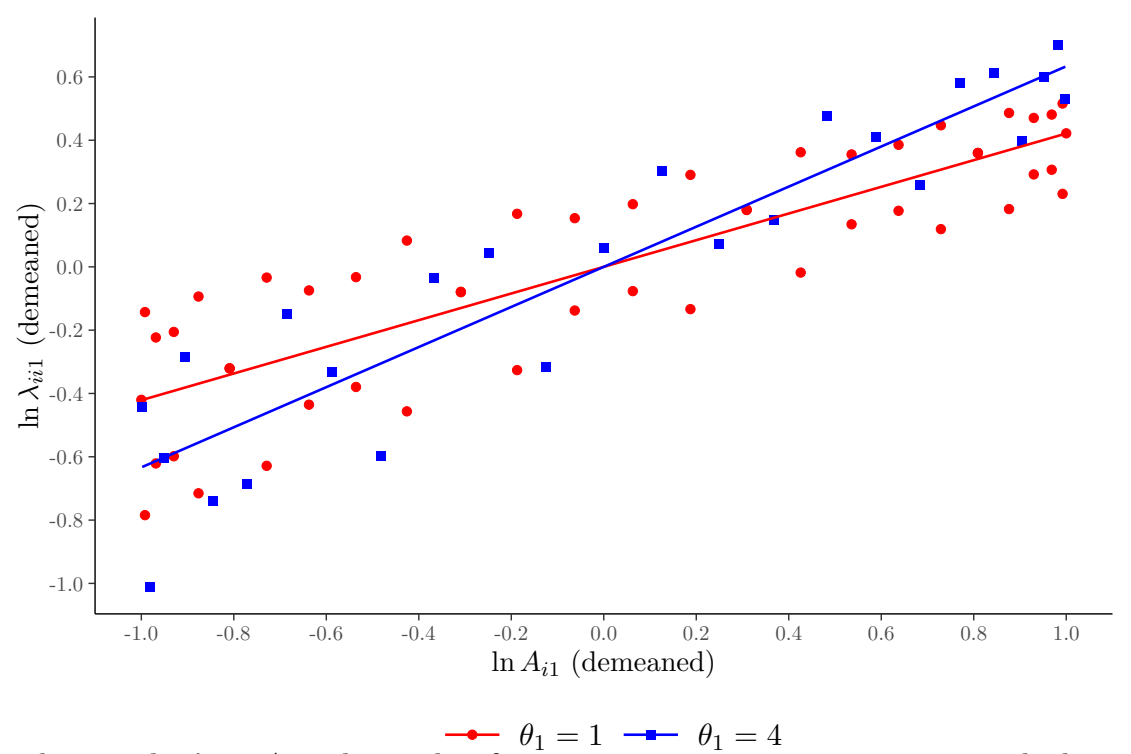

Notes: This figure depicts the $\lambda_{i i s}-A_{i s}$ relationship for $s=1$ in a two-sector economy in which sectoral productivity follows a sine wave with frequency $\theta_{s}$. The two series depicted are frequencies $\theta_{1}=1$ and $\theta_{1}=4$ for the first sector. The second sector has frequency $\theta_{2}=10$ in both cases. The two sectors have identical trade costs $\tau_{i j s}$, expenditure shares $\alpha_{i 1}=\alpha_{i 2}=\frac{1}{2}$, and trade elasticities $\epsilon_{1}=\epsilon_{2}$. The two lines are the line of best fit for each series. When productivities are more spatially correlated (when $\theta_{1}$ is lower), $\operatorname{cov}\left(\ln \lambda_{i i 1}, \ln A_{i 1}\right)$ is lower. See Table A.2 in Appendix A.3 for details of this example.

The predictions in the main text concern the spatial correlation of absolute advantage $A_{i}$ when comparative advantage is symmetric across countries. Most quantitative trade models assume this pattern of comparative advantage. ${ }^{54}$ In this appendix section, we relax this assumption to examine how the spatial correlation of comparative advantage may interact with the spatial correlation of absolute advantage. Our thought experiment varies the spatial correlation of absolute advantage, holding the pattern of comparative advantage fixed. ${ }^{55}$

To consider the role of spatially correlated patterns of comparative advantage, we extend the Eaton and Kortum (2002) model, in which comparative advantage is symmetric across countries, to have "continents" of countries with correlated relative productivities. The world economy consists of $N$ countries partitioned across $k=1, \ldots, K$ continents. Country $i$ belongs to continent $k(i)$ and its productivity in good $\omega$ is $z_{i}(\omega)$. We depart from Eaton and Kortum (2002) by assuming that the vector of productivities $\left(Z_{1}, \ldots, Z_{N}\right)$ is drawn from a multivariate nested Fréchet distribution:

$$
F\left(z_{1}, \ldots, z_{n}\right)=\exp \left\{-\sum_{k=1}^{K}\left(\sum_{i: k(i)=k}\left(T_{i} z_{i}^{-\vartheta}\right)^{\frac{1}{\rho_{k}}}\right)^{\rho_{k}}\right\}
$$

\footnotetext{
${ }^{54}$ A notable exception is recent work by Lind and Ramondo (2019) that generalizes quantitative Ricardian models by tractably relaxing this assumption.

${ }^{55}$ Consistent with this assumption, column 2 of Table C. 1 shows that the distance elasticity of trade is unaffected by ENSO, our source of exogenous variation in the spatial correlation of absolute advantage. In the Eaton and Kortum (2002) model, this elasticity embodies the pattern of comparative advantage.
} 
Table A.3: Estimates of $\beta_{1}$ and within-continent correlation $1-\rho$

\begin{tabular}{cccccccccccc}
\hline \multicolumn{10}{c}{ Within-continent correlation $1-\rho$} \\
\cline { 2 - 11 } & 0 & 0.1 & 0.2 & 0.3 & 0.4 & 0.5 & 0.6 & 0.7 & 0.8 & 0.9 \\
\hline 2 & -0.112 & -0.111 & -0.108 & -0.101 & -0.090 & -0.073 & -0.049 & -0.022 & 0.002 & 0.014 \\
3 & -0.112 & -0.110 & -0.106 & -0.099 & -0.088 & -0.071 & -0.048 & -0.021 & 0.005 & 0.018 \\
4 & -0.112 & -0.108 & -0.103 & -0.094 & -0.082 & -0.064 & -0.041 & -0.013 & 0.013 & 0.029 \\
\hline
\end{tabular}

Notes: This table reports estimates of $\beta_{1}$ obtained from the regression $\ln \lambda_{i i t}=\beta_{0} \ln A_{i t}+\beta_{1} I_{t} \ln A_{i t}+\pi_{i}^{I}+$ $\pi_{t}^{T}+\mu_{i t}$ on equilibrium outcomes from a simulated global economy with 50 countries as described in the text of Appendix A.4. Moran's $I$ is computed using spatial weight $\omega_{i j}=\frac{1}{1+\left\|l_{i}-l_{j}\right\|}$ for $i \neq j$. The correlation parameter $\rho_{k}=\rho \forall k$, the dispersion parameter is $\vartheta=8.28$ (Eaton and Kortum, 2002), and the level parameter $\ln T_{i}$ follows a sine wave, as in Section 2.1, with $\theta=1, \ldots, 8$. In the standard model, $1-\rho=0$.

where the location parameter $T_{i}$ governs the absolute advantage of country $i$ and the dispersion parameter $\vartheta$ is common across countries. Parameters $\left(\rho_{1}, \ldots, \rho_{k}\right)$ govern the degree of within-continent correlation in productivities, which is decreasing in $\rho_{k}$. When $\rho_{k}=1 \forall k$, these productivities are independent, as in Eaton and Kortum (2002). Note that $\lambda_{i i}$ is a sufficient statistic for welfare only in the case in which $\rho_{k}=1 \forall k$. Here, we focus on the consequences of the spatial correlation of comparative advantage for how the observed expenditure-productivity relationship varies with the spatial correlation of absolute advantage.

After considerable algebraic manipulations, it can be shown that the gravity equation for this generalized productivity distribution is

$$
\lambda_{i j}=\frac{\left(T_{i}\left(w_{i} \tau_{i j}\right)^{-\vartheta}\right)^{\frac{1}{\rho_{k(i)}}}}{\sum_{m: k(m)=k(i)}\left(T_{m}\left(w_{m} \tau_{m j}\right)^{-\vartheta}\right)^{\frac{1}{\rho_{k(i)}}}} \frac{\Phi_{k(i) j}}{\Phi_{j}},
$$

where $\Phi_{k j}=\left(\sum_{i: k(i)=k}\left(T_{i}\left(w_{i} \tau_{i j}\right)^{-\vartheta}\right)^{\frac{1}{\rho_{k}}}\right)^{\rho_{k}}$ and $\Phi_{j}=\sum_{k=1}^{K} \Phi_{k j}$.

To study the interaction of the spatial correlation of comparative advantage and the spatial correlation of absolute advantage, we simulate a world economy with a symmetric geography and a sine-wave productivity distribution, as in Section 2.1. We divide the 50 countries into two, three, or four continents with $\rho_{k}=\rho \forall k$. As we increase within-continent correlation in comparative advantage by lowering $\rho$ from 1.0 to 0.1 in steps of size 0.1 , we find that the effect of spatial correlation in absolute advantage is initially dampened and then reversed. As reported in Table A.3, for the highest values of $1-\rho$, the estimated $\beta_{1}$ is positive. That is, for sufficiently high within-continent correlation of comparative advantage, the $\operatorname{cov}\left(\ln \lambda_{i i}, \ln A_{i}\right)$ relationship depicted in Figure 3 becomes steeper with greater spatial correlation of $A_{i}$, not flatter. In short, when neighboring countries specialize in similar products, a neighbor's productivity improvement may actually worsen a country's terms of trade by increasing the world supply of that country's exports and thereby depressing its export price. 
Thus, our empirical estimate of $\beta_{1}$ in equation (3) captures the effect of spatial correlation in absolute advantage as mediated by the existing spatial correlation in comparative advantage. Most quantitative trade models have symmetric patterns of comparative advantage, in which case $\beta_{1}$ should be negative. If patterns of comparative advantage within cereals are very spatially correlated, $\beta_{1}$ could be positive. Our empirical estimates in Section 4 reject this possibility.

\section{A.5 Mobile labor}

In an economic-geography model in which welfare differences are arbitraged away by mobile factors of production (e.g., Allen and Arkolakis 2014), greater spatial correlation of productivities makes population density, rather than welfare per capita, more unequal across locations. We demonstrate this using a symmetric geography with four locations, like the geography used in Appendix Section A.2.2, in which the population of each location is endogenously determined. Locations' productivities vary exogenously, and their amenities are identical.

Given four locations with trade costs given by equation (A.5), total population $L$, and an elasticity of substitution $\sigma$, the endogenous populations $\left\{L_{i}\right\}_{i=1}^{4}$ and welfare level $W$ must satisfy two equations:

$$
L_{i}^{\tilde{\sigma}}=A_{i}^{\tilde{\sigma}(\sigma-1)} W^{1-\sigma} \sum_{j=1}^{4} \tau_{j i}^{1-\sigma} A_{j}^{(1-\tilde{\sigma})(\sigma-1)} L_{j}^{\tilde{\sigma}} \quad \text { and } \quad L=\sum_{j=1}^{4} L_{j}
$$

where $\tilde{\sigma} \equiv \frac{\sigma-1}{2 \sigma-1}$. Let $\mathbf{L}$ denote the vector containing $L_{1}, \ldots, L_{4}$, let $\mathbf{T}$ denote the (symmetric) matrix of trade costs raised (element-wise) to the power $\frac{1}{1-\sigma}$, and let $\mathbf{A}$ denote the 4 -by-4 diagonal matrix with $\left\{A_{1}, \ldots, A_{4}\right\}$ on the diagonal.

The equilibrium equation of interest can then be written as

$$
\left(\mathbf{I}-\frac{1}{W^{\sigma-1}} \mathbf{A}^{\tilde{\sigma}(\sigma-1)} \mathbf{T} \mathbf{A}^{(1-\tilde{\sigma})(\sigma-1)}\right) \mathbf{L}^{\tilde{\sigma}}=0 .
$$

$W^{\sigma-1}$ is the eigenvalue and $\mathbf{L}^{\tilde{\sigma}}$ is the eigenvector of the matrix $\mathbf{A}^{\tilde{\sigma}(\sigma-1)} \mathbf{T} \mathbf{A}^{(1-\tilde{\sigma})(\sigma-1)}$.

Let $\mathbf{A}_{c}$ and $\mathbf{A}_{u}$ denote diagonal matrices whose diagonal elements are $(\tilde{a}, \tilde{a}, 1,1)$ and $(\tilde{a}, 1, \tilde{a}, 1)$, respectively, with $\tilde{a}>1$. Also, let $\bar{a} \equiv \tilde{a}^{\sigma-1}>1, \bar{d}_{1} \equiv d_{1}^{1-\sigma}$, and $\bar{d}_{2} \equiv d_{2}^{1-\sigma}$.

Consider the eigenvalue $\lambda_{c}=W_{c}^{\sigma-1}$ and eigenvector $\mathbf{L}_{c}^{\tilde{\sigma}}$ associated with $\mathbf{A}_{c}^{\tilde{\sigma}(\sigma-1)} \mathbf{T} \mathbf{A}_{c}^{(1-\tilde{\sigma})(\sigma-1)}$. We can verify that the eigenvector $\mathbf{L}_{c}^{\tilde{\sigma}}=\left(x_{c}, x_{c}, 1,1\right)$ and the eigenvalue $\lambda_{c}=\bar{a}^{1-\tilde{\sigma}}\left(d_{1}^{1-\sigma}+d_{2}^{1-\sigma}\right) x_{c}+$ $d_{1}^{1-\sigma}+1$ satisfy the equation of interest. This implies that the equilibrium value of $x_{c}$ is given by

$$
\bar{a}^{1-\tilde{\sigma}}\left(\bar{d}_{1}+\bar{d}_{2}\right) x_{1}^{2}-\left(\bar{a}-\bar{d}_{1}-1+\bar{a} \bar{d}_{1}\right) x_{1}-\left(\bar{d}_{1}+\bar{d}_{2}\right) \bar{a}^{\tilde{\sigma}}=0
$$

Similarly, in the case of $\mathbf{A}_{u}$, consider the eigenvalue $\lambda_{u}=W_{u}^{\sigma-1}$ and the eigenvector $\mathbf{L}_{u}^{\tilde{\sigma}}$ associated with $\mathbf{A}_{u}^{\tilde{\sigma}(\sigma-1)} \mathbf{T} \mathbf{A}_{u}^{(1-\tilde{\sigma})(\sigma-1)}$. We can verify that the eigenvector $\mathbf{L}_{u}^{\tilde{\sigma}}=\left(x_{u}, 1, x_{u}, 1\right)$ and the eigenvalue $\lambda_{u}=2 \bar{a}^{1-\tilde{\sigma}} \bar{d}_{1} x_{2}+\bar{d}_{2}+1$ satisfy the equation of interest. This implies that the 
equilibrium value of $x_{u}$ is given by

$$
2 \bar{a}^{1-\tilde{\sigma}} \bar{d}_{1} x_{u}^{2}-\left(\bar{a}-\bar{d}_{2}-1+\bar{a} \bar{d}_{2}\right) x_{u}-2 \bar{a}^{\tilde{\sigma}} \bar{d}_{1}=0 .
$$

The quadratic equations (A.10) and (A.11) each have one positive and one negative root. Restricting attention to the positive roots, we can compare the relative sizes of $x_{c}$ and $x_{u}$. It can be shown that $x_{c}>x_{u}$.

The equilibrium values of $\mathbf{L}_{c}$ and $\mathbf{L}_{c}$ are

$$
\mathbf{L}_{c}=\frac{L}{2 x_{c}^{\frac{1}{\tilde{\tilde{\sigma}}}}+2}\left[\begin{array}{c}
x_{x}^{\frac{1}{\tilde{c}}} \\
x_{c}^{\frac{1}{\tilde{c}}} \\
1 \\
1
\end{array}\right] \text { and } \mathbf{L}_{u}=\frac{L}{2 x_{u}^{\frac{1}{\tilde{\tilde{\sigma}}}}+2}\left[\begin{array}{c}
x^{\frac{1}{\tilde{u}}} \\
1 \\
x_{u}^{\frac{1}{\tilde{\tilde{u}}}} \\
1
\end{array}\right] .
$$

It can then be shown that $\operatorname{cov}\left(\ln A_{i}, \ln L_{i}\right)$ is greater for $\mathbf{A}_{c}$ than $\mathbf{A}_{u}$ because $x_{c}>x_{u}$. Thus, with welfare equalized across locations, the productivity-population relationship is more positive when productivities are more spatially correlated.

\section{B Data sources and construction}

Agricultural data Our cereal data cover barley, maize, millet, oats, rice, rye, sorghum, and wheat. We use cereal-level measures of output (in metric tons, 1961-2013), yield (in metric tons per harvested hectare, 1961-2013), trade quantity (in metric tons, 1961-2013), trade value (in nominal USD, 1961-2013), producer prices (in nominal local currency, 1966-2013), and change in storage (in metric tons, 1961-2013) for each country and year obtained from the FAO. ${ }^{56}$ Domestic share of expenditure aggregated across cereals $c=1, \ldots, C$ for country $i$ in year $t$ is

$$
\lambda_{i i t}=\frac{\sum_{c=1}^{C} X_{c i i t}}{\sum_{c=1}^{C} X_{c i i t}+\sum_{j \neq i} \sum_{c=1}^{C} X_{c j i t}}
$$

where $X_{c j i t}$ is the value of cereal $c$ sold to $i$ by $j$ in year $t$. We observe $X_{c j i t}$ for $j \neq i$. We construct $X_{c i i t}$ using data on output quantities, export quantities, and prices. $X_{c i i t}=\left(q_{c i t}-\operatorname{exports}_{c i t}\right) \cdot p_{c i t}$, where $q_{c i t}$ is domestic output quantity, exports ${ }_{c i t}$ is export quantity, and $p_{c i t}$ is domestic price.

There are two potential data sources for price $p_{\text {cit }}$, neither of which are ideal. The first data source is export unit values, $\frac{\sum_{j \neq i} X_{c i j t}}{\text { exports }_{c i t}}$, which are observed when a country exports a cereal. Unfortunately, only $53 \%$ of the cereal-country-year observations in our sample with positive output quantities have positive export quantities. The second price measure, producer prices in nominal local currency, presents two challenges. First, producer prices are available for only $59 \%$ of the cereal-country-year observations with positive cereal output. Second, due to resource constraints at the time, the FAO did not standardize the collection of 1966-1990 producer prices as it did for

\footnotetext{
${ }^{56}$ Available at http://www.fao.org/faostat/en/\#data.
} 
prices since 1991. As such, the FAO warns against the combined use of the full 1966-2013 panel and notes that it is "not in a position to give any explanation for the existing differences" between 1966-1990 and 1991-2013 producer prices. ${ }^{57}$ Thus, despite extensive efforts to convert 1966-1990 FAO producer prices into nominal US dollars, use of producer prices raises concerns.

In light of these limitations and to ensure sufficient statistical power in our estimation, we elect to approximate domestic expenditure $\sum_{c=1}^{C} X_{c i i t}$ by domestic quantity times average export unit value, $\left(\sum_{c=1}^{C}\left(q_{c i t}-\operatorname{exports}_{c i t}\right)\right)\left(\frac{\sum_{c=1}^{C} \sum_{j \neq i} X_{c i j t}}{\sum_{c=1}^{C} \text { exports }_{c i t}}\right)$. This measure is available for every year that a country exports at least one cereal, yielding a sizable estimation sample. This approximation of domestic expenditure $\sum_{c=1}^{C} X_{\text {ciit }}$ makes our outcome variable a noisy measure of the domestic share of expenditure. Table F. 8 shows results for alternative approximations of the domestic share of expenditure. Our country-year measure of aggregate cereal yield is harvested area-weighted cereal-level yield.

For several robustness checks, we use bilateral trade data from the U.N. Comtrade database. ${ }^{58}$ Comtrade data has the disadvantage of using cereal codes that differ from that used by the FAO. As such, despite careful matching of cereal categories across the two datasets, we prefer to use production and trade data that is consistently reported by the FAO. However, trade data at the bilateral level is available from Comtrade starting in 1962, whereas it is only available from the FAO starting in 1986. Thus, for the gravity equations estimated in Table C.1, we use Comtrade bilateral trade data. As a robustness check, we show in column 5 of Table F.8 that our main result is unaffected when we alternatively construct domestic expenditure share using Comtrade data.

We also use bilateral trade data from Comtrade to construct a measures of the change in a country's terms of trade each year. A country is better off if its initial net export vector is more expensive at new prices than at old prices (Dixit and Norman, 1980, p.132). Define the normalized net export vector for country $i$ in year $t-1$ by a vector whose $2 \times C \times(N-1)$ elements are exports $_{c i j t-1}$ and - exports $_{c j i t-1}$ for $j \neq i$ multiplied by a scalar so that its norm is one. ${ }^{59,60}$ Define the accompanying price-change vector for country $i$ in year $t$ by a vector whose $2 \times C \times(N-1)$ elements are $\Delta p_{c i j t}$ and $\Delta p_{c j i t}$ for $j \neq i$, where $\Delta$ denotes the time difference operator. We use changes in unit values of bilateral trade flows to proxy for these price changes. The change in the terms of trade is the inner product of these two vectors, which we denote $\Delta \mathrm{ToT}_{i t}$, with $\Delta \mathrm{ToT}_{i t}>0$ indicating an improvement in country $i$ 's terms of trade. Our measure is imperfect because unit values are a noisy measure of prices and the price-change element $\Delta p_{\text {cijt }}$ is not observed if exports $_{c i j t}=0$. Absent further information, we impose $\Delta p_{c i j t}=0$ for these elements. Beyond cereals, the change in the terms of trade for a broader set of commodities, such as all products in SITC sector 0 "food and live animals", can be computed analogously using the quantities and unit

\footnotetext{
${ }^{57}$ See here: http://fenixservices.fao.org/faostat/static/documents/PA/PA_e.pdf

${ }^{58}$ Available at https://comtrade.un.org

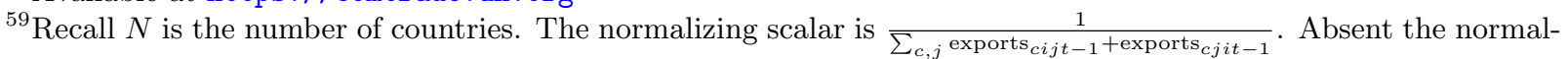
ization, larger economies would mechanically exhibit larger terms-of-trade changes.

${ }^{60}$ Note that exports $\mathrm{cijt-1}$ and - $\operatorname{exports}_{c j i t-1}$ are distinct elements in this net export vector, so that the same cereal imported and exported by the same country is not assumed to be a homogeneous good.
} 
values reported in Comtrade data.

ENSO index Annual ENSO variations can be detected using different indices, with the most commonly used being equatorial Pacific sea surface temperature (SST) anomalies. We primarily utilize 1960-2013 values of the monthly Kaplan NINO4 index which averages SST over the area $5^{\circ} \mathrm{S}-5^{\circ} \mathrm{N}, 160^{\circ} \mathrm{E}-150^{\circ} \mathrm{W}$. For robustness checks in Table F.6, we also use the NINO3 $\left(5^{\circ} \mathrm{S}-5^{\circ} \mathrm{N}\right.$, $\left.150^{\circ} \mathrm{W}-90^{\circ} \mathrm{W}\right)$, NINO34 $\left(5^{\circ} \mathrm{S}-5^{\circ} \mathrm{N}, 170^{\circ} \mathrm{W}-120^{\circ} \mathrm{W}\right)$, and NINO12 $\left(10^{\circ} \mathrm{S}-0^{\circ}, 90^{\circ} \mathrm{W}-80^{\circ} \mathrm{W}\right)$ indices (Kaplan et al., 1998). ${ }^{61}$

Historical temperature and precipitation Global temperature (in degrees centigrade) and precipitation (in $\mathrm{mm} / \mathrm{month}$ ) variables constructed from monthly gridded global weather data at a $0.5^{\circ}$ latitude by $0.5^{\circ}$ longitude resolution were obtained from the Center for Climatic Research at the University of Delaware (Willmott and Matsuura, 2001). 1960-2013 monthly data was first spatially aggregated from pixel to country-level using cross-sectional crop-area weights in 2000 from Ramankutty et al. (2008). For robustness checks in Table F.6, we also aggregate temperature from pixel to country-level using total country area. Annual values are then constructed by averaging January-December monthly values.

Projected temperature under climate change Global multi-model ensemble mean temperature (in degrees centigrade) from monthly gridded global data at the $2.5^{\circ}$ latitude by $2.5^{\circ}$ longitude resolution from the Coupled Model Intercomparison Project version 5 (CMIP5). ${ }^{62}$ 2014-2099 monthly data was first spatially aggregated from pixel to country-level using cross-sectional croparea weights in 2000 from Ramankutty et al. (2008). Annual values are then constructed by averaging January-December monthly values.

Geography Country latitude and longitude are defined as crop area-weighted average using the global cross-sectional distribution of crop area in 2000 from Ramankutty et al. (2008). Great-circle distances between these country centroids are computed using the haversine formula.

Global oil prices Monthly West Texas Intermediate crude oil spot price obtained from the St. Louis Federal Reserve for 1961-2013. ${ }^{63}$ Annual values are then constructed by averaging JanuaryDecember monthly values.

Export restrictions Export restrictions come from the United Nations Conference on Trade and Development's (UNCTAD) TRAINS database. ${ }^{64}$ To construct the dummy variable used in column 6 of Table F.3, we employ all export-related measures (Chapter P of the International Classification of Non-Tariff Measures), excluding export subsidies. The indicator equals one for

\footnotetext{
${ }^{61}$ Available at http://iridl.ldeo.columbia.edu/SOURCES/.Indices/.nino/.EXTENDED/

${ }^{62}$ Available at https://climexp.knmi.nl/selectfield_cmip5.cgi

${ }^{63}$ Available at https://fred.stlouisfed.org/series/WTISPLC

${ }^{64}$ Available at http://trains.unctad.org
} 
country-year observations in which a new restriction on exporting any cereal to any trading partner was introduced.

Tariffs Importer-exporter-year ad-valorum tariff data at the cereal level come from the World Bank's World Integrated Trade Solution (WITS) database. ${ }^{65}$ We use the WITS-defined effective tariff rate, which generally takes the lowest available value among Most-Favored Nation, Bound, and Preferential tariffs. To construct an aggregate cereal tariff value, we take the simple average of nonmissing values across the eight major cereals.

\section{Gravity regressions}

The theoretical model of Section 2 implies that the value of cereals exported by exporter $i$ to importer $j$ in year $t$ satisfies a gravity equation:

$$
\ln X_{i j t}=-\epsilon \ln \tau_{i j}+\ln \left(\frac{\chi_{i t}}{w_{i t}^{\epsilon}}\right)+\ln \left(\frac{X_{j t}}{\Phi_{j t}}\right)
$$

Two assumptions embodied in this gravity equation are pertinent to our main empirical test in equation (3). First, trade costs $\tau_{i j}$ must be positively related to bilateral distance for spatial correlation of productivities to be relevant for welfare inequality. Second, we interpret equation (2) assuming that the trade elasticity, $\epsilon$, is constant. In particular, we assume that time-series variation in the global spatial correlation of productivities does not alter the trade elasticity, allowing us to use the observed change in the covariance between country productivity and own expenditure share as a measure of the change in welfare inequality. Similarly, we assume that the trade elasticity does not vary across trading partners. By contrast, in the model of spatially correlated comparative advantage in Section A.4, the trade elasticity for pairs of countries on the same continent is higher (in absolute value) when $\rho<1$. The constant-elasticity assumption underlies the sufficient statistic for welfare in Arkolakis, Costinot and Rodríguez-Clare (2012).

To examine these assumptions, Table C.1 reports several variants of gravity regressions. To account for the typical preponderance of zero-valued bilateral trade observations ( $\approx 70 \%$ of sample), we use the Poisson pseudo-maximum likelihood estimator (Silva and Tenreyro, 2006). We find that observed trade in cereals declines with distance and is consistent with a constant trade elasticity.

Column 1 of Table C.1 estimates a standard gravity equation following Head and Mayer (2014) using bilateral distance as a (time-invariant) source of variation in bilateral trade costs $\left(\tau_{i j}\right)$ and exporter-year $(i t)$ and importer-year $(j t)$ fixed effects to capture the second and third terms of equation (C.1) respectively. Unsurprisingly, bilateral trade declines with distance: the distance elasticity of trade is -1.4. The modest distance elasticity is consistent with cereals produced by different countries serving as imperfect substitutes. ${ }^{66}$ The regression exhibits the typical explanatory

\footnotetext{
${ }^{65}$ Available at https://wits . worldbank.org/tariff/trains/country-byhs6product . aspx?lang=en

${ }^{66}$ Relatedly, there would be no two-way trade if cereals were perfectly homogeneous commodities. Yet, $63 \%$ of countries that trade cereals in a given year both import and export cereals that year. At the level of importer-
} 
power, accounting for $87 \%$ of the variation in cereal trade flows. ${ }^{67}$

In column 2 of Table C.1, we examine whether the distance coefficient responds to global ENSO time-series variation. To do so, we introduce an interaction between bilateral distance and a quadratic function of the sum of contemporaneous and lagged ENSO (i.e., $\mathrm{ENSO}_{t}+\mathrm{ENSO}_{t-1}$ ), the functional form for ENSO used for our main IV results in Table 2. We introduce importer-exporter fixed effects that absorb time-invariant components, including (uninteracted) bilateral distance. The distance elasticity of trade does not vary with ENSO: the coefficients on the interactions are very close to zero. Assuming the distance elasticity of trade costs is also invariant to ENSO, this supports the assumption that our plausibly exogenous variation in the spatial correlation of productivities does not alter the trade elasticity.

Finally, we use bilateral tariff variation to examine whether the trade elasticity varies with the bilateral distance between trading partners. Assuming full passthrough of tariffs to costs, the coefficient on a bilateral ad valorem tariff is the trade elasticity. Following Lind and Ramondo (2019), we interact bilateral distance with time-varying tariffs to estimate distance-dependent trade elasticities. Tariff data have two disadvantages: they are only available after 1990 and have many missing values. ${ }^{68,69}$ With these caveats noted, column 3 reports a trade elasticity of $\epsilon=-7.7$, which is similar to the Caliendo and Parro (2015) estimate of $\epsilon=-8.59$ that we employ in our welfare calculations. If comparative advantage were spatially correlated, so that neighboring countries have more similar productivity distributions across varieties, we would find a positive coefficient on the interaction between tariffs and distance. To the contrary, column 3 shows a (noisily estimated) negative coefficient. We cannot reject the hypothesis that the trade elasticity is invariant to bilateral distance.

\footnotetext{
exporter pairs, $19 \%$ of trading pairs sell cereal in both directions.

${ }^{67}$ The pseudo R-squared when omitting the distance covariate is 0.74 , implying that distance explains $50 \%$ of the residual variation after accounting for importer-year and exporter-year fixed effects.

${ }^{68}$ The shorter time span means tariff data are not well suited for estimating whether the trade elasticity varies over time with ENSO, the test in column 2 of Table C.1.

${ }^{69} 91 \%$ of Comtrade observations with positive trade value at the importer-exporter-cereal-year level have missing WITS tariff values.
} 
Table C.1: Gravity regression for international trade in cereals

\begin{tabular}{|c|c|c|c|}
\hline & (1) & $(2)$ & $(3)$ \\
\hline ln distance $i j$ & $\begin{array}{l}-1.430 \\
(0.014) \\
{[0.000]}\end{array}$ & & \\
\hline $\ln _{\text {distance }} i j \times\left(E N S O_{t}+E N S O_{t-1}\right)$ & & $\begin{array}{c}0.008 \\
(0.011) \\
{[0.491]}\end{array}$ & \\
\hline $\ln _{\text {distance }_{i j}} \times\left(E N S O_{t}+E N S O_{t-1}\right)^{2}$ & & $\begin{array}{c}0.003 \\
(0.009) \\
{[0.730]}\end{array}$ & \\
\hline $\ln \operatorname{tariff}_{i j t}$ & & & $\begin{array}{l}-7.725 \\
(4.997) \\
{[0.122]}\end{array}$ \\
\hline $\ln \operatorname{tariff}_{i j t} \times \ln$ distance $_{i j}$ & & & $\begin{array}{c}-2.791 \\
(4.310) \\
{[0.517]}\end{array}$ \\
\hline Observations & 640,482 & 466,364 & 10,028 \\
\hline Sample period & $1962-2013$ & $1962-2013$ & $1991-2013$ \\
\hline Pseudo R-squared & 0.869 & 0.952 & 0.997 \\
\hline
\end{tabular}

Notes: The dependent variable is annual bilateral (importer-reported) cereal trade value from Comtrade. All models use the Poisson pseudomaximum likelihood estimator. Columns 1 and 2 include importer-year and exporter-year fixed effects. Column 3 further includes importerexporter fixed effects. Standard errors, clustered by year, in parentheses; p-values in brackets. 


\section{Welfare calculations}

This section details the welfare calculations in the main text.

\section{D.1 Historical variance of welfare effect}

This section details the within-sample welfare calculation discussed in Section 4.2 and shown in Table 2. Recall the expression for the variance of welfare in equation (2):

$$
\operatorname{var}\left(\ln \left(C_{i} / L_{i}\right)\right)=\operatorname{var}\left(\ln A_{i}\right)+2 \operatorname{cov}\left(\ln A_{i}, \frac{-1}{\epsilon} \ln \lambda_{i i}\right)+\operatorname{var}\left(\frac{1}{\epsilon} \ln \lambda_{i i}\right)
$$

We employ this expression to quantify the magnitude of our regression results in welfare terms. Consider the following thought experiment: suppose the spatial correlation of productivities increases from the 1961-2013 historical mean, $\bar{I}=.214$, by one standard deviation, $\sigma_{I}=.0191$. What is the resulting percentage change in the cross-sectional variance of welfare, holding everything else fixed? We denote these two hypothetical states as uncorrelated state $u$ and correlated state $c$.

For the uncorrelated state, we define variance productivity as the average cross-sectional productivity variance during 1961-2013:

$$
\operatorname{var}\left(\ln A_{i}^{u}\right) \equiv E_{t}\left[\operatorname{var}_{i}\left(\ln A_{i t} \mid t\right)\right]
$$

Next, we define covariance between productivity and domestic share of expenditure during the uncorrelated state as the average cross-sectional covariance during 1961-2013:

$$
\operatorname{cov}\left(\ln A_{i}^{u}, \ln \lambda_{i i}^{u}\right) \equiv E_{t}\left[\operatorname{cov}_{i}\left(\ln A_{i t}, \ln \lambda_{i i t} \mid t\right)\right]
$$

We further define the variance of domestic share of expenditure during the uncorrelated states as the average variance during 1961-2013:

$$
\operatorname{var}\left(\ln \lambda_{i i u}\right) \equiv E_{t}\left[\operatorname{var}_{i}\left(\ln \lambda_{i i t} \mid t\right)\right]
$$

Note that the values in definitions (D.1), (D.2), (D.3) can be directly computed from data since $\ln A_{i t}$ and $\ln \lambda_{i i t}$ are observed.

For the correlated state c, $\operatorname{var}\left(\ln A_{i}^{c}\right)$ is also given by definitions (D.1) since we assume productivity variance is unaltered by changes in spatial correlation. $\operatorname{cov}\left(\ln A_{i}^{c}, \ln \lambda_{i i}^{c}\right)$ and $\operatorname{var}\left(\lambda_{i i}^{c}\right)$, however, have to be calculated as one does not directly observe data from a year in which only $I_{t}=\bar{I}+\sigma_{I}$ while everything else is fixed at the historical mean. To do this, first recall the expression for $\ln \lambda_{i t}$ in equation (3):

$$
\ln \lambda_{i i t}=\beta_{0} \ln A_{i t}+\beta_{1} I_{t} \ln A_{i t}+\Pi^{\prime} \mathbb{Z}_{i t}+\mu_{i t}
$$


Our estimates of this equation can be employed to construct each component of equation (2) for the correlated state. The covariance between productivity and domestic share of expenditure during the correlated state is:

$$
\begin{aligned}
\operatorname{cov}\left(\ln A_{i}^{c}, \ln \lambda_{i i}^{c}\right) & \equiv\left(\widehat{\beta}_{0}+\widehat{\beta}_{1}\left(\bar{I}+\sigma_{I}\right)\right) E_{t}\left[\operatorname{var}_{i}\left(\ln A_{i t} \mid t\right)\right] \\
& +E_{t}\left[\operatorname{cov}_{i}\left(\ln A_{i t}, \widehat{\Pi}^{\prime} \mathbb{Z}_{i t} \mid t\right)\right]+E_{t}\left[\operatorname{cov}_{i}\left(\ln A_{i t}, \widehat{\mu}_{i t} \mid t\right)\right]
\end{aligned}
$$

The variance of domestic share of expenditure during the correlated state is:

$$
\begin{aligned}
\operatorname{var}\left(\ln \lambda_{i i}^{c}\right) & \equiv\left(\widehat{\beta}_{0}^{2}+2 \widehat{\beta}_{0} \widehat{\beta}_{1}\left(\bar{I}+\sigma_{I}\right)+\widehat{\beta}_{1}^{2}\left(\bar{I}+\sigma_{I}\right)^{2}\right) E_{t}\left[\operatorname{var}_{i}\left(\ln A_{i t} \mid t\right)\right] \\
& +E_{t}\left[\operatorname{var}_{i}\left(\widehat{\Pi}^{\prime} \mathbb{Z}_{i t} \mid t\right)\right]+E_{t}\left[\operatorname{var}_{i}\left(\widehat{\mu}_{i t} \mid t\right)\right] \\
& +2\left(\widehat{\beta}_{0}+\widehat{\beta}_{1}\left(\bar{I}+\sigma_{I}\right)\right) E_{t}\left[\operatorname{cov}_{i}\left(\ln A_{i t}, \widehat{\Pi}^{\prime} \mathbb{Z}_{i t} \mid t\right)\right] \\
& +2\left(\widehat{\beta}_{0}+\widehat{\beta}_{1}\left(\bar{I}+\sigma_{I}\right)\right) E_{t}\left[\operatorname{cov}_{i}\left(\ln A_{i t}, \widehat{\mu}_{i t} \mid t\right)\right] \\
& +2 E_{t}\left[\operatorname{cov}_{i}\left(\widehat{\Pi}^{\prime} \mathbb{Z}_{i t}, \widehat{\mu}_{i t} \mid t\right)\right]
\end{aligned}
$$

Each term in equations (D.4) and (D.5) is either directly observable or can be obtained by estimating equation (3). For example, for the model estimated in column 4, panel B of Table 2, with $\widehat{\beta}_{0}=2.114$ and $\widehat{\beta}_{1}=-4.144$, we have:

$$
\begin{aligned}
E_{t}\left[\operatorname{var}_{i}\left(\ln A_{i t} \mid t\right)\right] & =.453 \\
E_{t}\left[\operatorname{var}_{i}\left(\widehat{\Pi}^{\prime} \mathbb{Z}_{i t} \mid t\right)\right] & =1.04 \\
E_{t}\left[\operatorname{var}_{i}\left(\widehat{\mu}_{i t} \mid t\right)\right] & =.083 \\
E_{t}\left[\operatorname{cov}_{i}\left(\ln A_{i t}, \widehat{\Pi}^{\prime} \mathbb{Z}_{i t} \mid t\right)\right] & =-.497 \\
E_{t}\left[\operatorname{cov}_{i}\left(\ln A_{i t}, \widehat{\mu}_{i t} \mid t\right)\right] & =-.026 \\
E_{t}\left[\operatorname{cov}_{i}\left(\widehat{\Pi}^{\prime} \mathbb{Z}_{i t}, \widehat{\mu}_{i t} \mid t\right)\right] & =-.001
\end{aligned}
$$

Applying equation (2), the percentage change in the variance of welfare in the correlated state, relative to the uncorrelated state, is

$$
\frac{\operatorname{var}\left(\ln \frac{C_{i}^{c}}{L_{i}}\right)-\operatorname{var}\left(\ln \frac{C_{i}^{u}}{L_{i}}\right)}{\operatorname{var}\left(\ln \left(C_{i}^{u} / L_{i}\right)\right)}=\frac{\operatorname{var}\left(\ln A_{i}^{c}\right)-\frac{2}{\epsilon} \operatorname{cov}\left(\ln A_{i}^{c}, \ln \lambda_{i i}^{c}\right)+\frac{1}{\epsilon^{2}} \operatorname{var}\left(\ln \lambda_{i i}^{c}\right)}{\operatorname{var}\left(\ln A_{i}^{u}\right)-\frac{2}{\epsilon} \operatorname{cov}\left(\ln A_{i}^{u}, \ln \lambda_{i i}^{u}\right)+\frac{1}{\epsilon^{2}} \operatorname{var}\left(\ln \lambda_{i i}^{u}\right)}-1
$$

To complete the calculation, let the agricultural trade elasticity be $\epsilon=8.59$ (Caliendo and Parro, 2015, Table A2). Values from equation (D.6) are shown in Table 2, with standard errors calculated using the delta method.

\section{D.2 Change in country-level welfare and welfare variance under climate change}

This section discusses how we calculate the percentage change in the global variance of welfare and the change in country-level welfare between the end of our estimation period, $\bar{t}=2013$, and 
the end of our projection period, $\mathcal{T}=2099$, under climate change, holding everything else fixed. ${ }^{70}$ We compare two projections, one which omits climate-induced changes in the spatial structure of agricultural productivity and another which allows for such changes.

We begin by showing how we quantify changes in country-level agricultural productivity as well as the global variance and spatial correlation of agricultural productivity under climate change. We then consider two projections of country-level domestic share of expenditure. The first projection, which would be a typical projection of climate impacts, omits climate-induced changes in the spatial structure of agricultural productivity. The second projection includes such changes. We then compare changes in the variance of welfare and in country-level welfare over the 20th century across these two projections.

Projecting agricultural productivity Recall equation (9) for $\ln A_{i t}$ during the estimation period, $t \in[1961,2013]$ :

$$
\ln A_{i t}=k\left(T_{i t}\right)+\Psi^{\prime} \mathbb{X}_{i t}+\nu_{i t}
$$

Column 1 of Table F.9 shows coefficients for $\widehat{k}()$ from our benchmark specification, which is also plotted in Figure 10. Using estimates from equation (9) and our business-as-usual CMIP5 ensemble mean projected temperatures under climate change, $\widehat{T}_{i t}$, we first compute country-year agricultural productivity under climate change during the projection period $t \in[2014,2099]$, holding everything but temperature fixed to estimated $\bar{t}=2013$ values:

$$
\widehat{\ln A}_{i t}=\widehat{k}\left(\widehat{T}_{i t}\right)+\widehat{\Psi}^{\prime} \mathbb{X}_{i \bar{t}}+\widehat{\nu}_{i \bar{t}}
$$

In the left panel of Figure 11, the black line shows $\operatorname{var}\left(\widehat{\ln A}_{i t}\right)$ while the blue line shows Moran's I, $\widehat{I}_{t}$ computed using $\widehat{\ln A}_{i t}$, for each projection year.

Projecting domestic share of expenditure omitting and including change in spatial structure We consider two projections of the domestic share of expenditure: one which holds the global spatial correlation of productivities fixed to the 2013 value and another which allows it to vary under climate change. Both projections use our benchmark estimate of $\beta_{1}$ and $\beta_{2}$ from equation (3), shown in column 4, panel B of Table 2.

Holding the spatial correlation of productivities fixed to the $\bar{t}=2013$ value (along with other unprojected determinants), the domestic share of expenditure during the projection period, $t \in$ [2014, 2099], is:

$$
\widehat{\ln \lambda}_{i i t}^{n}=\left(\widehat{\beta}_{0}+\widehat{\beta}_{1} I_{\bar{t}}\right) \widehat{\ln A}_{i t}+\widehat{\kappa}_{\bar{t}}+\widehat{\Pi}^{\prime} \mathbb{Z}_{i, \bar{t}}+\widehat{\mu}_{i \bar{t}}
$$

where spatial correlation affects both the average domestic share of expenditure $(\kappa)$ and its relationship to domestic productivity $\left(\beta_{1}\right) .{ }^{71}$

\footnotetext{
${ }^{70}$ Compared with the welfare calculation described in Appendix D.1 and reported in Table 2, there is an added complication as climate change also changes the variance of productivity.

${ }^{71}$ To obtain $\kappa$, we first recover year fixed effects from equation $(3) . \widehat{\kappa}=2.45$ is the coefficient from a linear regression of year fixed effects on $I_{t}$ and a linear time trend.
} 
Allowing the spatial correlation of productivities to vary under climate change, the domestic share of expenditure during the projection period, $t \in[2014,2099]$, is:

$$
\widehat{\ln \lambda}_{i i t}^{s}=\left(\widehat{\beta}_{0}+\widehat{\beta}_{1} \widehat{I}_{t}\right) \widehat{\ln A}_{i t}+\widehat{\kappa}_{t}+\widehat{\Pi}^{\prime} \mathbb{Z}_{i, \bar{t}}+\widehat{\mu}_{i, \bar{t}}
$$

Projecting changes in global welfare variance From equation (1), the expression for welfare of country $i$ in year $t$ is

$$
\ln \left(C_{i t} / L_{i t}\right)=\ln A_{i t}+\gamma-\frac{1}{\epsilon} \ln \lambda_{i i t}
$$

To compute the change in variance of welfare from the end of the estimation period, $\bar{t}=2013$, to any year during the projection period, $t \in[2014,2099]$, we difference equation (2):

$$
\begin{aligned}
\operatorname{var}\left(\ln \left(C_{i t} / L_{i t}\right)\right)-\operatorname{var}\left(\ln \left(C_{i \bar{t}} / L_{i \bar{t}}\right)\right) & =\left[\operatorname{var}\left(\widehat{\ln A}_{i t}\right)-\operatorname{var}\left(\ln A_{i \bar{t}}\right)\right] \\
& -(2 / \epsilon)\left[\operatorname{cov}\left(\widehat{\ln A}_{i t}, \widehat{\ln \lambda}_{i i t}\right)-\operatorname{cov}\left(\ln A_{i \bar{t}}, \ln \lambda_{i i \bar{t}}\right)\right] \\
& +\left(1 / \epsilon^{2}\right)\left[\operatorname{var}\left(\widehat{\ln \lambda}_{i i t}\right)-\operatorname{var}\left(\ln \lambda_{i i \bar{t}}\right)\right]
\end{aligned}
$$

For the projection which holds spatial structure fixed, equations (D.7) and (D.8) allow construction of $\operatorname{var}\left(\widehat{\ln \lambda}_{i i t}^{n}\right)$ and $\operatorname{cov}\left(\widehat{\ln A}_{i t}, \widehat{\ln \lambda}_{i i t}^{n}\right)$ for each year in the projection period. These then enter into equation (D.10) to compute the change in welfare variance between 2014-2099 for the projection that omits changes in spatial structure, $\operatorname{var}\left(\ln \left(C_{i \mathcal{T}}^{n} / L_{i \mathcal{T}}^{n}\right)\right)-\operatorname{var}\left(\ln \left(C_{i \bar{t}} / L_{i \bar{t}}\right)\right)$. That projected welfare variance is shown as the solid gray line in the right panel of Figure 11.

Similarly, for the projection that allows climate-induced changes in spatial structure, equations (D.7) and (D.9) allow construction of $\operatorname{var}\left(\widehat{\ln \lambda}_{i i t}^{s}\right)$ and $\operatorname{cov}\left(\widehat{\ln A}_{i t}, \widehat{\ln \lambda}_{i i t}^{s}\right)$ for each year in the projection period. These then enter into equation (D.10) to compute the change in welfare variance between 2014-2099 for the projection that includes changes in spatial structure, $\operatorname{var}\left(\ln \left(C_{i \mathcal{T}}^{s} / L_{i \mathcal{T}}^{s}\right)\right)-\operatorname{var}\left(\ln \left(C_{i \bar{t}} / L_{i \bar{t}}\right)\right)$. That projected welfare variance is shown as the solid red line in the right panel of Figure 11.

We then calculate the percentage difference in the change in welfare variance between projections that include and omit changes in spatial structure:

$$
\frac{\operatorname{var}\left(\ln \left(C_{i \mathcal{T}}^{s} / L_{i \mathcal{T}}^{s}\right)\right)-\operatorname{var}\left(\ln \left(C_{i \bar{t}} / L_{i \bar{t}}\right)\right)}{\operatorname{var}\left(\ln \left(C_{i \mathcal{T}}^{n} / L_{i \mathcal{T}}^{n}\right)\right)-\operatorname{var}\left(\ln \left(C_{i \bar{t}} / L_{i \bar{t}}\right)\right)}-1
$$

When applying baseline estimated parameters and an agricultural trade elasticity of $\epsilon=8.59$ (Caliendo and Parro, 2015, Table A2) to equation (D.11), we find that allowing climate change to alter the spatial correlation of productivities predicts a $20 \%$ greater increase in welfare variance than when spatial correlation is held fixed.

Projecting changes in country-level welfare For the projection that omits changes in spatial structure, the difference in country $i$ welfare from $\bar{t}=2013$ to $\mathcal{T}=2099$ is:

$$
\ln \left(C_{i \mathcal{T}}^{n} / L_{i \mathcal{T}}^{n}\right)-\ln \left(C_{i \bar{t}} / L_{i \bar{t}}\right)=\left[\widehat{\ln A}_{i \mathcal{T}}-\ln A_{i \bar{t}}\right]-(1 / \epsilon)\left[\left(\widehat{\beta}_{0}+\widehat{\beta}_{1} I_{\bar{t}}\right)\left(\widehat{\ln A}_{i \mathcal{T}}-\ln A_{i \bar{t}}\right)\right]
$$


Likewise, for the projection that includes changes in spatial structre, the difference in country $i$ welfare from $\bar{t}=2013$ to $\mathcal{T}=2099$ is:

$\ln \left(C_{i \mathcal{T}}^{s} / L_{i \mathcal{T}}^{s}\right)-\ln \left(C_{i \bar{t}} / L_{i \bar{t}}\right)=\left[\widehat{\ln A}_{i \mathcal{T}}-\ln A_{i \bar{t}}\right]-(1 / \epsilon)\left[\left(\widehat{\beta}_{0}+\widehat{\beta}_{1} \widehat{I}_{\mathcal{T}}\right) \widehat{\ln A}_{i \mathcal{T}}-\left(\widehat{\beta}_{0}+\widehat{\beta}_{1} I_{\bar{t}}\right) \ln A_{i \bar{t}}+\widehat{\kappa}\left(\widehat{I}_{\mathcal{T}}-I_{\bar{t}}\right)\right]$

The difference in country welfare between projections that include and omit changes in spatial structure is:

$$
\left[\ln \left(C_{i \mathcal{T}}^{s} / L_{i \mathcal{T}}^{s}\right)-\ln \left(C_{i \bar{t}} / L_{i \bar{t}}\right)\right]-\left[\ln \left(C_{i \mathcal{T}}^{n} / L_{i \mathcal{T}}^{n}\right)-\ln \left(C_{i \bar{t}} / L_{i \bar{t}}\right)\right]=-(1 / \epsilon)\left[\left(\widehat{\beta}_{1} \widehat{\ln }_{i \mathcal{T}}+\widehat{\kappa}\right)\left(\widehat{I}_{\mathcal{T}}-I_{\bar{t}}\right)\right]
$$

Figures 12 and 13 show the country-level difference across projections.

\section{E Appendix figures}

Figure E.1: Welfare per capita, model vs approximation by linear regression

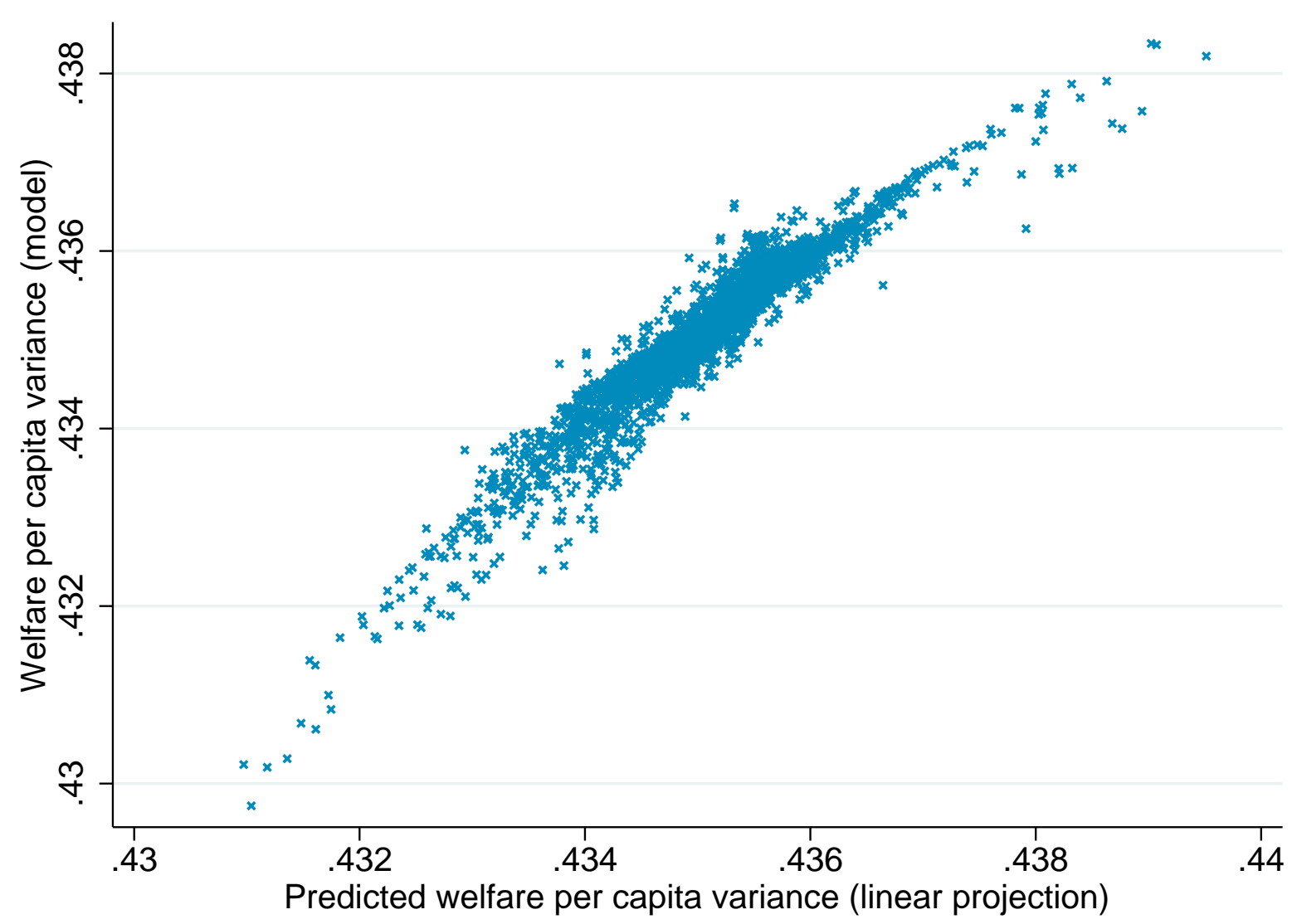

Notes: For each equilibrium depicted in Figure A.4, we compute equilibrium welfare per capita in the model (vertical axis) and welfare per capita predicted by an estimated linear regression (horizontal axis). The regression specification is akin to the line of best fit depicted in Figure A.4, see equation (3). Predicted welfare per capita is computed by plugging in predicted values of $\ln \lambda_{i i}$ into equation (2). The $R^{2}$ of the bivariate relationship is .93. $\operatorname{cov}\left(\ln A_{i}, \ln \lambda_{i i}\right)-\operatorname{cov}\left(\ln \bar{A}_{i}, \ln \bar{\lambda}_{i i}\right)$ is at least the same order of magnitude as $\operatorname{var}\left(\ln \lambda_{i i}\right)-\operatorname{var}\left(\ln \bar{\lambda}_{i i}\right)$ in $99 \%$ of swaps; it is an order of magnitude larger in $16 \%$. 
Figure E.2: Location of ENSO sea-surface temperature measurements

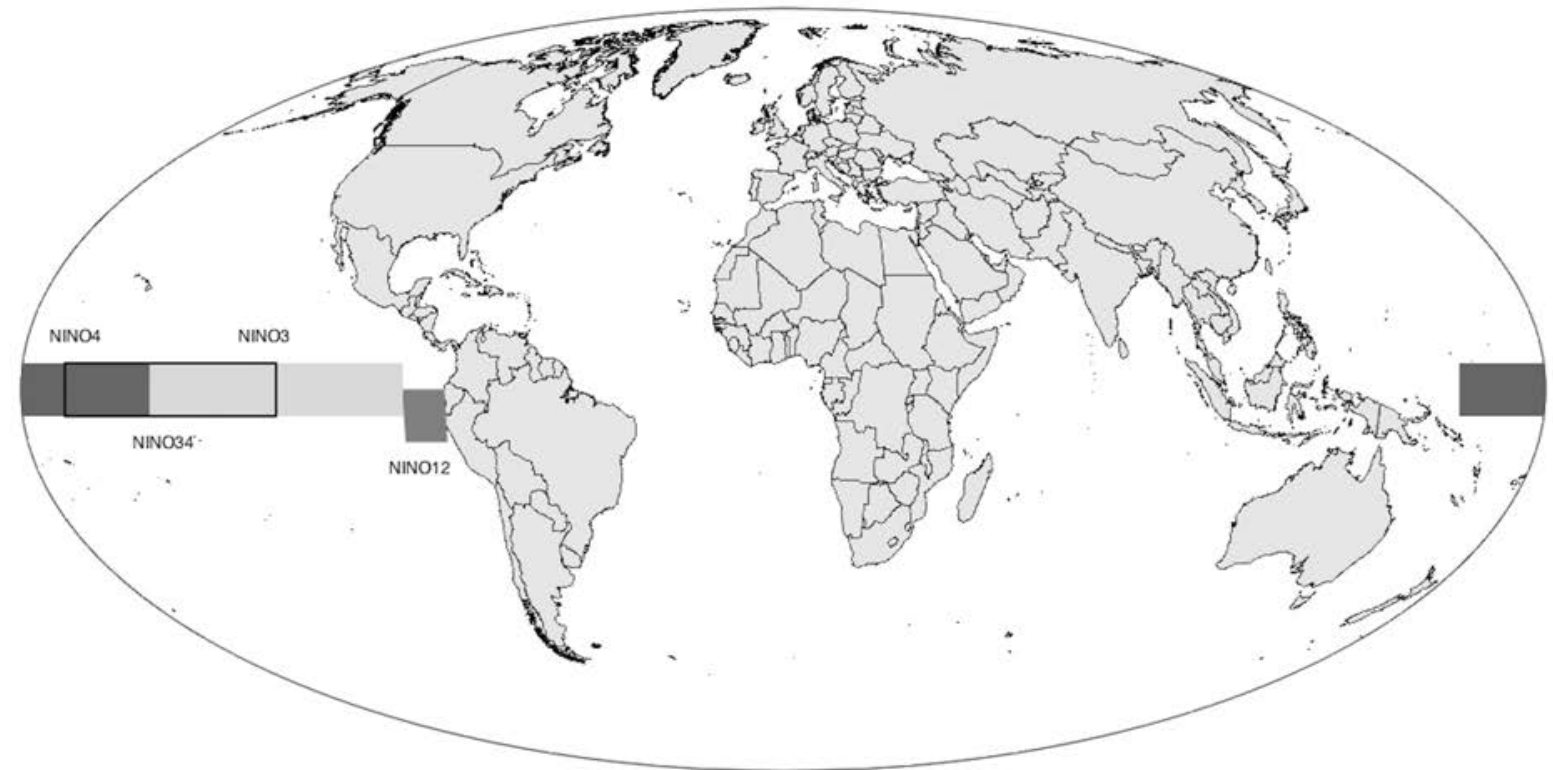

Notes: ENSO indices defined as average sea surface temperature over a region minus the long-term mean sea surface temperature for that region. Spatial definitions for standard ENSO indices: NINO4 $\left(5^{\circ} \mathrm{S}-5^{\circ} \mathrm{N}, 160^{\circ} \mathrm{E}-150^{\circ} \mathrm{W}\right)$, NINO3 $\left(5^{\circ} \mathrm{S}-5^{\circ} \mathrm{N}, 150^{\circ} \mathrm{W}-90^{\circ} \mathrm{W}\right)$, NINO34 $\left(5^{\circ} \mathrm{S}-5^{\circ} \mathrm{N}, 170^{\circ} \mathrm{W}-120^{\circ} \mathrm{W}\right)$, and NINO12 $\left(10^{\circ} \mathrm{S}-0^{\circ}, 90^{\circ} \mathrm{W}-80^{\circ} \mathrm{W}\right)$.

Figure E.3: Monthly ENSO index for top 10 positive events

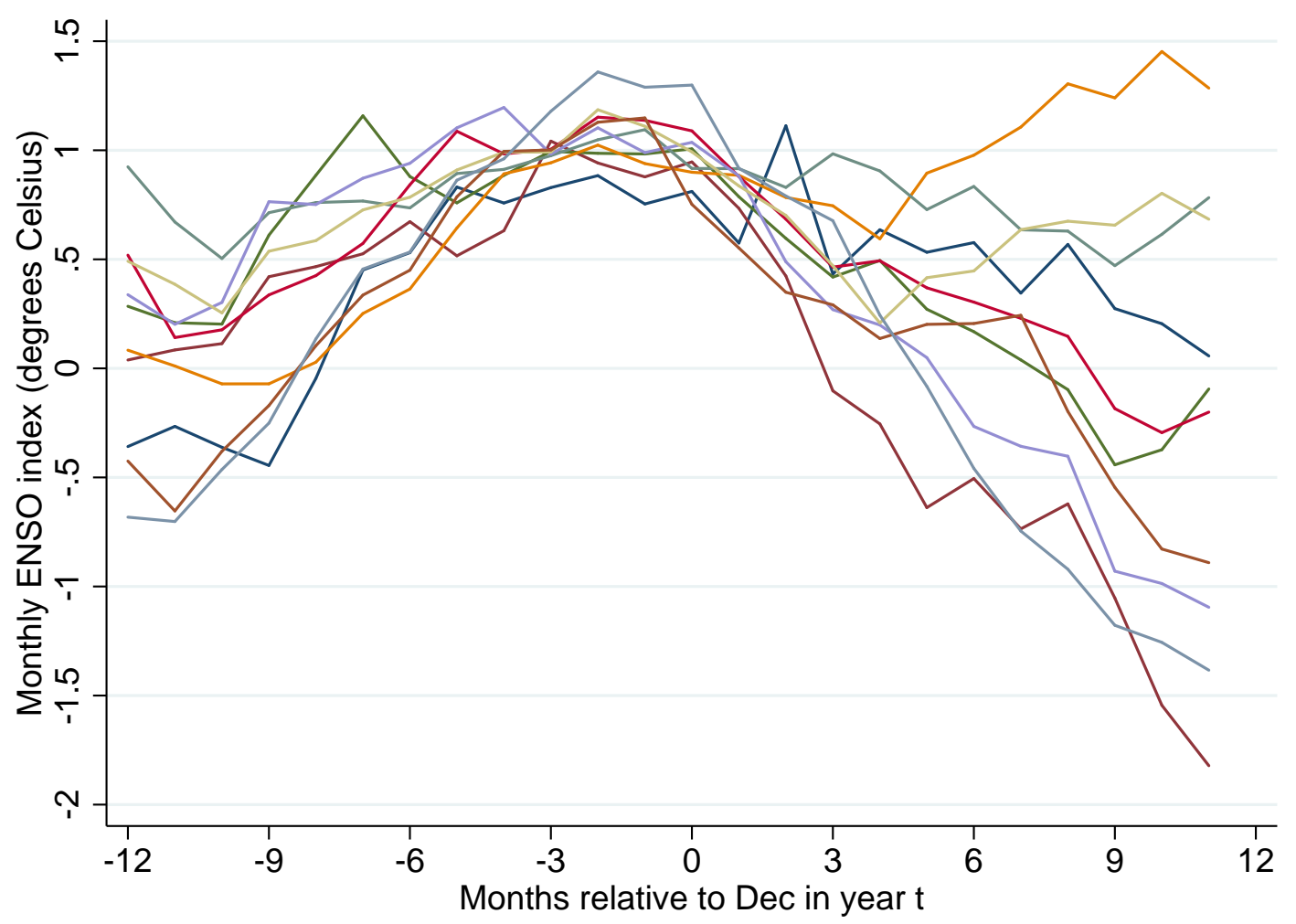

Notes: Time evolution of monthly ENSO index 12 months before and after the 10 most positive ENSO events over 1961-2013. ENSO events occur during the winters of 1965, 1972, 1982, 1986, 1991, 1994, 1997, 2002, 2006 , and 2009. 
Figure E.4: Observed log cereal yields and temperature in 2013

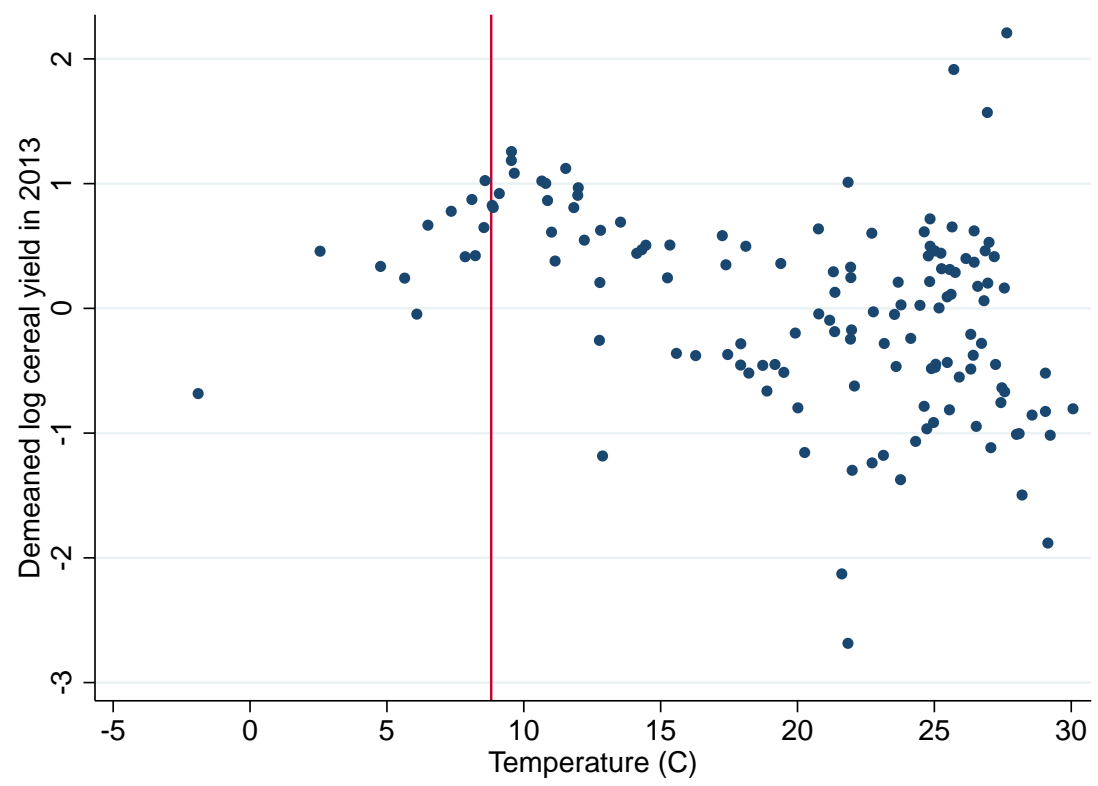

Notes: Observed country-level log cereal yields in 2013 with cross-sectional mean removed plotted against temperature in 2013. From equation (9), observed log cereal yield is sum of the nonlinear temperature relationship $k\left(T_{i t}\right)$, controls $\Psi^{\prime} \mathbb{X}_{i t}$, and the residual term $\nu_{i t}$. Vertical line shows the predicted log yield maximizing temperature from Figure 10.

Figure E.5: Differences in welfare projections from projected changes in spatial correlation and yields

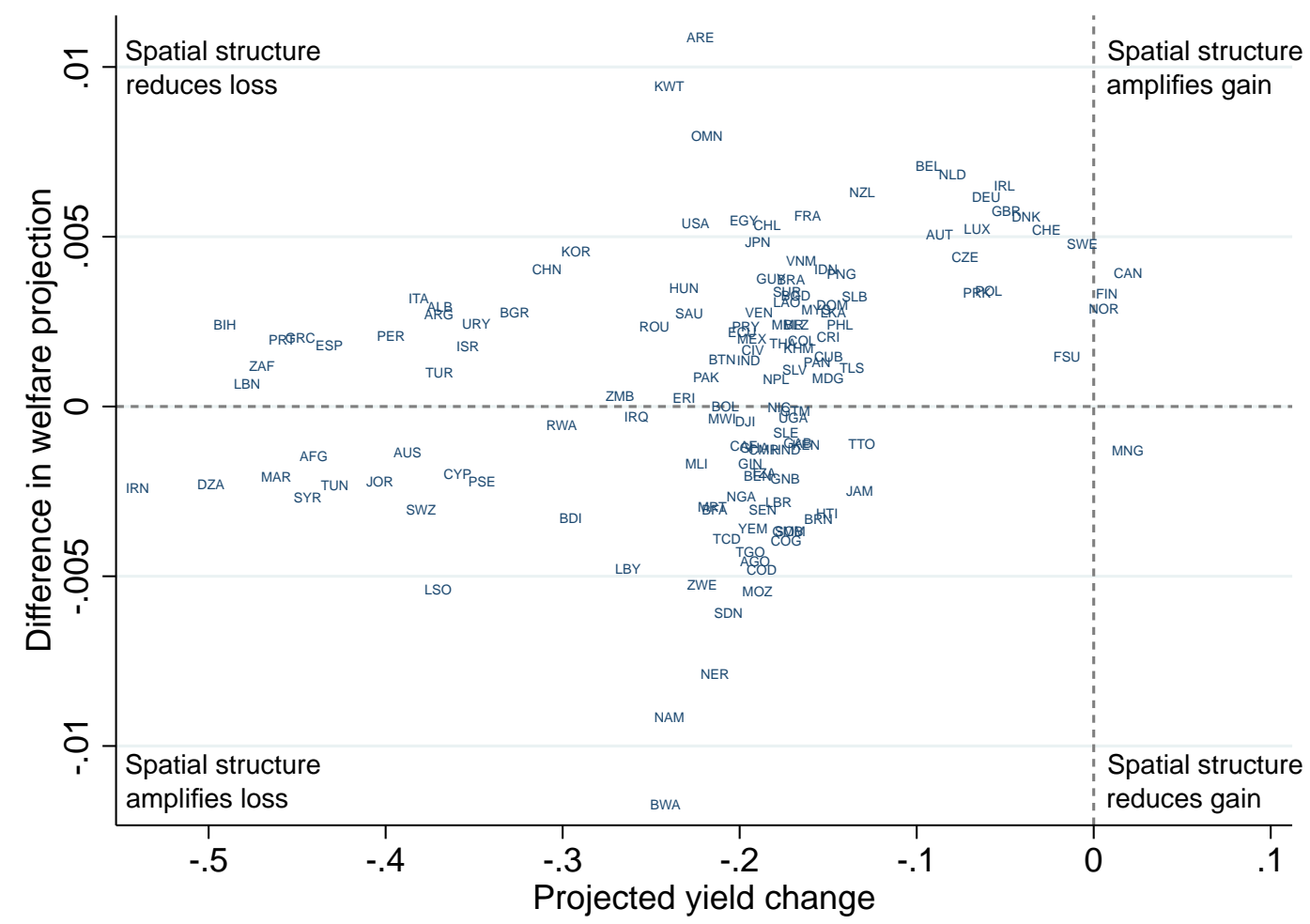

Notes: Scatter shows the difference in projected country-level welfare change between projections that include and omit changes in spatial correlation (from Figure 12) plotted against change in log cereal yields over 2013-2099 under climate change. Countries labeled by ISO3 identifier. 


\section{F Appendix tables}

Table F.1: Statistical significance of first-stage coefficients

\begin{tabular}{|c|c|c|c|c|c|}
\hline & $(1)$ & $(2)$ & $(3)$ & $(4)$ & $(5)$ \\
\hline$\alpha_{11}^{\prime}$ joint F-stat p-value & 0.022 & 0.007 & 0.011 & 0.011 & 0.008 \\
\hline$\alpha_{12}^{\prime}$ joint $\mathrm{F}$-stat $\mathrm{p}$-value & 0.006 & 0.038 & 0.097 & 0.178 & 0.218 \\
\hline$\alpha_{21}^{\prime}$ joint $\mathrm{F}$-stat $\mathrm{p}$-value & 0.071 & 0.004 & 0.007 & 0.006 & 0.003 \\
\hline$\alpha_{22}^{\prime}$ joint F-stat $\mathrm{p}$-value & 0.041 & 0.062 & 0.028 & 0.041 & 0.071 \\
\hline Number of temperature splines in $f()$ & 2 & 3 & 4 & 5 & 6 \\
\hline Observations & 5452 & 5452 & 5452 & 5452 & 5452 \\
\hline
\end{tabular}

Table F.2: Alternative error structures Outcome is log domestic share of expenditure

\begin{tabular}{|c|c|c|c|c|}
\hline & $(1)$ & $(2)$ & $(3)$ & $(4)$ \\
\hline \multirow[t]{3}{*}{$\ln A_{i t}\left(\beta_{0}\right)$} & 2.114 & 2.114 & 2.114 & 2.114 \\
\hline & $(0.604)$ & $(0.581)$ & $(0.830)$ & $(0.698)$ \\
\hline & {$[0.001]$} & {$[0.001]$} & {$[0.014]$} & {$[0.004]$} \\
\hline \multirow{3}{*}{$\ln A_{i t} \times I_{t}\left(\beta_{1}\right)$} & -4.144 & -4.144 & -4.144 & -4.144 \\
\hline & $(1.834)$ & $(1.659)$ & $(2.157)$ & $(1.939)$ \\
\hline & {$[0.028]$} & {$[0.016]$} & {$[0.060]$} & {$[0.037]$} \\
\hline Clustering & year cluster & $\begin{array}{c}\text { year cluster } \\
\text { and } 20 \text { year } \mathrm{HAC}\end{array}$ & $\begin{array}{c}\text { year cluster } \\
\text { and cntry cluster }\end{array}$ & year cluster \\
\hline Bekker adjustment & No & No & No & Yes \\
\hline Observations & 5452 & 5452 & 5452 & 5452 \\
\hline
\end{tabular}


Table F.3: Controlling for time-varying trade costs

Outcome is log domestic share of expenditure

\begin{tabular}{|c|c|c|c|c|c|c|c|}
\hline & (1) & $(2)$ & $(3)$ & (4) & $(5)$ & (6) & (7) \\
\hline \multirow[t]{3}{*}{$\ln A_{i t}\left(\beta_{0}\right)$} & 2.114 & 2.178 & 2.163 & 2.492 & 2.297 & 2.115 & 2.270 \\
\hline & $(0.604)$ & $(0.612)$ & $(0.593)$ & $(0.737)$ & $(0.641)$ & $(0.604)$ & $(0.796)$ \\
\hline & {$[0.001]$} & {$[0.001]$} & {$[0.001]$} & {$[0.001]$} & {$[0.001]$} & {$[0.001]$} & {$[0.006]$} \\
\hline \multirow[t]{3}{*}{$\ln A_{i t} \times I_{t}\left(\beta_{1}\right)$} & -4.144 & -4.254 & -4.189 & -4.748 & -4.227 & -4.145 & -4.281 \\
\hline & $(1.834)$ & $(1.865)$ & $(1.825)$ & $(2.095)$ & $(1.844)$ & $(1.833)$ & $(1.985)$ \\
\hline & {$[0.028]$} & {$[0.027]$} & {$[0.026]$} & {$[0.028]$} & {$[0.026]$} & {$[0.028]$} & {$[0.036]$} \\
\hline \multicolumn{2}{|l|}{$\ln$ oil price $\times$ average $\ln \lambda_{i i}$} & Yes & & & & & \\
\hline \multicolumn{2}{|l|}{ ln oil price $\times$ centrality } & & Yes & & & & \\
\hline \multicolumn{2}{|l|}{ Year $\mathrm{FE} \times$ average $\ln \lambda_{i i}$} & & & Yes & & & \\
\hline \multicolumn{2}{|l|}{ Year FE $\times$ centrality } & & & & Yes & & \\
\hline \multicolumn{2}{|l|}{ Export restrictions } & & & & & Yes & \\
\hline \multicolumn{2}{|l|}{ Precipitation } & & & & & & Yes \\
\hline Cragg-Donald F-stat & 5.174 & 5.249 & 5.077 & 4.875 & 4.042 & 5.163 & 3.932 \\
\hline Stock-Yogo crit. value: $10 \% \max$ LIML size & 3.580 & 3.580 & 3.580 & 3.580 & 3.580 & 3.580 & 3.580 \\
\hline Kleibergen-Paap F-stat & 3.963 & 3.911 & 3.903 & 4.146 & 3.523 & 3.967 & 3.497 \\
\hline Observations & 5452 & 5452 & 5452 & 5452 & 5452 & 5452 & 5452 \\
\hline \multicolumn{8}{|c|}{$\begin{array}{l}\text { NotES: Estimates of } \beta_{0} \text { and } \beta_{1} \text { from equation (3). Column } 1 \text { replicates benchmark model from column } 4 \text {, panel } \\
\text { B, of Table } 2 \text {. Column } 2(3) \text { controls for the interaction of global log oil price and cross-sectional average log } \\
\text { domestic share of expenditure (output-weighted inverse distance averaged across all other countries). Column } 4 \\
\text { (5) controls for the interaction of year fixed effects and cross-sectional average log domestic share of expenditure } \\
\text { (output-weighted inverse distance averaged across all other countries). Column } 6 \text { controls for introductions of export } \\
\text { restrictions. Column } 7 \text { controls for quadratic precipitation terms. Standard errors, clustered by year, in parentheses; } \\
\text { p-values in brackets. }\end{array}$} \\
\hline
\end{tabular}

Table F.4: Sample splits

Outcome is log domestic share of expenditure

\begin{tabular}{lcccc}
\hline & $(1)$ & $(2)$ & $(3)$ & $(4)$ \\
\hline $\ln A_{i t}\left(\beta_{0}\right)$ & & & & \\
& 2.114 & 2.152 & 1.845 & 1.692 \\
& $(0.604)$ & $(0.595)$ & $(2.807)$ & $(0.511)$ \\
$\ln A_{i t} \times I_{t}\left(\beta_{1}\right)$ & {$[0.001]$} & {$[0.001]$} & {$[0.517]$} & {$[0.003]$} \\
& -4.144 & -4.226 & -4.639 & -2.708 \\
& $(1.834)$ & $(1.925)$ & $(12.564)$ & $(1.627)$ \\
& {$[0.028]$} & {$[0.033]$} & {$[0.715]$} & {$[0.108]$} \\
Include large producers? & No & Yes & No & No \\
Sample period & $1961-2013$ & $1961-2013$ & $1961-1987$ & $1988-2013$ \\
Cragg-Donald F-stat & 5.174 & 5.020 & 1.628 & 3.810 \\
Stock-Yogo crit. value: $10 \%$ max LIML size & 3.580 & 3.580 & 3.580 & 3.580 \\
Kleibergen-Paap F-stat & 3.963 & 4.473 & 1.137 & 4.052 \\
Anderson-Rubin weak-id robust joint p-value & 0.000 & 0.000 & 0.000 & 0.000 \\
Observations & 5452 & 4952 & 2655 & 2793 \\
\hline
\end{tabular}

Notes: Estimates of $\beta_{0}$ and $\beta_{1}$ from equation (3). Column 1 reproduces benchmark estimates from column 4 , panel B of Table 2. Column 2 excludes the following ten countries, which together account for more than half of world cereal output in each year: China, United States, India, Former Soviet Union, France, Indonesia, Canada, Brazil, Germany, and Bangladesh. Column 3 restricts sample to 1961-1987. Column 4 restricts sample to 19882013. Standard errors, clustered by year, in parentheses; p-values in brackets. 
Table F.5: Dynamic effects Outcome is log domestic share of expenditure

\begin{tabular}{|c|c|c|c|c|}
\hline & $(1)$ & $(2)$ & $(3)$ & $(4)$ \\
\hline \multirow[t]{3}{*}{$\ln A_{i t}$} & 2.217 & & & 1.326 \\
\hline & $(0.651)$ & & & $(0.634)$ \\
\hline & {$[0.001]$} & & & {$[0.041]$} \\
\hline \multirow[t]{3}{*}{$\ln A_{i t} \times I_{t}$} & -4.152 & & & -3.233 \\
\hline & $(1.874)$ & & & $(1.590)$ \\
\hline & {$[0.031]$} & & & {$[0.047]$} \\
\hline \multirow[t]{3}{*}{$\ln A_{i t+1}$} & & 0.724 & & \\
\hline & & $(0.503)$ & & \\
\hline & & {$[0.156]$} & & \\
\hline \multirow[t]{3}{*}{$\ln A_{i t+1} \times I_{t+1}$} & & -0.830 & & \\
\hline & & $(1.642)$ & & \\
\hline & & {$[0.615]$} & & \\
\hline \multirow[t]{3}{*}{$\ln A_{i t-1}$} & & & 0.851 & \\
\hline & & & $(0.526)$ & \\
\hline & & & {$[0.112]$} & \\
\hline \multirow[t]{3}{*}{$\ln A_{i t-1} \times I_{t-1}$} & & & -2.039 & \\
\hline & & & $(1.354)$ & \\
\hline & & & {$[0.138]$} & \\
\hline 2nd stage sample period & $1962-2012$ & $1962-2012$ & 1962-2012 & 1961-2013 \\
\hline Include stored cereals? & No & No & No & Yes \\
\hline Cragg-Donald F-stat & 4.480 & 5.688 & 5.293 & 5.345 \\
\hline Stock-Yogo crit. value: $10 \%$ max LIML size & 3.580 & 3.580 & 3.580 & 3.580 \\
\hline Kleibergen-Paap F-stat & 3.632 & 2.592 & 3.532 & 3.622 \\
\hline Observations & 5237 & 5236 & 5235 & 5191 \\
\hline
\end{tabular}

NOTES: Estimates of $\beta_{0}$ and $\beta_{1}$ from equation (3). Column 1 reproduces benchmark model using log yields in year $t$ instrumented by December ENSO in years $t$ and $t-1$ and local temperature in year $t$. Column 2 uses $\log$ yields in year $t+1$, instrumented by December ENSO conditions in years $t+1$ and $t$ and local temperature in year $t+1$. Column 3 uses $\log$ yields in year $t-1$, instrumented by December ENSO conditions in years $t-1$ and $t-2$ and local temperature in year $t-1$. Column 4 uses log yields in year $t$ to examine effects on a measure of domestic share of expenditure that includes stored cereals. Sample period for 2nd stage equation is 1962-2012 for columns 1-3 and 1961-2013 for column 4. Standard errors clustered by year in parentheses; p-values in brackets. 
Table F.6: ENSO and local temperature definitions

Outcome is log domestic share of expenditure

\begin{tabular}{|c|c|c|c|c|}
\hline & $(1)$ & $(2)$ & $(3)$ & $(4)$ \\
\hline \multicolumn{5}{|c|}{ Panel A: Crop-area-weighted country temperature } \\
\hline \multirow{3}{*}{$\ln A_{i t}\left(\beta_{0}\right)$} & 2.114 & 2.108 & 2.084 & 2.722 \\
\hline & $(0.604)$ & $(0.715)$ & $(0.706)$ & $(0.987)$ \\
\hline & {$[0.001]$} & {$[0.005]$} & {$[0.005]$} & {$[0.008]$} \\
\hline \multirow[t]{3}{*}{$\ln A_{i t} \times I_{t}\left(\beta_{1}\right)$} & -4.144 & -4.064 & -4.465 & -6.026 \\
\hline & $(1.834)$ & $(2.414)$ & $(2.406)$ & $(3.127)$ \\
\hline & {$[0.028]$} & {$[0.098]$} & {$[0.069]$} & {$[0.059]$} \\
\hline ENSO index & 4 & 3 & 34 & 12 \\
\hline Cragg-Donald F-stat & 5.174 & 5.013 & 5.195 & 3.781 \\
\hline Stock-Yogo crit. value: $10 \%$ max LIML size & 3.580 & 3.580 & 3.580 & 3.580 \\
\hline Kleibergen-Paap F-stat & 3.963 & 2.897 & 3.993 & 2.333 \\
\hline Observations & 5452 & 5452 & 5452 & 5452 \\
\hline \multicolumn{5}{|c|}{ Panel B: Total-area-weighted country temperature } \\
\hline \multirow[t]{3}{*}{$\ln A_{i t}\left(\beta_{0}\right)$} & 1.632 & 1.722 & 1.562 & 1.871 \\
\hline & $(0.500)$ & $(0.626)$ & $(0.597)$ & $(0.729)$ \\
\hline & {$[0.002]$} & {$[0.008]$} & {$[0.012]$} & {$[0.013]$} \\
\hline \multirow[t]{3}{*}{$\ln A_{i t} \times I_{t}\left(\beta_{1}\right)$} & -3.960 & -4.125 & -4.155 & -4.517 \\
\hline & $(1.617)$ & $(2.155)$ & $(2.071)$ & $(2.331)$ \\
\hline & {$[0.018]$} & {$[0.061]$} & {$[0.050]$} & {$[0.058]$} \\
\hline ENSO index & 4 & 3 & 34 & 12 \\
\hline Cragg-Donald F-stat & 4.423 & 3.928 & 4.186 & 3.103 \\
\hline Stock-Yogo crit. value: $10 \%$ max LIML size & 3.580 & 3.580 & 3.580 & 3.580 \\
\hline Kleibergen-Paap F-stat & 3.490 & 2.653 & 3.344 & 1.957 \\
\hline Observations & 5605 & 5605 & 5605 & 5605 \\
\hline
\end{tabular}


Table F.7: Using spatial correlation of temperature instead of ENSO Outcome is $\log$ domestic share of expenditure

\begin{tabular}{lccccc}
\hline & $(1)$ & $(2)$ & $(3)$ & $(4)$ & $(5)$ \\
\hline & & & & & \\
$\ln A_{i t}\left(\beta_{0}\right)$ & 2.486 & 2.540 & 1.918 & 1.647 & 1.686 \\
& $(1.310)$ & $(1.182)$ & $(0.600)$ & $(0.618)$ & $(0.624)$ \\
& {$[0.063]$} & {$[0.036]$} & {$[0.002]$} & {$[0.010]$} & {$[0.009]$} \\
$\ln A_{i t} \times I_{t}\left(\beta_{1}\right)$ & -5.044 & -5.135 & -3.092 & -2.348 & -2.394 \\
& $(4.173)$ & $(4.011)$ & $(1.884)$ & $(1.943)$ & $(2.021)$ \\
& {$[0.232]$} & {$[0.206]$} & {$[0.107]$} & {$[0.232]$} & {$[0.241]$} \\
Number of temperature splines in f & & & & & \\
Temperature Moran's I polynomial order in g & 2 & 3 & 4 & 5 & 6 \\
Number of instruments & 1 & 1 & 1 & 1 & 1 \\
Cragg-Donald F-stat & 4 & 6 & 8 & 10 & 12 \\
Stock-Yogo crit. value: 10\% max 2SLS bias & 7.560 & 9.480 & 10.220 & 10.580 & 10.780 \\
Stock-Yogo crit. value: 10\% max 2SLS size & 16.870 & 21.680 & 25.640 & 29.320 & 32.880 \\
Stock-Yogo crit. value: 10\% max LIML size & 4.720 & 4.060 & 3.780 & 3.640 & 3.580 \\
Kleibergen-Paap F-stat & 2.813 & 2.217 & 2.145 & 2.389 & 2.061 \\
BIC for first stage equations & -30779.0 & -30789.6 & -30873.7 & -30862.6 & -30845.5 \\
Observations & 5452 & 5452 & 5452 & 5452 & 5452 \\
\hline
\end{tabular}

Notes: LIML estimates of $\beta_{0}$ and $\beta_{1}$ from equation (3) with $g\left(E N S O_{t}+E N S O_{t-1}\right)$ in first-stage equations (4) and (5) replaced with the annual global spatial correlation of temperature, $I_{t}\left(T_{i t}\right)$. Columns show estimates that vary by the number of temperature spline terms in $f()$. All models include country fixed effects, year fixed effects, and country-specific linear trends as included instruments. Standard errors, clustered by year, in parentheses; p-values in brackets.

Table F.8: Alternative domestic expenditure share constructions Outcome is log domestic share of expenditure

\begin{tabular}{lcccccc}
\hline & $(1)$ & $(2)$ & $(3)$ & $(4)$ & $(5)$ & $(6)$ \\
\hline & & & & & & \\
$\ln A_{i t}\left(\beta_{0}\right)$ & 2.114 & 1.365 & 1.825 & 1.568 & 1.249 & 1.867 \\
& $(0.604)$ & $(0.397)$ & $(0.559)$ & $(0.432)$ & $(0.430)$ & $(0.536)$ \\
$\ln A_{i t} \times I_{t}\left(\beta_{1}\right)$ & {$[0.001]$} & {$[0.001]$} & {$[0.002]$} & {$[0.001]$} & {$[0.005]$} & {$[0.001]$} \\
& -4.144 & -3.068 & -3.622 & -2.835 & -2.452 & -3.520 \\
& $(1.834)$ & $(1.423)$ & $(1.585)$ & $(1.337)$ & $(1.152)$ & $(1.549)$ \\
& {$[0.028]$} & {$[0.036]$} & {$[0.026]$} & {$[0.039]$} & {$[0.038]$} & {$[0.027]$} \\
Price data & & & & & & \\
Price imputation & FAO & FAO & FAO & FAO & Comtrade & FAO \\
& average & export+ & lowest & highest & average & average \\
Drop outliers? & export & producer & export & export & export & export \\
Cragg-Donald F-stat & No & No & No & No & No & $1 \%$ \\
Stock-Yogo crit. value: $10 \%$ max LIML size & 5.174 & 8.049 & 5.174 & 5.174 & 5.346 & 5.259 \\
Kleibergen-Paap F-stat & 3.580 & 3.580 & 3.580 & 3.580 & 3.580 & 3.580 \\
Observations & 3.963 & 3.864 & 3.963 & 3.963 & 2.406 & 3.832 \\
Pbsen & 5452 & 2918 & 5452 & 5452 & 4148 & 5366 \\
\hline
\end{tabular}

Notes: Estimates of $\beta_{0}$ and $\beta_{1}$ from equation (3). Column 1 reproduces benchmark estimates from column 4 , panel B of Table 2 with average export-volume-weighted cereal export unit value used for imputing cereal-level prices in constructing domestic expenditure share. Column 2 uses cereal-level export unit values with missing observations imputed using producer prices to construct domestic expenditure. Columns 3 and 4 use cereal-level export unit values with missing observations imputed using the lowest and highest observed export unit value for a given country and year, respectively. Column 5 replicates column 1 but constructs domestic expenditure share using Comtrade bilateral trade data instead of FAO trade data. FAO trade data available for 1961-2013. Comtrade data available for 1962-2013. Column 6 replicates column 1 but drops observations with outcome variable being in the bottom and top $1 \%$ of distribution. Standard errors, clustered by year, in parentheses; p-values in brackets. 
Table F.9: Log cereal yield and local temperature Outcome is log cereal yields

\begin{tabular}{|c|c|c|c|c|c|c|}
\hline & (1) & $(2)$ & $(3)$ & (4) & $(5)$ & $(6)$ \\
\hline \multirow[t]{3}{*}{ Temperature 1st term } & 0.004 & 0.004 & 0.005 & 0.005 & 0.007 & 0.005 \\
\hline & $(0.009)$ & $(0.009)$ & $(0.010)$ & $(0.010)$ & $(0.011)$ & $(0.011)$ \\
\hline & {$[0.686]$} & {$[0.677]$} & {$[0.629]$} & {$[0.631]$} & {$[0.519]$} & {$[0.623]$} \\
\hline \multirow[t]{3}{*}{ Temperature 2nd term } & -0.183 & -0.165 & -0.222 & -0.203 & -0.126 & -0.100 \\
\hline & $(0.041)$ & $(0.040)$ & $(0.071)$ & $(0.071)$ & $(0.060)$ & $(0.059)$ \\
\hline & {$[0.000]$} & {$[0.000]$} & {$[0.003]$} & {$[0.006]$} & {$[0.041]$} & [0.093] \\
\hline \multirow[t]{3}{*}{ Temperature 3rd term } & 0.650 & 0.599 & 0.418 & 0.393 & 0.020 & -0.031 \\
\hline & $(0.160)$ & $(0.159)$ & $(0.196)$ & $(0.196)$ & $(0.212)$ & $(0.205)$ \\
\hline & {$[0.000]$} & {$[0.000]$} & {$[0.038]$} & {$[0.050]$} & {$[0.924]$} & {$[0.882]$} \\
\hline \multirow[t]{3}{*}{ Temperature 4 th term } & -1.162 & -1.100 & 0.356 & 0.248 & 1.320 & 1.394 \\
\hline & $(0.533)$ & $(0.539)$ & $(0.649)$ & $(0.644)$ & $(0.674)$ & $(0.658)$ \\
\hline & {$[0.034]$} & {$[0.047]$} & {$[0.586]$} & {$[0.702]$} & {$[0.056]$} & {$[0.039]$} \\
\hline \multirow[t]{3}{*}{ Temperature 5th term } & & & -2.204 & -1.801 & -2.895 & -3.370 \\
\hline & & & $(1.775)$ & $(1.760)$ & $(1.880)$ & $(1.864)$ \\
\hline & & & {$[0.220]$} & {$[0.311]$} & {$[0.130]$} & {$[0.076]$} \\
\hline \multirow[t]{3}{*}{ Temperature 6 th term } & & & & & 1.830 & 3.213 \\
\hline & & & & & $(3.814)$ & $(3.791)$ \\
\hline & & & & & {$[0.633]$} & {$[0.401]$} \\
\hline \multirow[t]{3}{*}{ Precipitation } & & 0.003 & & 0.003 & & 0.003 \\
\hline & & $(0.001)$ & & $(0.001)$ & & $(0.001)$ \\
\hline & & {$[0.000]$} & & {$[0.000]$} & & {$[0.000]$} \\
\hline \multirow[t]{3}{*}{ Precipitation squared } & & -0.000 & & -0.000 & & -0.000 \\
\hline & & $(0.000)$ & & $(0.000)$ & & $(0.000)$ \\
\hline & & {$[0.000]$} & & {$[0.000]$} & & {$[0.000]$} \\
\hline Number of temperature splines & 4 & 4 & 5 & 5 & 6 & 6 \\
\hline Precipitation & No & Yes & No & Yes & No & Yes \\
\hline Temp. joint p-value & 0.0004 & 0.0014 & 0.0009 & 0.0030 & 0.0015 & 0.0049 \\
\hline Optimal temp. & 8.81 & 8.91 & 8.87 & 8.94 & 7.80 & 7.70 \\
\hline Observations & 7226 & 7226 & 7226 & 7226 & 7226 & 7226 \\
\hline
\end{tabular}

